NBER WORKING PAPER SERIES

A MODEL OF FICKLE CAPITAL FLOWS AND RETRENCHMENT

\author{
Ricardo J. Caballero \\ Alp Simsek \\ Working Paper 22751 \\ http://www.nber.org/papers/w22751
}

NATIONAL BUREAU OF ECONOMIC RESEARCH

1050 Massachusetts Avenue

Cambridge, MA 02138

October 2016, Revised July 2019

We thank three anonymous referees, and the editor Harald Uhlig especially, for their detailed, constructive comments. Masao Fukui, Antoine Levy, Andrea Manera, and Zilu Pan provided outstanding research assistance. We are also grateful to Daron Acemoglu, Chris Ackerman, Charles Engel, Kristin Forbes, Sebnem Kalemli-Ozcan, Anton Korinek, Signe Krogstrup, Arvind Krishnamurthy, Jonathan Ostry, Andrei Shleifer, and Frank Warnock, as well as the seminar participants at YALE SOM, Harvard University, Duke University, Tufts University, Brown University and the conference participants at the NBER IFM Meeting, Chicago International Macro Finance Conference, Harvard/MIT Financial Economics Workshop, the ECB/FED/ FEDNY Global Research Forum on International Macroeconomics and Finance, for their comments. Simsek acknowledges support from the National Science Foundation (NSF) under Grant Number SES-1455319. A previous version of this paper circulated under the title "A Model of Fickle Capital Flows and Retrenchment: Global Liquidity Creation and Reach for Safety and Yield." First draft: August 31, 2016. The views expressed herein are those of the authors and do not necessarily reflect the views of the National Bureau of Economic Research.

NBER working papers are circulated for discussion and comment purposes. They have not been peer-reviewed or been subject to the review by the NBER Board of Directors that accompanies official NBER publications.

(C) 2016 by Ricardo J. Caballero and Alp Simsek. All rights reserved. Short sections of text, not to exceed two paragraphs, may be quoted without explicit permission provided that full credit, including $\odot$ notice, is given to the source. 
A Model of Fickle Capital Flows and Retrenchment

Ricardo J. Caballero and Alp Simsek

NBER Working Paper No. 22751

October 2016, Revised July 2019

JEL No. E3,E4,F3,F4,F6,G1

\section{ABSTRACT}

We develop a model of gross capital flows and analyze their role in global financial stability. In our model, consistent with the data, when a country experiences asset fire sales, foreign investments exit (fickleness) while domestic investments abroad return home (retrenchment). When countries have symmetric expected returns and financial development, the benefits of retrenchment dominate the costs of fickleness and gross flows increase fire-sale prices. Fickleness, however, creates a coordination problem since it encourages local policymakers to restrict capital inflows. When countries are asymmetric, capital flows are driven by additional mechanisms, reach-for-safety and reach-for-yield, that can destabilize the receiving country.

Ricardo J. Caballero

Department of Economics, E52-528

MIT

50 Memorial Drive

Cambridge, MA 02142

and NBER

caball@mit.edu

Alp Simsek

Department of Economics, E52-552

MIT

50 Memorial Drive

Cambridge, MA 02142

and NBER

asimsek@mit.edu

A Dynamic link to the most recent version of the paper is available at

https:/www.dropbox.com/s/zf48a2dd5cfga64/fickleFlowsMostRecent_Public.pdf?dl=0 


\section{Introduction}

Capital inflows are large, often exceeding 10 percent of a country's GDP per year. But they are also fickle - foreign investors tend to exit when a country is in financial distress. Fickleness can exacerbate asset fire sales, where assets are traded at a lower price than when investors with the highest valuation have sufficient liquidity. ${ }^{1}$ Consistent with this mechanism, we show that the decline of capital inflows into a country is typically associated with higher future stock returns in that country (see Section 2). Concerns about fickle capital inflows exacerbating asset fire sales have spawned an academic and policy literature that emphasizes the need to regulate capital flows (see, e.g., IMF (2012)).

Less studied than fickleness, but as prevalent, is retrenchment. Retrenchment occurs when local investors reduce their foreign investments and bring home their global liquidity during domestic distress. Empirically, capital outflows are highly correlated with inflows, meaning that local investors come home as foreign investors leave the country (see Section 2). Since retrenchment increases domestic liquidity during distress, it tends to offset the financial instability caused by fickleness and weakens the case for regulating capital flows. In this paper, we address this tension and its implications. We develop a stylized model of capital flows that assumes fickleness, and we ask whether capital flows can still be a useful source of liquidity.

Our model features a continuum of countries, each associated with a risky asset. The asset always pays a fixed amount, but the timing of the payoff is uncertain. Specifically, each country experiences a "liquidity shock" with some probability, in which case its asset's payoff is delayed to a future period. When this happens, the asset is traded at an endogenous price. In each country, there is one group of agents ("distressed sellers") that sell their legacy risky assets to make new investments, and another group of agents ("banks") that can purchase risky assets. We make parametric assumptions so that the asset experiences a fire sale and its price is determined by banks' available liquidity. We analyze how cross-country investments impact the severity of asset price declines when there is a liquidity shock.

Specifically, in the ex-ante period banks have three choices: invest in the local risky asset, invest in foreign risky assets, or consume. These decisions are the source of ex-ante capital flows in our model. If banks invest in the foreign risky asset, there are capital outflows from the sending country and capital inflows into the receiving country. Our key assumption is that, ex post, banks are homebiased in that they are extremely fickle in foreign countries. If the foreign country experiences a liquidity shock, banks sell their risky asset in that country regardless of the price. This assumption captures a variety of factors that might handicap foreigners during domestic distress: asymmetric information or Knightian uncertainty, deteriorating property rights, asymmetric regulation, and so on. We are agnostic about the source of fickleness and view it as a modeling device to capture the asymmetric behavior of foreigners and locals during crises that we see in the data. In particular, while foreign banks in our model sell local assets, local banks retrench and use their global liquidity

\footnotetext{
${ }^{1}$ By liquidity we mean financial resources that can be immediately deployed to purchase other financial or real assets. For early models of fire sales, see, e.g., Shleifer and Vishny (1992) and Kiyotaki and Moore (1997).
} 
to purchase local assets at fire-sale prices.

In our baseline model, countries are identical except for their liquidity shocks. In this case, a natural question is whether banks invest in foreign countries at all, since fickleness (which occasionally forces banks to sell at fire-sale prices) reduces their expected return from foreign risky assets relative to the local risky asset. However, funds invested abroad can provide valuable liquidity during local fire sales. In our model, this liquidity effect is strong enough that there is always foreign investment and capital flows despite fickleness.

We then analyze how these fickle capital flows among similar countries affect global financial stability. Our main positive result is that capital flows increase fire-sale asset prices despite their fickleness. The intuition is that fickle foreign banks sell local assets at fire-sale prices, but local banks obtain liquidity from their diversified foreign assets at relatively high valuations. In a symmetric environment, every pre-crisis inflow is matched by a pre-crisis outflow of equal size. Thus symmetric capital flows provide liquidity and increase fire-sale prices.

In this symmetric environment, we also assess policies that regulate capital flows. Our main normative result is that regulating capital flows is subject to a coordination problem. Even though capital flows increase fire-sale prices in global equilibrium, local policymakers trying to increase firesale prices in their home country might restrict capital inflows. This tension arises because there is a public-goods aspect to the global liquidity generated via fickle capital flows. Every capital inflow into one country is an outflow from some other country. Local regulators restrict inflows to reduce the country's exposure to fickleness, but they do not recognize the retrenchment benefits that a stable source of foreign assets has for banks in other countries.

We also investigate the determinants of gross capital flows in our baseline model. First, we show that a greater scarcity of safe assets increases gross capital flows - a situation reminiscent of the period before the global financial crisis. Foreign assets (imperfectly) substitute for safe assets by creating liquidity during local liquidity shocks. Second, we show that an increase in the perceived correlation between liquidity shocks reduces gross capital flows - a situation reminiscent of the period after the financial crisis. When banks think liquidity shocks are more likely to be global, they perceive that foreign assets create less liquidity. The resulting decline in foreign investment reduces liquidity and fire-sale prices even if the global shock is not realized.

Our baseline symmetric model roughly captures gross capital flows among developed countries. However, when liquidity or investment returns are substantially asymmetric across regions, gross capital flows may not be stabilizing. We identify two potentially destabilizing mechanisms, reachfor-safety and reach-for-yield, that apply when developed markets with substantial liquidity but relatively low returns trade capital flows with emerging markets with less liquidity but relatively high returns.

The reach-for-safety mechanism is driven by cross-country differences in liquidity (captured by the supply of local safe assets in our model). Greater liquidity in a developed market country makes its assets relatively attractive to foreign banks. Other things equal, this induces the developed country to experience greater inflows relative to its outflows (or run current account deficits). 
Moreover, the inflows into the developed market country end up in stable, low-yield safe assets, whereas the outflows are directed to risky, high-yield assets. Banks in the developed market country effectively sell liquidity insurance to emerging markets. These types of reach-for-safety flows reduce fire-sale prices in the developed market while increasing them in emerging markets. (See Lane and Milesi-Ferretti (2007) for empirical evidence on the risk composition of cross-country assets and liabilities, and Gourinchas and Rey (2007); Gourinchas et al. (2010, 2012) for evidence on the venture capitalist and insurer roles the U.S. plays in the global system).

The reach-for-yield mechanism is driven by cross-country differences in investment returns. If the return in an emerging market country is greater than in other markets, foreign banks invest in this country not only to have a source of liquidity during their local liquidity shocks but also to chase higher returns. This process stops only when fickle inflows are large enough that, in the event of a local liquidity shock, the emerging market country has lower fire-sale prices compared to other countries (thereby reducing its appeal to foreign banks). Thus, we find that fickle flows driven by the pursuit of higher returns destabilize the emerging markets receiving these flows.

Related literature. International diversification is at the core of our mechanism. An extensive literature studies capital flows in frictionless models of international risk sharing (see e.g., Grubel (1968); Cole and Obstfeld (1991); Van Wincoop (1994); Lewis (2000); Coeurdacier and Rey (2013)). The main reason for diversification in our paper is different from the reasons highlighted in this literature. In our model, investments abroad provide valuable liquidity to local banks during fire sales.

Our paper is part of a literature that focuses on gross positions held by sophisticated financial intermediaries and their role in allocating international liquidity where it is most valuable (see, for instance, Brunnermeier et al. (2012); Bruno and Shin (2013); Miranda-Agrippino and Rey (2015); Gabaix and Maggiori (2015); Fostel et al. (2015)). A related literature emphasizes the costs of capital flows: while flows improve capital allocation, their fickleness may exacerbate local fire-sale externalities and justify macroprudential regulation (see, for instance, Caballero and Krishnamurthy (2004); Jeanne and Korinek (2010); Ostry et al. (2010); Caballero and Lorenzoni (2014); Calvo (2016); Korinek and Sandri (2016)). We explore the global equilibrium implications of fickleness and the policy coordination issues that arise in this global context.

We take fickleness as given. In this sense we take a similar approach to Scott and Uhlig (1999), who take the fickleness of financial investors as given and study the impact of fickleness on economic growth. The all-or-nothing attitude of fickle foreign banks is extreme in our model, but it is intended to capture a variety of reasons that foreign investors exit during turmoil (see Remark 3). One important reason is the attitude of Knightian agents facing an unfamiliar situation. As such, our model is related to Caballero and Krishnamurthy (2008) and Caballero and Simsek (2013). We develop this Knightian uncertainty interpretation in Online Appendix A.1.

One central reason for capital flows in our model is investors seeking safe assets. Because safe assets are scarce, investors diversify in foreign risky assets to secure liquidity during local fire sales. In this sense, our work is related to the literature on the limited availability of safe assets and its 
macroeconomic consequences (e.g., Caballero (2006); Caballero et al. (2008, 2016); Bernanke et al. (2011); Gorton et al. (2012); Krishnamurthy and Vissing-Jorgensen (2012); Gorton (2016)).

The endogenous liquidity creation aspect of our model is similar to Holmström and Tirole (1998), although our context and mechanism are different. The liquidity pricing of local assets is similar to the literature on limits-to-arbitrage and fire sales, e.g., Allen and Gale (1994); Shleifer and Vishny (1997); Gabaix et al. (2007); Lorenzoni (2008); Krishnamurthy (2010); Gromb and Vayanos (2016); Holmström and Tirole (2001). In addition to these mechanisms, we highlight the benefit of gross flows as a stabilization channel.

The rest of the paper is organized as follows. Section 2 reviews and extends the empirical literature documenting the fickleness and retrenchment aspects of capital flows. Section 3 presents our baseline model with symmetric countries. Section 4 illustrates how symmetric capital flows create liquidity and mitigate financial distress. Section 5 concerns the optimal regulation of capital flows in our environment. Section 6 develops a special case of the baseline model, to analyze the determinants of gross capital flows. Section 7 considers a variant of the baseline model in which an (infinitesimal) country has different return and liquidity parameters from the remaining countries, and uses it to analyze asymmetric flows driven by reach-for-safety and reach-for-yield. Section 8 concludes. Online Appendix A contains various extensions of the model as well as proofs of the propositions, and Online Appendix B describes the data sources and the details of the empirical analysis.

\section{Fickleness and Retrenchment: Some Facts}

Our model is built on the observation that capital inflows are fickle (i.e., foreign investors exit when a country is in distress) and that capital outflows retrench (i.e., local investors reduce their foreign investments during domestic distress and bring home their global liquidity). In this section we discuss the evidence for these phenomena and motivate our modeling ingredients. ${ }^{2}$

Systematic analysis of gross capital flows typically relies on the International Monetary Fund's (IMF) Balance of Payments Statistics. Using this data, Broner et al. (2013a,b) document that fickleness and retrenchment are broad empirical regularities (see also, Forbes and Warnock (2012) and Bluedorn et al. (2013)). They write: "during contractions foreigners reduce their investments in domestic assets and domestic agents reduce their investments abroad. This retrenchment toward home financial markets is particularly acute during crises." Figure 1, which extends their dataset until 2017, illustrates this pattern for three developed economies from different regions: the U.S., Spain, and Japan. For each country, we plot capital inflows by foreign agents (henceforth, capital inflows) and capital outflows by domestic agents (henceforth, capital outflows) together with a local

\footnotetext{
${ }^{2}$ For a policy motivation, see Obstfeld (2012) who documents the fickleness and retrenchment that occurred in the U.S. at the peak of the subprime financial crisis, and argues that retrenchment mitigated the crisis. Specifically, he writes: "...over the two quarters of intensive global deleveraging following the Lehman Brothers collapse in September $2008 \ldots$ [U.S.] Gross capital inflows... went into reverse, as foreigners liquidated $\$ 198.5$ billion in U.S. assets. In addition, the U.S. financed a current account shortfall of $\$ 231.1$ billion... Where did the total of nearly $\$ 430$ billion in external finance come from? It came from U.S. sales of $\$ 428.4$ billion of assets held abroad..."
} 
A

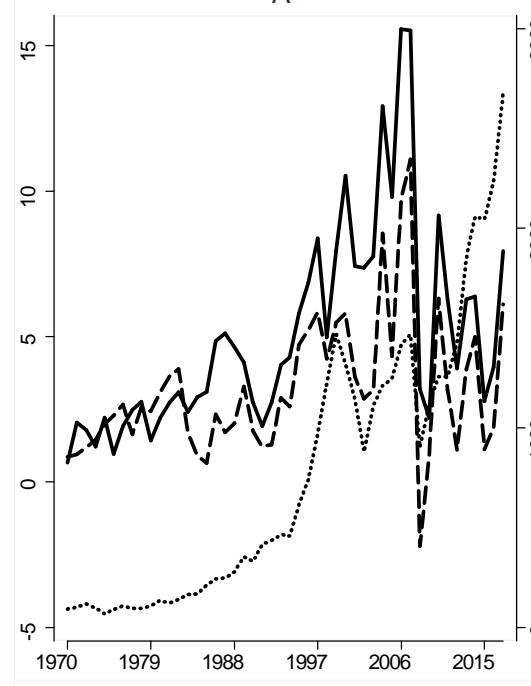

B

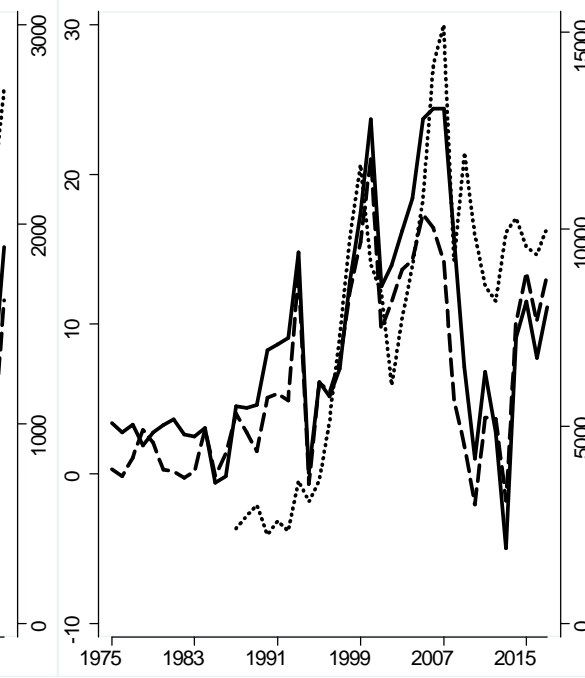

C

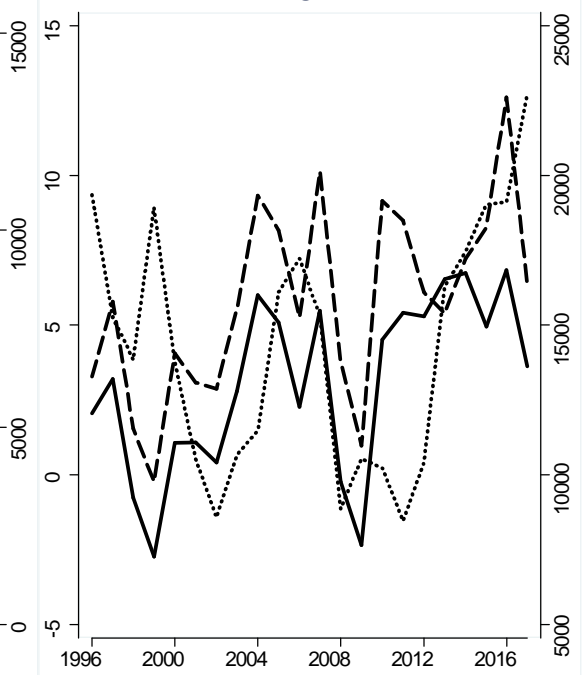

Capital inflows scaled by trend GDP (percent)

Capital outflows scaled by trend GDP (percent)

Figure 1: Gross capital flows and a stock price index for three countries. Sources: IMF, World Bank, and Global Financial Data (see Online Appendix B for details). A, United States; B, Spain; C, Japan.

stock market index to visualize the correlation of flows with each other and with domestic financial distress.

To quantify these correlations, we first regress capital outflows on capital inflows. We standardize the capital flow measures in Figure 1 by the mean and standard deviation of each measure within each country. We focus on the period between 1970 and 2017 and consider two separate samples: a large sample of 170 countries for which we have data on capital flows, and a smaller sample of 30 OECD countries for which we have additional data on stock prices and returns (see Online Appendix B.1 for data sources and details). We include country-specific linear time trends in all regressions. The first two columns of Table 1 illustrate our results. Inflows and outflows are strongly correlated in both samples and the magnitudes are especially large for the OECD sample. The last two columns illustrate that the results remain largely unchanged when we include time fixed effects: that is, inflows and outflows in an individual country are highly correlated even after controlling for the average flows in sample countries (see Jeanne and Sandri (2017) and Alberola et al. (2016) for similar evidence). As Broner et al. (2013a,b) note, these patterns are difficult to reconcile with standard frictionless macroeconomic models, because the shocks (e.g., to domestic productivity) in those models typically affect domestic agents' and foreigners' domestic investments in the same direction. Rather, the evidence is more easily reconciled with models where crises affect domestic agents and foreigners asymmetrically.

We model this asymmetry by assuming that foreign banks sell their assets in a distressed country regardless of the price, even if the expected return is high (fickleness). As foreign banks sell, local banks use their global liquidity to purchase local assets at a high expected return (retrenchment). 
Table 1: Correlations between capital inflows and outflows

\begin{tabular}{lcccc}
\hline \hline & \multicolumn{4}{c}{ Outflows/trend GDP (std) } \\
& $(1)$ & $(2)$ & $(3)$ & $(4)$ \\
\hline Inflows/trend GDP (std) & $0.441^{* *}$ & $0.820^{* *}$ & $0.417^{* *}$ & $0.752^{* *}$ \\
& $(0.043)$ & $(0.034)$ & $(0.036)$ & $(0.047)$ \\
\hline Time FE & No & No & Yes & Yes \\
Country specific linear trend & Yes & Yes & Yes & Yes \\
Sample & Full & OECD & Full & OECD \\
Observations & 5102 & 838 & 5102 & 838 \\
$\mathrm{R}^{2}$ (adjusted) & 0.23 & 0.74 & 0.28 & 0.76 \\
\hline
\end{tabular}

Note: The full sample (resp. the OECD sample) is an unbalanced panel of 170 countries (resp. 30 countries) between 1970 and 2017 (see Online Appendix B for details). Estimation is via OLS. Standard errors are in parentheses and double-clustered by country and year. ${ }^{*}$ and ${ }^{* *}$ indicate significance at 0.05 and 0.01 levels, respectively.

To assess the plausibility of these ingredients, we investigate the relationship between capital flows and expected stock returns. Using our OECD sample, we regress future stock returns on current capital flows.

Our baseline specification focuses on the annualized log return of the local stock market index (including dividends) measured in local currency over the subsequent five years (see Online Appendix B.2 for similar results with the return measured in U.S. dollars or over different horizons). We control for country fixed effects and include country-specific linear time trends. The first two columns of Table 2 illustrate that a decline in capital inflows or outflows in a country is followed by high stock returns. The effects are statistically significant and economically large: a one standard deviation decline in the inflow (resp. outflow) to GDP ratio is associated with a 3.3 (resp. 3.4) percentage point increase in the annualized log stock return over the subsequent five years. Consistent with our model, foreigners seem to exit when expected stock returns are high, whereas locals seem to return home.

One possibility is that these excess-return findings are dominated by global shocks, where all investors retrench to their respective home countries, and the results reflect the excess return associated with global "risk-off" episodes. While we allow for global shocks, gross flows in our model create liquidity due to non-global shocks (where not all countries are hit symmetrically). To focus on non-global shocks, we consider a specification with time fixed effects, which absorbs global changes in flows and returns. The last two columns of Table 2 show that the results remain significant, although with a smaller magnitude. Consistent with our model, foreigners seem to exit a country when the expected stock return there is high, even after controlling for the average flows and stock returns in sample countries. Moreover, our model also predicts that non-global shocks should reduce local asset prices (and raise excess returns) less than global shocks, as in Table 2. When shocks are mostly local, domestic investors obtain greater liquidity from their foreign assets (see Section 4.2). 
Table 2: Return prediction regressions using gross capital flows

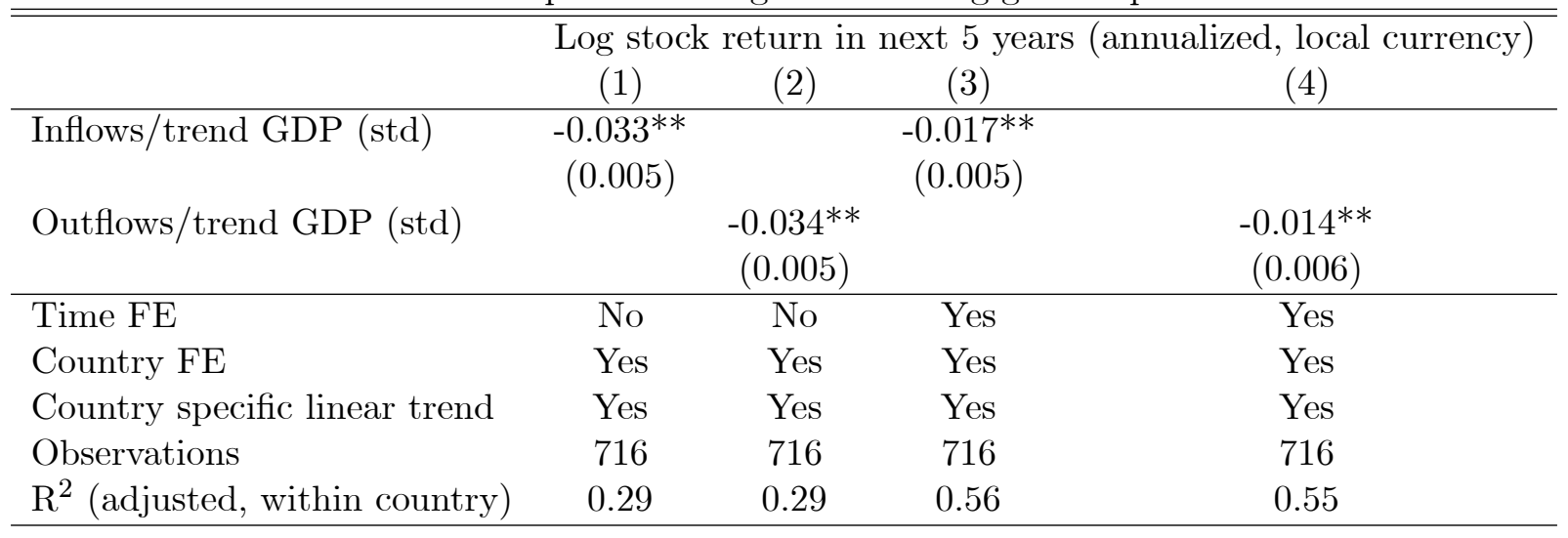

Note: The sample is an unbalanced panel of 30 OECD countries between 1970 and 2017 (see Online Appendix B for details). Estimation is via OLS. Standard errors are in parentheses and double-clustered by country and year. * and $* *$ indicate significance at 0.05 and 0.01 levels, respectively.

Remark 1 (Additional Facts on the Role of Banks). In recent work, Avdjiev et al. (2017) further analyze international capital flows by the sectors that send or receive them (banks, corporates, or sovereigns) and find that global banks are largely responsible for the fickleness and retrenchment patterns in aggregate data. These banks seem to be especially important for understanding retrenchment in developed markets, whereas sovereigns (which increase their borrowing or draw down their reserves during crises) seem to account for some retrenchment in emerging markets. This motivates our emphasis on "banks" as the main empirical counterpart to the agents in our model, as well as our interpretation that our baseline symmetric model applies most naturally to developed markets. Moreover, retrenchment by emerging market sovereigns suggests that many of the mechanisms that we emphasize are also relevant in emerging markets with "central banks" taking the functional role of "banks" in our model.

\section{The Model}

The baseline model features three periods, $t \in\{0,1,2\}$, and a single consumption good in each period. There is a continuum of mass one of countries denoted by superscript $j \in J$, which are symmetric except for their local shocks in period 1.

Shocks. In period 1, an aggregate state $s \in S=\{1, \ldots,|S|\}$ is drawn with probability $\gamma_{s}>0$, where $\sum_{s \in S} \gamma_{s}=1$. The aggregate state determines the probability of a liquidity shock in a given country, which is the same across countries and denoted by $\pi_{s} \in[0,1]$. Specifically, a random variable $\omega^{j}$ is drawn for each country $j$ and i.i.d. across $j$, with $\pi_{s}=\operatorname{Pr}\left(\omega^{j}=b\right)$ and $1-\pi_{s}=\operatorname{Pr}\left(\omega^{j}=g\right)$. We say that a country with $\omega^{j}=b$ experiences a liquidity shock (thus, $b$ and $g$ stand for bad and good states, respectively). The ex-ante probability of a liquidity shock is 
positive but less than one, $\sum_{S} \gamma_{s} \pi_{s} \in(0,1)$. We also assume $\pi_{s}$ is strictly increasing in $s$ so that aggregate states with greater $s$ are associated with a greater likelihood of liquidity shocks.

Assets. There are three types of assets. First, each country $j$ has a risky asset whose payoff depends on the realization of $\omega^{j}$. If $\omega^{j}=g$, then each unit of the asset pays $R$ units in period 1 and 0 units in period 2. If instead $\omega^{j}=b$, so that the country experiences a liquidity shock, then each unit of the asset pays 0 units in period 1 and $R$ units in period 2 . In this case, the asset has an endogenous price $p_{s}^{j}$ in period 1 . We focus on symmetric equilibria in which the price in period 1 is the same for all countries that experience a liquidity shock, that is, $p_{s}^{j} \equiv p_{s}$ for each country $j$ with $\omega^{j}=b$. Initially, each country has $e$ units of the risky asset, which we refer to as legacy assets (endowed to local distressed sellers that will be described below). In period 0, agents can produce more risky assets according to a linear technology. Specifically, they can convert one unit of the consumption good in period 0 into one unit of the risky asset in any country (therefore, the price of the risky asset in period 0 is equal to one).

Second, there is a risk-free asset that pays 1 unit of the consumption good in period 1 (and 0 units in period 2). The risk-free asset is in fixed supply: specifically, there are $\eta$ units in each country (endowed to local banks that will be described below). In period 0, the risk-free asset is traded at an endogenous price $q_{f}$.

Third, there are Arrow-Debreu financial securities that facilitate aggregate risk sharing. Specifically, for each aggregate state $s \in S$, there is an Arrow-Debreu security that pays 1 unit of the consumption good in period 1 if state $s$ is realized (and 0 units in all other states or in period 2). The Arrow-Debreu securities are in zero net supply. In period 0, the Arrow-Debreu security for state $s$ is traded at an endogenous price $q_{s}{ }^{3}$

Agents. There are two types of agents. First, each country $j$ has a mass one of agents that we refer to as "distressed sellers." These agents are our modeling device to generate liquidity-driven asset sales while keeping the analysis tractable (see Remark 5 for an interpretation in the context of a more conventional model). Therefore, we model them rather mechanically: they are born in period 1 endowed with $e$ units of the local risky asset (all of the legacy assets). They maximize the utility function $E\left[\tilde{c}_{2, s}^{j}\right]$, where $\tilde{c}_{2, s}^{j}$ denotes their consumption in period 2 conditional on the aggregate state $s$. They have access to a linear technology that converts 1 unit of the consumption good in period 1 into $\lambda$ units of the consumption good in period 2. The payoff from this technology cannot be pledged to other agents, so the distressed sellers can only invest in their technology using the liquidity from their legacy assets. Specifically, if $\omega^{j}=g$ is realized in their country, they receive $R e$ units of the consumption good from their legacy assets. They invest these liquid resources in

\footnotetext{
${ }^{3}$ Note that agents cannot trade financial contracts whose payoffs are contingent on local liquidity shocks, $\left\{\omega^{j}\right\}_{j}$. In Online Appendix A.2, we first show that when markets are complete, fickleness is irrelevant for fire-sale prices. We then consider the case in which markets are partially complete: in particular, agents can sell contingent contracts subject to a collateral constraint. We show that, as long as markets are not fully complete, fickleness affects fire-sale prices and our analysis generalizes. We adopt the incomplete-markets setting as our baseline model because it features the tension between fickleness and retrenchment while simplifying the exposition.
} 
their technology and consume the output in period 2, that is, $\tilde{c}_{2, s}^{j}\left(\omega^{j}=g\right)=\lambda R e$. If instead $\omega^{j}=b$ is realized, then they decide whether to keep their legacy assets or to sell them. We let $\tilde{\chi}_{s}^{j} \in[0, e]$ denote their holdings of the legacy assets at the end of period 1, and note that their consumption in period 2 is,

$$
\tilde{c}_{2, s}^{j}\left(\omega^{j}=b\right)=\tilde{\chi}_{s}^{j} R+\lambda\left(e-\tilde{\chi}_{s}^{j}\right) p_{s}
$$

As long as $\lambda p_{s}>R$ for each $s$, distressed sellers optimally choose $\tilde{\chi}_{s}^{j}=0$ and sell all of their legacy assets regardless of the aggregate state. We will make parametric assumptions so that this is the case along the equilibrium path for most of our analysis.

In each country $j$, there is also a second group of agents with mass one, which we refer to as "banks." These are the main agents in our model and their preferences are,

$$
E\left[u\left(c_{0}^{j}\right)+c_{1, s}^{j}+c_{2, s}^{j}\right]
$$

where the utility function, $u(\cdot)$, satisfies $u^{\prime}(c)>0, u^{\prime \prime}(c)<0$ for each $c>0$ as well as the Inadatype conditions, $\lim _{c \rightarrow 0} u^{\prime}(c)=\infty$ and $u^{\prime}(1)<R$. Note that these preferences also imply that, if $\omega^{j}=b$ is realized, then (local) banks would be indifferent to holding the asset if and only if $p_{s}=R$. We will make parametric assumptions so that the equilibrium asset price will be below this level, $p_{s}<R$, which we refer to as a fire sale. ${ }^{4}$

Banks' budget constraints. Banks in each country $j$ are endowed with one unit of the consumption good in period 0 , as well as $\eta$ units (all of the fixed supply) of the risk-free asset. In period 0 , they choose an investment strategy in risky assets, $x^{j^{\prime}, j}$, across countries, $j^{\prime}$. We impose that $x^{j, j}$ is a point mass, and $x^{j^{\prime}, j}$ for $j^{\prime} \neq j$ is a density with respect to the Lebesgue measure. Banks also choose how many consumption units to invest in the risk-free asset, $y^{j}$, or in Arrow-Debreu securities, $\left(z_{s}^{j}\right)_{s}$. Their budget constraint in period 0 is,

$$
c_{0}^{j}+x^{j, j}+x^{o u t, j}+y^{j} q_{f}+\sum_{s \in S} z_{s}^{j} q_{s}=1+\eta q_{f}, \quad \text { where } x^{o u t, j}=\int_{j^{\prime} \neq j} x^{j^{\prime}, j} d j^{\prime} .
$$

Here, $x^{\text {out }, j}$ denotes the outflows: the aggregate amount banks in country $j$ invest in other countries. Banks are not allowed to short-sell risky assets, $x^{j^{\prime}, j} \geq 0$ for each $j^{\prime}$, but they are allowed to take unrestricted positions in the risk-free asset or the Arrow-Debreu securities subject to obtaining nonnegative consumption in all periods and states.

In period 1 , if $\omega^{j^{\prime}}=g$ and $j^{\prime} \neq j$, then banks in country $j$ receive $R$ units of the consumption good from each unit of their risky asset investment in country $j^{\prime}$. By an exact law of large numbers, these investments generate $x^{\text {out }, j}\left(1-\pi_{s}\right) R$ units of the consumption good (see Uhlig (1996) for

\footnotetext{
${ }^{4}$ Recall that we assume the assets in countries without a liquidity shock $\left(\omega^{j}=g\right)$ pay early in period 1 . This simplifies the exposition by ensuring that we do not need to worry about asset prices or fire sales in these countries (the ex-dividend price would always be zero). Equivalently, we could assume the risky asset always pays later (in period 2), but make parametric assumptions (e.g., on the legacy asset endowment of distressed sellers) such that the countries without liquidity shocks are not subject to fire sales $\left(p_{s}\left(\omega^{j}=g\right)=R\right)$.
} 
details)..$^{5}$ If instead $\omega^{j^{\prime}}=b$ and $j^{\prime} \neq j$, then banks in country $j$ sell their risky asset holdings in country $j^{\prime}$, which captures our main fickleness assumption (see Remark 3 below for various interpretations). By the same law of large numbers, these sales generate $x^{o u t, j} \pi_{s} p_{s}$ units of the consumption good. Hence, the total resources banks in country $j$ receive from investments in other countries is given by $x^{\text {out }, j} \bar{R}_{s}$, where

$$
\bar{R}_{s}=\left(1-\pi_{s}\right) R+\pi_{s} p_{s},
$$

denotes the expected one-period payoff from a unit of foreign investment conditional on the aggregate state $s$. In addition, banks receive $y^{j}+z_{s}^{j}$ units of the consumption good from their investments in the risk-free asset and the Arrow-Debreu securities.

Banks' total resources in period 1 and how they use these resources depend on the shock in their own country. If $\omega^{j}=g$, then banks' risky asset investments in their own country pay $R x^{j, j}$ units in period 1. Moreover, banks have no more remaining investment opportunity so they consume all of their available resources in period 1 . Then, their budget constraint in state $\omega^{j}=g$ can be written as,

$$
c_{1, s}^{j}\left(\omega^{j}=g\right)=x^{j, j} R+x^{o u t, j} \bar{R}_{s}+y^{j}+z_{s}^{j} \quad \text { and } \quad c_{2, s}^{j}\left(\omega^{j}=g\right)=0 .
$$

If instead $\omega^{j}=b$, then banks' risky investments in their own country pay zero units in period 1 . However, banks are not required to sell their holdings in their own country. We let $\chi_{s}^{j} \geq 0$ denote banks' position in the local risky asset in period 1 with $\omega^{j}=b$ and aggregate state $s$. Then, banks' budget constraints in state $\omega^{j}=b$ can be written as,

$$
c_{1, s}^{j}\left(\omega^{j}=b\right)+\chi_{s}^{j} p_{s}=x^{j, j} p_{s}+x^{o u t, j} \bar{R}_{s}+y^{j}+z_{s}^{j} \quad \text { and } \quad c_{2, s}^{j}\left(\omega^{j}=b\right)=\chi_{s}^{j} R .
$$

Banks' problem. Putting everything together, banks in each country $j$ make an investment plan, $\left[x^{j^{\prime}, j} \geq 0\right]_{j^{\prime}}, y^{j},\left(z_{s}^{j}, \chi_{s}^{j} \geq 0\right)_{s}$, to maximize their expected utility in (2), where $c_{0}^{j}$ is determined by Eq. (3), $c_{1, s}^{j}\left(\omega^{j}=g\right)$ and $c_{2, s}^{j}\left(\omega^{j}=g\right)$ are determined by Eq. $(5), c_{1, s}^{j}\left(\omega^{j}=b\right)$ and $c_{2, s}^{j}\left(\omega^{j}=b\right)$ are determined by Eq. (6), and consumption in all periods and states is nonnegative, $c_{0}^{j} \geq 0, c_{1, s}^{j} \geq$ $0, c_{2, s}^{j} \geq 0$

Equilibrium. The equilibrium with symmetric prices is a collection of optimal allocations for distressed sellers and banks, together with prices, $\left(p_{s}\right)_{s}, q_{f},\left(q_{s}\right)_{s}$, that ensure market clearing. The market clearing condition for the risky asset in a country $j$ with $\omega^{j}=b$ in period 1 is,

$$
e+x^{i n, j}+x^{j, j}=\tilde{\chi}_{s}^{j}+\chi_{s}^{j} \text { where } x^{i n, j}=\int_{j^{\prime} \neq j} x^{j, j^{\prime}} d j^{\prime} .
$$

\footnotetext{
${ }^{5}$ More precisely, conditional on the aggregate state $s$, the return from these countries corresponds to an integral over random variables, $\int_{j^{\prime} \in[0,1]} R x^{j^{\prime}, j} \mathbf{1}\left[\omega^{j^{\prime}}=g\right] d j^{\prime}$ (where $\mathbf{1}\left[\omega^{j^{\prime}}=g\right]$ denotes the indicator variable). We obtain the law of large numbers by interpreting this as a Pettis integral, which is a generalization of the Lebesgue integral to vector-valued functions. We then use a slight extension of Theorem 3 in Uhlig (1996) to evaluate the integral as equal to $\int_{j^{\prime} \in[0,1]} R x^{j^{\prime}, j}\left(1-\pi_{s}\right) d j^{\prime}=R\left(1-\pi_{s}\right) x^{o u t, j}$ with probability one.
} 
Here, $x^{i n, j}$ denotes the inflows: the aggregate amount foreign banks invest in a country $j$. The left side of the equation captures the supply of risky assets, which comes from the distressed sellers' endowment of legacy assets, the ex-ante inflows, and the ex-ante local investments. The right side captures demand, which only comes from distressed sellers and local banks, because foreign banks sell all of their asset holdings in country $j$ when $\omega^{j}=b$. The market clearing condition for the risk-free asset in period 0 is given by,

$$
\int_{j} y^{j} d j=\int_{j} \eta d j=\eta
$$

Finally, the market clearing condition for the Arrow-Debreu security for each state $s$ is given by,

$$
\int_{j} z_{s}^{j} d j=0
$$

Remark 2 (Interpreting Assets). We view the risky assets in our model as securities that are held by banks and that can be subject to fire sales. Some examples are, equity, long-term debt (bank loans and portfolio debt), and unsecured short-term debt subject to default risk. In contrast, safe assets are not subject to fire sales and yield a relatively high payoff during distress events, e.g., short-term debt that is highly collateralized or issued by entities with negligible default risk.

Remark 3 (Interpreting Fickleness). Our fickleness assumption captures a variety of factors that, during a local distress event, reduce foreign banks' valuation of the local risky asset relative to locals' valuation. One interpretation is asymmetric information or uncertainty: foreign banks have an information disadvantage that worsens when the local market is distressed (see Online Appendix A.1 for a formalization based on Knightian uncertainty). This interpretation is broadly consistent with the large literature on portfolio home bias (see, for instance, Gehrig (1993); Brennan and Cao (1997); Van Nieuwerburgh and Veldkamp (2009)). Another example is weaker property rights for foreign banks. In distressed markets, foreign banks are more likely to be expropriated or defaulted against than locals (see Broner et al. (2014) for a formalization in the context of the European sovereign debt crisis). A related interpretation is asymmetric regulation that increases foreign banks' cost of investment in distressed markets relative to their local counterparts (see Uhlig (2014) for a model along these lines in the context of the same European crisis). Finally, the asymmetry might also stem from distorted higher valuation by local banks, e.g., because of "moral suasion" by local regulators and governments.

Remark 4 (Implementation with Lending to Local Firms). In practice, banks often lend to firms (or other banks), as opposed to investing in production technologies, and their fickleness can take the form of not renewing these loans, as opposed to selling loans. We could capture these realistic elements without changing anything substantive. In particular, our equilibrium has an equivalent implementation in which there are competitive local firms (with no funds) that invest in the domestic linear production technology in period 0 by borrowing from banks with a one-period, state-contingent debt contract. The contract promises $R$ units for each unit borrowed if the country does not expe- 
rience a liquidity shock, and $p_{s}$ units if there is a liquidity shock (while debt contracts in practice tend to be noncontingent, the promises in distress are often implicitly reduced, e.g., via lenders' decision to recall loans). With this implementation, when there is a local liquidity shock, foreign banks withdraw their financing (fickleness) and local firms pay them by selling or pledging their risky assets to local banks.

Remark 5 (An Alternative Model with Distressed Banks). In Online Appendix A.5, we build an alternative model in which there are no separate distressed sellers. Instead, we require banks to hold a minimum amount of the local risky asset (in view of their comparative advantage in lending in the local market), which corresponds to the legacy assets in the main model. We also model liquidity shocks as events in which local risky assets experience losses. These losses generate financial distress for banks due to their holdings of legacy assets. Banks are then forced to sell some of their legacy assets to another group of agents, "secondary buyers" (who reside in the same country). These buyers convert the assets to an alternative use that generates lower payoffs, following the standard fire-sale mechanism as in, e.g., Kiyotaki and Moore (1997). Our main results hold in this setting. Hence, "distressed sellers" introduce the standard balance sheet channel into our model while substantially simplifying the analysis. By endowing these agents with legacy assets and a technology with high return (large $\lambda$ ), we mechanically generate liquidity-driven asset sales and the misallocation of capital (from high to low-marginal-value agents) that results from these sales.

\section{Gross Flows and Global Liquidity Creation}

In this section we characterize the equilibrium. We show that, despite their fickleness, gross flows exist, contribute to global liquidity creation, and mitigate fire sales. We also show that foreign investment in period 0 is associated with a risk premium even though banks have linear utility in period 1 (thus risk aversion, the standard source of the risk premium, is absent). Throughout the rest of the paper, we focus on the following parametric condition.

Assumption 1. $e R / \lambda<\eta<e R$.

The right side of the inequality ensures the equilibrium features fire sales, $p_{s}<R$. The left side ensures $\lambda p_{s}>R$, so that distressed sellers always sell their legacy assets, $\tilde{\chi}_{s}^{j}=0$ [cf. Eq. (1)].

\subsection{Equilibrium and liquidity creation}

Under Assumption 1, we conjecture an equilibrium with symmetric prices that satisfy $p_{s} \in(R / \lambda, R)$ for each $s$. We also conjecture a symmetric equilibrium allocation in which each country invests the same amount in the risky asset of each other country, $x^{j^{\prime}, j}=x^{\text {out }, j}$ for each $j^{\prime} \neq j$; and all countries choose identical allocations. We denote these symmetric allocations by dropping the superscript $j$, that is,

$$
x^{\text {out }, j} \equiv x^{\text {out }}, y^{j} \equiv y, z_{s}^{j} \equiv z_{s} \text { for each } j .
$$


Note that these assumptions imply that the inflows into a country are equal to its outflows, $x^{i n, j} \equiv$ $x^{\text {in }}=x^{\text {out }}$ [cf. Eqs. (3) and (7)]. When it is clear from the context, we also drop the superscript "in" or "out" and denote these symmetric gross flows with $x$.

Since banks have linear utility between periods 1 and 2 , the presence of fire sales $\left(p_{s}<R\right)$ implies that banks in countries with state $\omega^{j}=b$ invest all of their resources in period 1 in the local risky asset, that is, $c_{1, s}^{j}\left(\omega^{j}=b\right)=0$, and their position on the risky asset, $\chi_{s}^{j}$, is determined by Eq. (6). In addition, since countries have symmetric allocations, the market clearing conditions (8) and (9) imply $y^{j}=y=\eta$ and $z_{s}^{j}=z_{s}=0$. Combining these observations with the budget constraints $(3),(5),(6)$, we obtain,

$$
\begin{aligned}
c_{0}^{j}+x^{j, j}+x^{\text {out }} & =1, \\
c_{1, s}^{j}\left(\omega^{j}=g\right) & =x^{j, j} R+x^{\text {out }} \bar{R}_{s}+\eta, \\
c_{2, s}^{j}\left(\omega^{j}=b\right) & =\left(x^{j, j} p_{s}+x^{\text {out }} \bar{R}_{s}+\eta\right) \frac{R}{p_{s}} .
\end{aligned}
$$

Substituting these expressions into the objective function in (2), and rearranging terms, the representative bank's problem can be written as,

$$
\begin{aligned}
& \max _{x^{j, j}, x^{\text {out }}} u\left(1-x^{j, j}-x^{\text {out }}\right)+x^{j, j} R+\sum_{s} \gamma_{s}\left(x^{\text {out }} \bar{R}_{s}+\eta\right) M_{s}, \\
& \text { where } M_{s} \equiv 1-\pi_{s}+\pi_{s} \frac{R}{p_{s}} .
\end{aligned}
$$

Here, $M_{s}$ denotes the expected period-1 marginal value of the consumption good conditional on the aggregate state $s$. When $\omega^{j}=g$, local banks do not have an investment opportunity in period 1 and consume their available resources. When $\omega^{j}=b$, local banks take advantage of local fire sales in period 1 to invest their available resources and obtain greater marginal value, $R / p_{s}>1$. The expression for expected marginal value, $M_{s}$, combines these two cases.

To solve problem (10), first note that the ex-ante marginal value from investing in the local risky asset is simply equal to its payoff, $R$. In contrast, the ex-ante marginal value from investing in foreign risky assets is given by, $\sum_{s} \gamma_{s} \mu_{s}\left(p_{s}\right)$, where

$$
\mu_{s}\left(p_{s}\right) \equiv \bar{R}_{s} M_{s}=\left(\left(1-\pi_{s}\right) R+\pi_{s} p_{s}\right)\left(1-\pi_{s}+\pi_{s} \frac{R}{p_{s}}\right)
$$

The function $\mu_{s}\left(p_{s}\right)$, captures the ex-ante marginal value conditional on the aggregate state $s$ and given the price level $p_{s}$. For banks, expected payoff from foreign investment is relatively low, $\bar{R}_{s}<R$, because they are fickle and sell their risky assets when there is a liquidity shock in the foreign country. On the other hand, expected period-1 marginal value is relatively high, $M_{s}>1$, because they retrench and use the liquidity from foreign assets to buy underpriced, distressed assets during a local liquidity shock. The ex-ante marginal value, $\mu_{s}\left(p_{s}\right)=\bar{R}_{s} M_{s}$, combines banks' costs and benefits from foreign investment. Our next result characterizes this expression and shows that 
it always exceeds the ex-ante marginal value from local investment.

Lemma 1. For each aggregate state $s$ with $\pi_{s} \in(0,1)$, the ex-ante marginal value from foreign investment, $\mu_{s}\left(p_{s}\right)$, is strictly decreasing in $p_{s}$ over the range $p_{s} \in(0, R]$, and it satisfies $\mu_{s}(R)=R$. In particular, when $p_{s} \in(0, R)$, we have $\mu_{s}\left(p_{s}\right)>R$ and investing in foreign risky assets dominates investing in local risky assets, so banks set $x^{j, j}=0$.

The possibility of local fire sales induces banks to invest in a diversified portfolio of foreign risky assets as a form of liquidity insurance. Consistent with this intuition, a decline in the fire-sale price at home, $p_{s}$, increases the marginal value from foreign investment, $\mu_{s}\left(p_{s}\right)$.

Combining Lemma 1 with problem (10), we characterize the equilibrium level of foreign investment as the solution to,

$$
u^{\prime}\left(1-x^{\text {out }}\right)=E\left[\bar{R}_{s} M_{s}\right]=\sum_{s} \gamma_{s} \mu_{s}\left(p_{s}\right)
$$

Banks buy foreign risky assets until the ex-ante marginal value from investment is equal to their current marginal utility from consumption. Note that a reduction in the fire-sale price $p_{s}$ (in any aggregate state with $\pi_{s}>0$ ) increases $x^{\text {out }}$ : a lower price increases the value of liquidity insurance, and this insurance is obtained by increasing foreign investment.

Next consider the determination of the fire-sale asset prices, $p_{s}$. Recall that $c_{1, s}^{j}\left(\omega^{j}=b\right)=0$ and $\chi_{s}^{j}$ is determined by Eq. (6) after substituting $y^{j}=\eta$ and $z_{s}^{j}=0$. Substituting this expression and $\tilde{\chi}_{s}^{j}=0$ into the market clearing condition (7), we obtain an expression for the fire-sale price,

$$
p_{s}=\frac{\eta+x^{\text {out }} \bar{R}_{s}}{e+x^{\text {in }}}
$$

The denominator captures the total amount of sales, comprised of liquidity-driven sales $(e)$ and past inflows, all of which are liquidated in a crisis. The numerator corresponds to local banks' available liquidity, which comes from their safe assets and their foreign asset positions, determined by past outflows. Eq. (14) says that (when there are fire sales) the asset price is determined by the cash-in-the-market per asset for sale. This expression illustrates the key tension captured by our model: while past inflows tend to reduce the fire-sale price, past outflows provide liquidity to retrenching local banks and help stabilize fire-sale prices.

Recall that, in a symmetric equilibrium, inflows and outflows in period 0 are equal to each other, $x^{\text {in }}=x^{\text {out }}=x$. Using this observation and the expression $\bar{R}_{s}=\left(1-\pi_{s}\right) R+\pi_{s} p_{s}$, we can solve Eq. (14) to obtain the following expression for fire-sale prices,

$$
p_{s}=P_{s}^{m c}(x) \equiv \frac{\eta+x\left(1-\pi_{s}\right) R}{e+x\left(1-\pi_{s}\right)}
$$

The last equality defines the market clearing relation, $p_{s}=P_{s}^{m c}(x)$, which describes the price level in state $s$ as a function of gross flows. Increasing gross flows increases both the numerator and the denominator, which captures the competing effects of retrenchment and fickleness on fire-sale prices. 
The following lemma resolves this tension and shows that retrenchment dominates fickleness.

Lemma 2. Under Assumption 1, for each aggregate state $s$ with $\pi_{s}<1$, the market clearing price level, $P_{s}^{m c}(x)$, is strictly increasing in symmetric gross flows, $x$.

Eq. (14) provides the intuition for why retrenchment dominates fickleness. Note that past inflows ( $x$ in the denominator) are liquidated at the fire-sale return, $p_{s}$. However, past outflows ( $x$ in the numerator) provide liquidity to retrenching local banks at a higher return, $\bar{R}_{s}$. When $p_{s}<R$ and $\pi_{s}<1$, the fire-sale return is lower than the return from foreign investment, $p_{s}<$ $\bar{R}_{s}=\left(1-\pi_{s}\right) R+\pi_{s} p_{s}$. It follows that symmetric flows increase liquidity in the bad state and raise fire-sale prices. Despite their fickleness, gross flows reallocate excess liquidity from foreign financial markets to the local market, which needs liquidity.

The equilibrium levels of gross flows and prices, $x,\left(p_{s}\right)_{s}$, are characterized by solving Eq. (13) together with Eq. (15) for each aggregate state $s$. We can now state our main result, which establishes the existence of a unique symmetric equilibrium that features $x \in(0,1)$, and $p_{s} \in$ $(R / \lambda, R)$. The result also compares the equilibrium prices with those that would obtain in an autarky allocation where all foreign investment is banned. In autarky, banks solve the same portfolio problem as before, with the additional restriction that $x^{j^{\prime}, j}=0$ for any $j^{\prime} \neq j$. It is easy to check that banks hold some local risky assets, $x^{j, j}=\underline{x}>0$, where $\underline{x}$ is the solution to, $u^{\prime}(1-\underline{x})=R$. However, these local investments do not generate any additional liquidity when there is a local liquidity shock in period 1. Therefore, the fire-sale price is still characterized by Eq. (15) after substituting zero capital flows. This yields a fire-sale price in autarky $p^{a u t}=\eta / e$, which, by Lemma 2 , is lower than the equilibrium price $p_{s}$.

Proposition 1 (Equilibrium Capital Flows and Global Liquidity Creation). Consider the model with Assumption 1. There exists a unique symmetric equilibrium allocation, $x^{j, j},\left(x^{\text {out }}=x^{i n}=x\right), y,\left(z_{s}, \chi_{s}\right)_{s}$, with symmetric prices, $\left(p_{s}\right)_{s}, q_{f},\left(q_{s}\right)_{s}$. The equilibrium allocation satisfies $x^{j, j}=0, y=\eta, z_{s}=0$. The tuple $\left(x,\left(p_{s}\right)_{s}\right)$ is characterized by Eqs. (13) and (15), and satisfies $x \in(0,1)$ and $p_{s} \in(R / \lambda, R)$ for each $s$. Capital flows create liquidity, in the sense that the fire-sale price is greater than the price that would obtain in the autarky allocation, that is, $p_{s} \geq p^{\text {aut }}=\eta /$ e for each $s$, with strict inequality if $\pi_{s}<1$.

Figure 2 illustrates this result for the special case with a single aggregate state. In this case, let $\pi \equiv \pi_{s} \in(0,1)$ denote the probability of a liquidity shock, $p \equiv p_{s}$ denote the fire-sale price, and $\mu(p)$ and $P^{m c}(x)$ denote the functions characterized in Lemmas 1 and 2. The declining curve in Figure 2 corresponds to the optimality condition, $u^{\prime}(1-x)=\mu(p)$. The increasing curve corresponds to the market clearing relation, $p=P^{m c}(x)$. The equilibrium is the intersection. The equilibrium price is strictly greater than the autarky price, which illustrates that gross flows help create liquidity and mitigate fire sales despite their fickleness. 


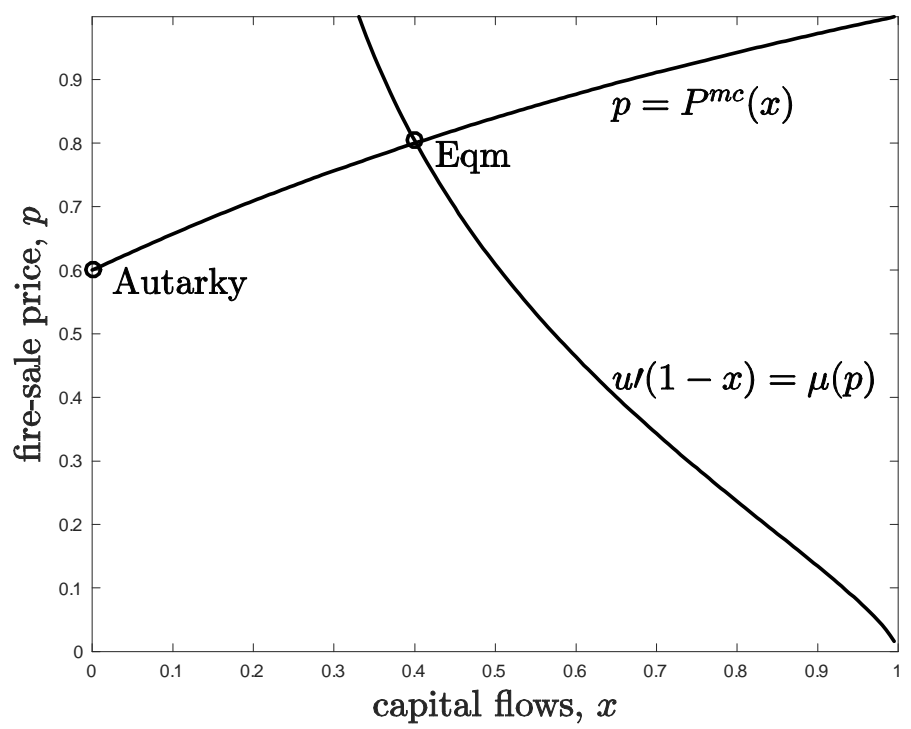

Figure 2: Equilibrium when there is a single aggregate state.

\subsection{Asset prices and returns}

Let us go back to the case with multiple aggregate states and characterize the equilibrium asset prices and returns. Recall our convention that $\pi_{s}$ is strictly increasing in $s$ so that states with a greater $s$ are associated with greater likelihood of liquidity shocks. Combining this with Eq. (15) illustrates that $p_{s}$ is strictly decreasing in $s$ : that is, states with a greater likelihood of liquidity shocks are associated with strictly lower equilibrium prices. Intuitively, these states have less global liquidity since more countries are simultaneously hit by the liquidity shock. This also implies that the payoff from foreign investment, $\bar{R}_{s}=\left(1-\pi_{s}\right) R+\pi_{s} p_{s}$, is strictly decreasing in $s$, whereas the marginal value in period $1, M_{s}=1-\pi_{s}+\pi_{s}\left(R / p_{s}\right)$ is strictly increasing in $s$.

Next consider the asset prices in period $0, q_{f},\left(q_{s}\right)_{s}$. Recall that the equilibrium features $y^{j}=\eta$ and $z_{s}^{j}=0$ for each $s$. Suppose banks in a country consider changing these allocations, $y^{j}, z_{s}^{j}$. Following similar steps as above (and using $x^{j, j}=0$ ) the optimal allocations solve,

$$
\begin{aligned}
& \max _{y^{j},\left(z_{s}^{j}\right)_{s}} u\left(c_{0}^{j}\right)+\sum_{s} \gamma_{s}\left(x^{\text {out }} \bar{R}_{s}+y^{j}+z_{s}^{j}\right) M_{s}, \\
& \text { where } c_{0}^{j}=1-x^{\text {out }}-q_{f}\left(y^{j}-\eta\right)-\sum_{s} q_{s} z_{s}^{j} .
\end{aligned}
$$

Using the optimality condition for $z_{s}^{j}$, we obtain an expression for Arrow-Debreu prices,

$$
\frac{q_{s}}{\gamma_{s}}=\frac{M_{s}}{u^{\prime}(1-x)}
$$

As usual, the stochastic discount factor (SDF), $q_{s} / \gamma_{s}$, is determined by the expected marginal value in the corresponding state divided by marginal utility in period 0 . Note also that $q_{s} / \gamma_{s}$ is strictly increasing in $s$ (because $M_{s}$ is strictly increasing). As expected, states with a greater probability 
of liquidity shocks feature more expensive state prices. For future reference, note that substituting Eq. (17) into (13) implies $1=\sum_{s} \bar{R}_{s} q_{s}$ : that is, the cost of foreign diversified investment is equal to the cost of the replicating portfolio of Arrow-Debreu securities.

Using the optimality condition for $y^{j}$, we solve for the risk-free asset price, $q_{f}=$ $E\left[M_{s}\right] / u^{\prime}(1-x)$. We define the risk-free return as the inverse of this price, $R_{f} \equiv 1 / q_{f}$. Using Eq. (13) to substitute for $u^{\prime}(1-x)$ in the expression for $q_{f}$, we obtain,

$$
R_{f}=\frac{E\left[\bar{R}_{s} M_{s}\right]}{E\left[M_{s}\right]}=E\left[\bar{R}_{s}\right]+\frac{\operatorname{cov}\left(\bar{R}_{s}, M_{s}\right)}{E\left[M_{s}\right]}
$$

Observing that covariance term is negative, since $\bar{R}_{s}$ is strictly decreasing in $s$ and $M_{s}$ is strictly increasing in $s$, we also find that the risk premium on foreign assets is positive,

$$
E\left[\bar{R}_{s}\right]-R_{f}=-\frac{\operatorname{cov}\left(\bar{R}_{s}, M_{s}\right)}{E\left[M_{s}\right]} \geq 0
$$

Here, the inequality is strict as long as there are multiple states. Intuitively, the risk-free asset provides valuable liquidity insurance in states (with higher $s$ ) in which aggregate liquidity is scarce, whereas risky foreign investment generates a relatively lower payoff in those states. In equilibrium, this reduces the risk-free rate and generates a risk premium on foreign investment.

Proposition 2 (Equilibrium Asset Prices and Risk Premia). Consider the symmetric equilibrium characterized in Proposition 1. The fire-sale price, $p_{s}$, is strictly decreasing in $s$ (which captures the likelihood of the liquidity shock). The state price, $q_{s} / \gamma_{s}$, is characterized by Eq. (17) and is strictly increasing in s. The return on the risk-free asset and the risk premium on foreign investment is characterized by Eqs. (18) and (19). The risk premium is strictly positive as long as there are multiple aggregate states.

\section{Regulating Gross Flows}

In this section, we analyze policies that regulate capital flows. We first characterize the constrained optimal allocation and show that the competitive equilibrium is constrained inefficient due to pecuniary externalities. We then show that there is a public-goods aspect to global liquidity creation that generates a need for coordinated policy.

Throughout, we focus on the special case with a single aggregate state, so we drop the subscript $s$ from all variables. We also assume the policymakers are utilitarian with identical welfare weights on all agents: the social welfare in each country $j$ is the sum of (local) banks' and (local) distressed sellers' expected utilities, $W^{j}=u\left(c_{0}^{j}\right)+E\left[c_{1}^{j}+c_{2}^{j}\right]+E\left[\tilde{c}_{2}^{j}\right]$.

\subsection{Constrained optimal allocation and externalities}

Consider a constrained social planner that can dictate (symmetric) period-0 local and foreign investment in each country but otherwise cannot interfere with the equilibrium allocations. We 
denote local investment with $x^{j, j}$, foreign investment with $x$, and the resulting equilibrium price with $p$. In view of Assumption 1, we conjecture that the resulting price satisfies $p \in(R / \lambda, R)$ for any choice of $\left(x^{j, j}, x\right)$.

Following similar steps as in Section 3, the market clearing condition (15) still applies. Moreover, the social welfare that results from this allocation is given by,

$$
W^{j}=u\left(1-x-x^{j, j}\right)+\left(x^{j, j}+x+e\right) R+\eta+(\lambda-1) e \bar{R},
$$

where $\bar{R}=(1-\pi) R+\pi p$. This expression is the sum of utility from investment activity by banks (first three terms) and net production by distressed sellers (last term). Conditional on risky investment $x+x^{j, j}$ in period 0 , the risky assets produce a total of $\left(x+x^{j, j}+e\right) R$ units of the consumption good in either period 1 or period 2. Safe assets produce an additional $\eta$ units of the consumption good in period 1. Finally, the investment activity by distressed sellers uses (in expectation) $e \bar{R}$ units of the consumption good in period 1 and delivers $\lambda e \bar{R}$ units in period 2 , for an expected net production of $(\lambda-1) e \bar{R}$. All of these resources are consumed by either banks or distressed sellers in periods 1 or 2 . Since these agents have linear utility over these periods, the utilitarian social welfare is given by (20) (see Online Appendix A.6 for details).

The constrained social planner chooses $x, x^{j, j} \geq 0$ to maximize (20) subject to the market clearing condition (15). Since $p$ is strictly increasing in $x$ (cf. Lemma 1) but does not depend on $x^{j, j}$, the optimum features $x^{j, j}=0$. That is, local investment is dominated both in equilibrium and in the constrained optimum.

However, the level of foreign investment in the constrained optimum can be different than in equilibrium. Specifically, the optimality condition for foreign investment implies,

$$
u^{\prime}(1-x)=R+(\lambda-1) e \pi \frac{d p}{d x} \quad \text { where } \quad \frac{d p}{d x}=\frac{(1-\pi)}{e+x(1-\pi)}(R-p) .
$$

To find the constrained optimum, we solve this expression together with the market clearing condition (15). Under Assumption 1, there exists a unique intersection that satisfies $x \in(0,1)$ and $p \in(R / \lambda, R)$. For comparison, recall that the equilibrium is characterized by solving a different optimality condition (13) together with the same market clearing condition (15) (see Figure 2). Hence, the equilibrium is typically constrained inefficient. The following proposition characterizes the direction of the inefficiency.

Proposition 3 (Constrained Optimal Allocation). Consider the model with Assumption 1 and a single aggregate state. The constrained optimal allocation, $(x, p)$, is characterized as the unique solution to Eqs. (21) and (15). Compared to the decentralized equilibrium allocation, denoted by $\left(x^{e q}, p^{e q}\right)$, the constrained planner chooses greater $x$ (which leads to greater $p$ ) if and only if,

$$
\frac{e \lambda+x^{e q}(1-\pi)+x^{e q} \pi\left(R / p^{e q}\right)}{e+x^{e q}}>\frac{R}{p^{e q}} .
$$

To understand this result, note that investing in foreign assets creates liquidity and increases the 
fire-sale price $p$ [via Eq. (15)]. The increase in the fire-sale price increases the wealth of the sellers and reduces the wealth of the buyers. These effects represent pecuniary externalities that the banks ignore but the planner takes into account. Condition (22) says that foreign investment is associated with net positive pecuniary externalities if and only if it increases sellers' average marginal value more than it decreases buyers' marginal value. Note that in a liquidity shock $e+x^{e q}$ units of the asset are sold (at the fire-sale price) from distressed sellers and fickle foreign banks to local banks. The right side of the expression describes the period-1 marginal value of the buyers (local banks), which is equal to $R / p^{e q}$. The left side describes the weighted average period-1 marginal value of the sellers, where the weights are proportional to the number of units that they sell. The distressed sellers have weight $e$ and marginal value $\lambda$, foreign investors in countries without a liquidity shock have weight $x^{e q}(1-\pi)$ and marginal value 1 , and foreign investors in countries with a liquidity shock have weight $x^{e q} \pi$ and marginal value $R / p^{e q}$.

In order to sharpen intuition, consider the extreme case where $\lambda \rightarrow \infty$. In this limit, condition (22) holds and thus the constrained optimal allocation features greater $x$ and $p$. In fact, foreign investment approaches one (its maximum feasible level) in the constrained optimum, whereas it is strictly below one in the competitive equilibrium. Intuitively, the sellers' average marginal value is dominated by distressed sellers' marginal value, which is large and exceeds buyers' marginal value. This leads to positive pecuniary externalities from foreign investment.

Now consider the case with lower $\lambda$. In this case, condition (22) can be violated because some of the sellers are fickle foreign banks that have lower marginal value than buyers (local banks). If the condition is violated, the constrained optimum features lower $x$ and $p$ than the equilibrium. Since raising fire-sale prices benefits both the distressed sellers and fickle foreigners with low marginal value, foreign investment generates negative pecuniary externalities when fickle foreigners benefit more than distressed sellers. The planner opts for lower foreign investment and lower fire-sale prices to transfer wealth from fickle foreign banks to local banks.

We view the distressed sellers in our setting as a modeling device to capture liquidity-driven sales that transfer risky assets from high to low-marginal value agents. In view of this interpretation, we take the case with high $\lambda$ and positive pecuniary externalities from foreign investment as the most natural benchmark for welfare analysis.

\subsection{Public-goods aspects of liquidity creation}

We next investigate whether local policymakers acting in isolation can achieve globally optimal outcomes without coordination. Specifically, suppose each country has a local policymaker that maximizes utilitarian social welfare in her own country. For the baseline scenario, we focus on the limit, $\lambda \rightarrow \infty$, while we relegate the discussion of the case with lower $\lambda$ to the end of this section. As $\lambda \rightarrow \infty$, maximizing the utilitarian social welfare becomes equivalent to maximizing the fire-sale

price in the local market, which we denote by $p^{j}$ (see Online Appendix A.3). That is, similar to the social planner in the previous subsection, local policymakers want to increase the fire-sale price. The difference is that they exclusively care about the price in their own country. 
To simplify the exposition, we equip local policymakers with a single binary policy instrument, $b^{j} \in\{0,1\}$, encoding the decision to allow or ban capital inflows. The local policymaker chooses $b^{j}$ at the beginning of period 0 , before any other decision is made. If $b^{j}=0$, then foreigners can invest in country $j$ as in our baseline model. If $b^{j}=1$, then foreign investment is banned in country $j$. In period 0 , banks choose their portfolio, $\left[x^{j^{\prime}, j} \geq 0\right]_{j^{\prime}}$, subject to the additional constraint that $x^{j^{\prime}, j}=0$ for each $j^{\prime} \neq j$ such that $b^{j^{\prime}}=1$. The remaining ingredients are the same as in Section 3 .

If all policymakers choose $b^{j}=0$, then we recover the equilibrium allocation with free flows. If instead all policymakers choose $b^{j}=1$, all foreign investment is banned, and we recover the autarky allocation. Recall that the price with free flows is strictly greater than in autarky (see Figure 2). Thus, a global policymaker that prescribes symmetric policies (with the objective of maximizing the symmetric fire-sale prices, $p$ ) would allow capital flows in all countries. Note that this is consistent with our analysis in Section 5.1: the global policymaker creates as much global liquidity as possible given the instruments she has access to.

We next characterize the Nash equilibrium outcome, and contrast it with the coordinated solution. First consider the equilibrium for a given configuration of policy choices. Suppose the sets of countries with $b^{j}=1$ ("banned countries") and $b^{j}=0$ ("free countries") are Lebesgue measurable with measures $B \in[0,1)$ and $1-B$, respectively. As before, we focus on a symmetric equilibrium in which each banned country chooses identical and fully diversified foreign investment in each free country, denoted by $x^{b a n} \geq 0$, and experiences identical fire-sale prices, $p^{b a n} \in(0, R)$. Likewise, each free country chooses identical and fully diversified foreign investment in each free country, denoted by $x^{\text {free }} \geq 0$, and experiences identical fire-sale prices, $p^{\text {free }} \in(0, R)$. Following similar steps as above, the fire-sale price levels satisfy,

$$
p^{\text {ban }}=\frac{\eta+(1-B) x^{b a n} \bar{R}^{\text {free }}}{e} \text { and } p^{\text {free }}=\frac{\eta+(1-B) x^{\text {free }} \bar{R}^{\text {free }}}{e+B x^{\text {ban }}+(1-B) x^{\text {free }}},
$$

where $\bar{R}^{\text {free }}=(1-\pi) R+\pi p^{\text {free }}$. The equilibrium tuple, $\left(p^{\text {ban }}, p^{\text {free }}, x^{\text {ban }}, x^{\text {free }}\right)$, is characterized by solving these equations jointly with the optimality conditions (see Online Appendix A.3). The expressions for fire-sale prices show that for banned countries, inflows (zero) are smaller than outflows $\left[(1-B) x^{b a n}\right]$. In contrast, for free countries, inflows $\left[B x^{b a n}+(1-B) x^{\text {free }}\right]$ are greater than outflows $\left[(1-B) x^{\text {free }}\right]$. These net imbalances raise the fire-sale price in banned countries while lowering the price in free countries. In equilibrium, the optimal levels of outflows also react to these changes, but these induced effects do not overturn the initial effect: that is, $p^{\text {ban }}>p^{\text {free }}$ in any symmetric equilibrium with $B \in[0,1)$.

Now consider the Nash equilibrium among the policymakers. Since $p^{\text {ban }}>p^{\text {free }}$ for $B<1$, the only candidate for equilibrium is the autarky allocation in which all policymakers ban capital inflows. In Online Appendix A.3, we verify that this is an equilibrium and establish the following result.

Proposition 4 (Nash Equilibrium with Restrictions on Capital Inflows). Consider the model with 
Assumption 1 in which local policymakers choose whether to ban capital inflows, $b^{j} \in\{0,1\}$. Suppose $\lambda \rightarrow \infty$ so that each policymaker's objective is to maximize the asset price in her own country, $p^{j}$. Then, the unique Nash equilibrium features bans on capital inflows, $b^{j}=1$ for each $j$, whereas the symmetric constrained optimum features free capital flows, $b^{j}=0$ for each $j$.

In particular, the Nash equilibrium generates strictly lower fire-sale prices and lower welfare in every country compared to a coordinated equilibrium (see Figure 2). This discrepancy arises because global liquidity is a public good: policymakers that make locally optimal policy choices ignore their impact on global liquidity. Every inflow into a country corresponds to an outflow that provides liquidity and raises fire-sale asset prices in the sending country. In the limit $\lambda \rightarrow \infty$, greater asset prices improve welfare by mitigating fire-sale externalities. Local planners ignore the beneficial effects of inflows for sending countries while fully internalizing the fickleness costs, as these costs are felt at the local level, which leads to smaller capital flows and liquidity.

Finally, consider the alternative scenario where $\lambda$ is lower. As our analysis in Section 5.1 suggests, the global policymaker might prefer to reduce foreign investment and fire-sale prices. Nonetheless, coordination improves welfare in this less standard case, too. Consider the extreme version where the policymakers have the objective function $-p^{j}$ : that is, they would like to minimize the local fire-sale price. We can check that a coordinated solution would ban capital flows whereas the Nash equilibrium would feature free capital flows. In this scenario, liquidity is a public "bad", which leads to a coordination problem in the opposite direction.

The general point is that, when liquidity has a first-order effect on welfare, capital flows must be coordinated because they contribute to global liquidity. Fickleness exacerbates the coordination problem because it lowers local liquidity during distress and induces local policymakers to take different actions than a global policymaker would prescribe.

\section{Determinants of Gross Flows}

In this section we analyze the determinants of gross flows in our setting.

\subsection{The beta model}

We conduct our analysis using a special case of the model ("the beta model") that leads to closed form solutions. In this model, liquidity shocks are either completely uncorrelated or fully correlated across countries. Specifically, there are three aggregate states, $s \in\{1,2,3\}$, with,

$$
\pi_{1}=0, \quad \pi_{2}=\pi, \quad \pi_{3}=1
$$

for some $\pi \in(0,1)$. In particular, state $s=2$ corresponds to the case in which the liquidity shocks are i.i.d. across countries. States $\{1,3\}$ together can be thought of as a "correlated shock" state in which the liquidity shocks are perfectly correlated across countries. Specifically, either all countries 
are hit (state 3 ) or no country is hit (state 1). We also assume the state probabilities are given by,

$$
\gamma_{1}=\beta(1-\pi), \quad \gamma_{2}=1-\beta, \quad \gamma_{3}=\beta \pi
$$

Here, the parameter $\beta \in(0,1)$ captures the probability that shocks are correlated.

Note that the expected returns and marginal values conditional on each aggregate state are,

$$
\begin{aligned}
\bar{R}_{1}=R, & \bar{R}_{2}=(1-\pi) R+\pi p_{2}, & \bar{R}_{3}=p_{3}, \\
M_{1}=1, & M_{2}=1-\pi+\pi R / p_{2}, & M_{3}=R / p_{3} .
\end{aligned}
$$

Next note that the ex-ante marginal value from foreign investment satisfies, $\mu_{1}\left(p_{1}\right)=\bar{R}_{1} M_{1}=R$ and $\mu_{3}\left(p_{3}\right)=\bar{R}_{3} M_{3}=R$. Thus, Eq. (13) becomes,

$$
u^{\prime}(1-x)=E\left[\bar{R}_{s} M_{s}\right]=\beta R+(1-\beta) \mu_{2}\left(p_{2}\right)
$$

where $\mu_{2}\left(p_{2}\right)=\bar{R}_{2} M_{2}$. The market clearing condition (15) implies,

$$
p_{2}=P_{2}^{m c}(x)=\frac{\eta+x(1-\pi) R}{e+x(1-\pi)} .
$$

Eqs. (27) and (28) determine the pair, $\left(x, p_{2}\right)$. Figure 3, which is a generalized version of Figure 2, provides a pictorial illustration of the equilibrium pair, $\left(x, p_{2}\right)$.

Using the market clearing condition (15), we calculate the price in state 3 (with $\pi_{3}=1$ ) as,

$$
p_{3}=\frac{\eta}{e}
$$

We omit the derivation of $p_{1}$, which plays no role since there are no liquidity shocks in state 1 $\left(\pi_{1}=0\right)$. This also implies that the average fire-sale price conditional on a correlated shock (states $\{1,3\})$ is equal to $p_{3}$. Note that we have $p_{3}<p_{2}$ : that is, the correlated shock state features lower fire-sale prices on average than the state with uncorrelated shocks.

Next consider the prices and returns for financial assets. Using Eq. (25), the expected return on foreign assets depends on the expected fire-sale price, that is,

$$
E\left[\bar{R}_{s}\right]=(1-\pi) R+\pi\left(\beta p_{3}+(1-\beta) p_{2}\right)
$$

State prices are given by $q_{s} / \gamma_{s}=M_{s} / u^{\prime}(1-x)$ where $M_{s}$ are characterized in (26).

Finally, combining Eq. (18) with Eqs. (26) and (27), the risk-free rate can be calculated as,

$$
R_{f}=\frac{E\left[\bar{R}_{s} M_{s}\right]}{E\left[M_{s}\right]}=\frac{\beta R+(1-\beta) \mu\left(p_{2}\right)}{\beta\left(1-\pi+\pi R / p_{3}\right)+(1-\beta)\left(1-\pi+\pi R / p_{2}\right)},
$$

The risk premium can be obtained from Eqs. (30) and (31). Thus, Eqs. (25-31) provide a closed-form characterization of the equilibrium in the beta model. We use this model to establish 

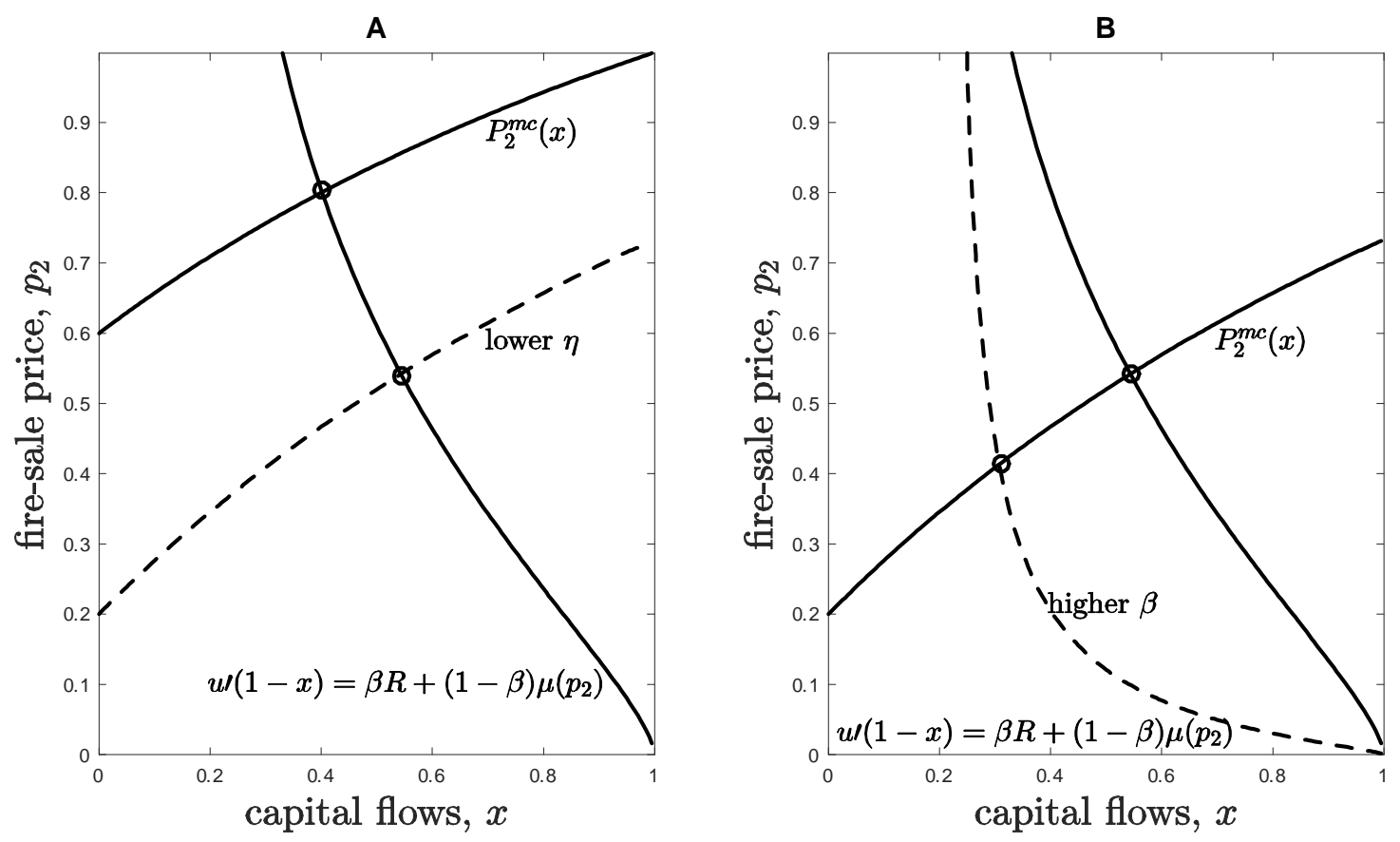

Figure 3: Comparative statics of equilibrium. A, change in the supply of safe assets; B, change in the probability of correlated liquidity shocks.

a number of comparative statics results.

\subsection{Safe-asset scarcity}

Consider a reduction in the supply of safe assets, $\eta$. By Eq. (29), this reduces the fire-sale price in the correlated shock state, $p_{3}$. To see the effect on the rest of the equilibrium, recall that the pair, $\left(x, p_{2}\right)$, is characterized by the optimality condition (27) and the market clearing relation (28). The left panel of Figure 3 shows that a decline in $\eta$ shifts the market clearing equation downward without affecting the optimality condition. This increases capital flows, $x$, while also reducing the fire-sale price in the uncorrelated state, $p_{2}$. Intuitively, the fire-sale price declines because banks have less liquidity to arbitrage asset fire sales [cf. Eq. (28)]. Anticipation of these more severe fire sales induces greater ex-ante investment in foreign risky assets to obtain liquidity insurance [cf. Eq. (27)]. When safe assets are scarcer, there is greater demand for global liquidity, and gross capital flows increase to meet this need.

Next consider the impact on expected asset returns in period 0. By Eq. (30), the expected return on risky foreign assets declines due to lower fire-sale prices. In Online Appendix A.6, we show that the risk-free return characterized by Eq. (31) also declines. Finally, consider the risk premium on foreign assets, $E\left[\bar{R}_{s}\right]-R_{f}$. We can check that the risk premium becomes zero as $\eta \rightarrow e R$ (as this limit features $p_{s} \rightarrow R$ and $M_{s} \rightarrow 1$ for each $s$ ), whereas it is strictly positive for any $\eta<e R$ [see Eq. (19)]. Thus, in the neighborhood of abundant safe assets, $\eta=e R$, the decline in $\eta$ also increases the risk premium. The following result summarizes this discussion. 
Proposition 5. Consider the beta model described in this section. A reduction in $\eta$ (which exacerbates safe-asset scarcity) increases gross flows, $x$, reduces fire-sale prices, $p_{2}$ and $p_{3}$, and reduces the expected risky and safe asset returns, $E\left[\bar{R}_{s}\right]$ and $R_{f}$. In the lower neighborhood of $\eta=e R$, the reduction in $\eta$ also increases the risk premium, $E\left[\bar{R}_{s}\right]-R_{f}$.

This result provides one explanation for the worldwide increase in gross capital flows in the run-up to the global financial crisis (see Bluedorn et al. (2013)). Through the lens of our model, gross flows increased, at least partly, as a response to the global safe asset scarcity that developed in early 2000s (see e.g., Caballero (2006)).

\subsection{Global shocks and the global financial cycle}

Now consider an increase in the probability of the correlated shock state, $\beta$. The right panel of Figure 3 illustrates that this increase shifts the optimality curve downward without affecting the market clearing equation. Hence, it lowers gross flows, $x$, and the fire-sale price in the uncorrelated state, $p_{2}$. Correlated shocks reduce the liquidity insurance value of capital flows, which translates into lower ex-ante foreign investment, $x$, and lower ex-post liquidity. Lower ex-post liquidity reduces the price even in the uncorrelated state. That is, the possibility of correlated shocks, by reducing capital flows, affects asset prices even if those shocks are ultimately unrealized. The impact on expected asset returns in period 0 is analogous to the impact of the decline in $\eta$ described in the previous subsection, which leads to the following result.

Proposition 6. Consider the beta model described in this section (with Assumption 1). An increase in $\beta$ (which increases the correlation of the liquidity shocks) reduces capital flows, $x$, reduces the fire-sale asset price in the uncorrelated state, $p_{2}$, and reduces the expected risky and safe asset returns, $E\left[\bar{R}_{s}\right]$ and $R_{f}$. In the neighborhood of $\beta=0$, an increase in $\beta$ also increases the risk premium, $E\left[\bar{R}_{s}\right]-R_{f}$.

An increase in $\beta$ in this model can be thought of as capturing a "risk-off" environment in which the banks become more concerned about investing abroad. This reduces capital flows and liquidity creation, while also reducing the risk-free rate and increasing the risk premium. This result is consistent with the large and persistent decline in gross capital flows in the aftermath of the global financial crisis illustrated in Figure 1 (see also Bluedorn et al. (2013); Lane and MilesiFerretti (2012), and Milesi-Ferretti and Tille (2011)). Through the lens of our model, the global crisis increased the (real or perceived) correlations of financial crises, which in turn reduced the usefulness of gross capital flows as liquidity insurance. ${ }^{6}$

\footnotetext{
${ }^{6}$ In Online Appendix B.3, we corroborate that the correlations of stock price changes in OECD countries increased after the crisis and remained elevated for several years (see Figure A1). However, note that other factors, such as the implementation of the Basel III accord that restricted banks' risk-taking, also contributed to depressing gross capital flows. Conversely, the increase in bank capital and leverage before the crisis arguably contributed to the growth of gross capital flows at that time.
} 


\section{Reach for Safety and Yield}

In our baseline model, countries are symmetric and gross capital flows are entirely driven by the liquidity insurance motive. In this section, we deviate from the baseline model by introducing asymmetries in liquidity supply and risky asset return across countries. We illustrate two additional mechanisms that might drive capital flows, reach-for-safety and reach-for-yield, and we investigate how they affect fire sales.

\subsection{The model with a special country}

Suppose all but one of the countries are "regular" and have the parameters described in the previous section. The remaining country is "special" and can have different parameters, $\left(\eta^{*}, R^{*}\right)$ : its supply of safe assets is given by $\eta^{*}$, and the return on its risky assets is given by $R^{*}$. As before, banks in the special country are endowed with all this country's safe assets as well as one unit of the consumption good in period 0 . The rest of the model is unchanged. To simplify the exposition, we assume $\pi_{1}>0$, so liquidity shocks happen with strictly positive probability in all aggregate states (see Online Appendix A.4 for cases with $\pi_{1}=0$ ).

Since the special country has Lebesgue measure zero, the equilibrium allocations and prices in the regular countries are the same as the symmetric equilibrium characterized in the previous sections, denoted by $x,\left(p_{s}\right)_{s}, q_{f},\left(q_{s}\right)_{s}$. Our goal is to characterize the equilibrium allocations and prices in the special country, which we denote by $x^{*, *}, x^{i n, *}, x^{\text {out }, *}, y^{*},\left(z_{s}^{*}\right)_{s},\left(\tilde{\chi}_{s}^{*}\right)_{s},\left(p_{s}^{*}\right)_{s}$. Throughout, we assume the parameters in the special country satisfy the following:

Assumption 2.

$$
R^{*}-R \in\left[0, \frac{\eta}{e} \frac{\sum_{s} q_{s} \pi_{s}}{\sum_{s} q_{s}\left(1-\pi_{s}\right)}\right], \eta^{*}-\eta \geq-\frac{\sum_{s} q_{s} p_{s} x}{q_{f}}
$$

In particular, the special country has weakly greater return, $R^{*} \geq R$, which suffices to cover the cases of interest, and its parameters are not too different from those in regular countries, which yields an interior solution.

First consider the investments regular countries' banks make in the special country, $x^{i n, *}$. In view of Assumption 2, we conjecture an equilibrium with strictly positive inflows, $x^{i n, *}>0$. We assume that foreign banks are indifferent between investing in the special country and regular countries at the margin. We can state this using a no-arbitrage condition between investments into the special country and other countries,

$$
1=\sum_{s} \bar{R}_{s}^{*} q_{s}=\sum_{s} \bar{R}_{s} q_{s}, \text { where } \bar{R}_{s}^{*}=\left(1-\pi_{s}\right) R^{*}+\pi_{s} p_{s}^{*}
$$

This condition says that (when there is positive investment into the special country) the cost of investment (one unit) must be equal to the value of a replicating portfolio of Arrow-Debreu securities. $^{7}$ The second equality (which we established in Section 4.2) says that the same condition

\footnotetext{
${ }^{7}$ We technically state this as an assumption because banks in regular countries are actually indifferent to taking
} 
holds for investment into regular countries.

Next consider investments by the special country's banks, $x^{\text {out }, *}, y^{*},\left(z_{s}^{*}\right)_{s}$. These values are not uniquely determined because there are multiple equivalent ways of obtaining the same payoff vector. We therefore define the country's liquidity purchase (or sale) in each aggregate state as,

$$
l_{s}^{*}=x^{o u t, *} \bar{R}_{s}+y^{*}+z_{s}^{*}-\eta^{*} .
$$

Note that $l_{s}^{*}$ captures the additions to the country's liquidity starting from its endowment, $\eta^{*}$. We conjecture that the equilibrium also features fire sales in the special country, $p_{s}^{*}<R^{*}$ for each $s$. Then, banks in the special country solve the following analogue of problem (10),

$$
\begin{aligned}
& \max _{x^{*, *} \geq 0,\left(l_{s}^{*} \geq-\eta^{*}\right)_{s}} u\left(c_{0}^{*}\right)+x^{*, *} R^{*}+\sum_{s} \gamma_{s} l_{s}^{*} M_{s}^{*}, \\
& \text { where } c_{0}^{*}+x^{*, *}+\sum_{s} q_{s} l_{s}^{*}=1 .
\end{aligned}
$$

In Online Appendix A.6, we show that $x^{*, *}=0$, that is, foreign investment dominates local investment for the special country. The remaining optimality conditions (for an interior solution) are,

$$
\frac{q_{s}}{\gamma_{s}}=\frac{M_{s}^{*}}{u^{\prime}\left(c_{0}^{*}\right)}=\frac{M_{s}}{u^{\prime}\left(c_{0}\right)}, \text { where } M_{s}^{*}=1-\pi_{s}+\pi_{s} \frac{R^{*}}{p_{s}^{*}} .
$$

Hence, the relative SDF is equal to the relative marginal value of banks in the special country and the regular countries (as we established in Section 4.2).

Finally, consider the equilibrium value of fire-sale prices in the special country, $\left(p_{s}^{*}\right)_{s}$. Using similar steps as before, these prices are determined by the following analogue of Eq. (14),

$$
\begin{aligned}
p_{s}^{*} & =\frac{\eta^{*}+l_{s}^{*}}{e-\tilde{\chi}_{s}^{*}+x^{i n, *}} \\
\text { where } \quad \tilde{\chi}_{s}^{*} & =0 \text { if } \lambda p_{s}^{*} \geq R^{*} \text { and } \tilde{\chi}_{s}^{*}=e \text { if } \lambda p_{s}^{*}<R^{*} .
\end{aligned}
$$

Here, $\tilde{\chi}_{s}^{*}$ denotes the optimal amount of legacy assets the distressed sellers in the special country retain [cf. Eq. (1)], which is not necessarily zero unless we strengthen Assumption 1 (specifically, we could ensure $\tilde{\chi}_{s}^{*}=0$ by considering the limit, $\left.\lambda \rightarrow \infty\right)$. The following result establishes the existence of an equilibrium.

Proposition 7. Consider the model with Assumption 1 and $\pi_{1}>0$, together with a special country that satisfies Assumption 2. There exists an equilibrium in which the allocations and prices for regular countries are characterized by Propositions 1-2. In the special country, there is no local investment, $x^{*, *}=0$. The remaining allocations, $x^{i n, *}, c_{0}^{*},\left(l_{s}^{*}\right)_{s},\left(p_{s}^{*}\right)_{s},\left(\tilde{\chi}_{s}^{*}\right)_{s}$, are characterized as the unique solution to the system of equations $(32-36)$.

any nonnegative position in the special country, as this country has measure zero. In a version of the model in which the special countries have strictly positive but small mass $\Delta>0$, condition (32) always holds in equilibrium. Hence, the equilibrium we analyze can be viewed as the limit of these equilibria as $\Delta \rightarrow 0$. 
We next use this model to illustrate capital flows driven by reach for safety and reach for yield. Unlike regular countries, the special country trades safe and contingent assets in equilibrium, which modifies the balance of payments accounting. We adopt the convention that total inflows are equal to foreign investment in local risky assets, $\bar{x}^{i n, *} \equiv x^{i n, *}$; whereas total outflows account for the local investment in foreign risky assets and the net trade of safe and contingent assets, ${ }^{8}$

$$
\begin{aligned}
\bar{x}^{\text {out }, *} & \equiv x^{\text {out }, *}+q_{f}\left(y^{*}-\eta^{*}\right)+\sum_{s} q_{s} z_{s}^{*} \\
& =\sum_{s} q_{s} l_{s}^{*}=1-c_{0}^{*} .
\end{aligned}
$$

Here, the second line uses the definition of $l_{s}^{*}$ (together with the no-arbitrage condition, $\sum_{s} \bar{R}_{s} q_{s}=$ 1) as well as the budget constraint (33). Hence, total outflows are equal to the value of banks' liquidity purchases in period 0 . Since there is no local investment in period 0 , these purchases are also equal to the banks' endowment in period 0 net of their consumption.

\subsection{Reach for safety and global imbalances}

We first abstract away from return differences (i.e., $R^{*}=R$ ), and focus on the effect of asymmetries in the liquidity supply (i.e., $\eta^{*} \neq \eta$ ). We can think of a developed country with deep financial markets and a large supply of safe assets - such as the U.S. - featuring $\eta^{*}>\eta$. Conversely, an emerging market country can be thought of as having $\eta^{*}<\eta$.

As a benchmark, consider the autarky allocation in which the special country does not exchange capital flows with regular countries. It is easy to check that the special country's autarky price is characterized by $p_{s}^{*}=\min \left(R, \eta^{*} / e\right)$ for each $s$ (see Proposition 1 for a similar result for regular countries). In particular, a special developed country with sufficiently high liquidity, $\eta^{*}>e R$, would completely avoid fire sales whereas regular countries would experience fire sales, that is, $p_{s}^{*}=R>p_{s}$ for each $s$. In contrast, a special emerging market country with $\eta^{*}<\eta$ would experience more severe fire sales than regular countries, $p_{s}^{*}=\eta^{*} / e<p_{s}$ for each $s$.

Next, we analyze the equilibrium with free capital flows. Using Proposition 7, we can verify that the equilibrium in the special country obtains when, $c_{0}^{*}=c_{0}, \tilde{\chi}_{s}^{*}=0$, and,

$$
\begin{aligned}
p_{s}^{*} & =p_{s}<R \\
x^{i n, *} & =x+(e+x)(\Lambda-1), \\
\bar{x}^{\text {out }, *} & =x, \\
l_{s}^{*} & =\Lambda x \bar{R}_{s}-\left(\eta^{*}-\Lambda \eta\right),
\end{aligned}
$$

\footnotetext{
${ }^{8}$ With trade in safe and contingent assets, gross flows are indeterminate since the special country can always sell a financial asset to regular countries and purchase exactly the same asset from those countries. This would increase inflows and outflows without any additional effects. Our definition excludes these types of spurious flows and focuses on the lowest level of gross flows that can emerge in our setting.
} 
where we refer to $\Lambda$ as the leverage ratio of outflows, and define it as,

$$
\Lambda=\frac{x+q_{f} \eta^{*}}{x+q_{f} \eta}
$$

The first line in (38) says that the asset prices in the special country are the same as asset prices in regular countries. In particular, even though a developed country with $\eta^{*}>e R$ would avoid fire sales in autarky, it cannot escape fire sales in equilibrium with free capital flows. Conversely, an emerging market country with $\eta^{*}<\eta$ obtains higher fire-sale prices with free capital flows than it would obtain in autarky.

To understand these results, consider the case of a developed country with $\eta^{*}>\eta$ (the case with $\eta^{*}<\eta$ is symmetric). All else equal, greater liquidity in this special country increases its fire-sale prices, which increases the expected return, $\sum_{s} \bar{R}_{s}^{*} q_{s}$, above the level obtained in regular countries, $\sum_{s} \bar{R}_{s} q_{s}$. This temporarily violates the indifference condition (32) and makes the special country's assets attractive to foreign banks. The special country's increased appeal translates into greater inflows, $x^{\text {in,* }}$ and lower fire-sale prices as illustrated by Eq. (35). This process stops only when the special country also experiences severe fire sales that equate its expected return with the expected returns in regular countries. In fact, the second and the third lines of Eq. (38) illustrate that the developed country receives more inflows than outflows (it has a current account deficit). These net inflows neutralize the country's initial liquidity advantage and induce a fire sale in equilibrium.

While this intuition explains why fire sales in the developed country are as severe as in the regular countries on average, it does not explain why asset prices are equated state-by-state. In fact, from the earlier market clearing condition (15), one could expect a developed country to have relatively high prices in states with high $\pi_{s}$ where global liquidity is low-because its greater local liquidity supply can provide some cushion. This does not happen in our model because banks in the developed country do not necessarily retain their initial endowments of liquidity. Rather, as captured by Eqs. (34) and (35), they trade financial assets to move their liquidity across aggregate states.

The last line in (38) characterizes the equilibrium outcome from these trades. Banks in the developed country sell some of their safe asset endowments, $\eta^{*}-\Lambda \eta$ (which is positive when $\eta^{*}>\eta$ ), to increase their investment in a diversified foreign portfolio. We refer to $\Lambda$ as the leverage ratio of outflows, because it captures the value of foreign risky asset investments divided by the value of outflows [note that $\left(\sum_{s} \Lambda x \bar{R}_{s} q_{s}\right) / x=\Lambda$ in view of Eq. (32)]. For regular countries (that feature $\left.\eta^{*}=\eta\right)$, the leverage ratio is normalized to one. For a developed country, the leverage ratio is greater than one, $\Lambda>1$, meaning that the country's outflows are riskier than outflows in other countries. Intuitively, banks in the developed country are selling some of their excess liquidity to take advantage of the positive risk premium on foreign assets [cf. Eq. (19)]. In our model, this effect is strong and ensures that the special country has the same (fire-sale) asset price as the regular countries in every state.

Conversely, an emerging market country with $\eta^{*}<\eta$ has more outflows relative to its inflows 
$\left(\bar{x}^{\text {out }, *}=x>x^{i n, *}\right)$, and its outflows are also safer than those in regular countries, $\Lambda<1$. Intuitively, the scarcity of liquidity in the special country reduces its inflows, while also inducing its banks to purchase safe assets from abroad to obtain additional liquidity (by paying the risk premium). These forces improve fire-sale prices relative to what the country would obtain in autarky. The following result summarizes this discussion.

Proposition 8. Consider the setup in Proposition 7 with $R^{*}=R$ and $\eta^{*} \neq \eta$. With free financial flows, the equilibrium allocations in the special country are given by (38). Regardless of its liquidity supply, the special country experiences fire sales with prices that are equal to those in regular countries, $p_{s}^{*}=p_{s}<R$ for each $s$. When $\eta^{*}>\eta$, the country receives more inflows than outflows, $x^{\text {in,* }}>\bar{x}^{\text {out }, *}=x$, and has riskier (more leveraged) outflows than regular countries, $\Lambda>1$. When $\eta^{*}<\eta$, the country has more outflows than inflows, $\bar{x}^{\text {out }, *}=x>x^{i n, *}$, and safer (less leveraged) outflows than regular countries, $\Lambda<1$.

These results suggest that reach-for-safety flows have potentially destabilizing effects for developed markets with $\eta^{*}>\eta$ but stabilizing effects for emerging markets with $\eta^{*}<\eta$.

Our results are consistent with the empirical work in Gourinchas and Rey (2007) and Gourinchas et al. (2010), who document that outflows from the U.S. are riskier than its inflows. They show that the U.S. earns a risk premium on capital flows in normal times, but it transferred resources and provided insurance to the rest of the world during the global financial crisis. Our model suggests that these transfers exacerbated the severity of the crisis in the U.S., while mitigating its impact in the countries that held the (relatively) safe U.S. assets.

In Online Appendix A.4, we extend this analysis to the beta model from Section 6 to investigate how the global risk conditions affect the reach for safety. We show that an increase in the correlation parameter, $\beta$, increases the absolute value of the country's imbalances as a fraction of outflows, $\left|x^{\text {in }, *}-x\right| / x$, as well the absolute value of its relative leverage ratio, $|\Lambda-1|$. These results suggest that the "risk off" induced by the increase in $\beta$ strengthens the flows driven by reach for safety.

\subsection{Reach for yield}

We next abstract away from differences in liquidity supply (i.e., $\eta^{*}=\eta$ ), and investigate the effect of asymmetries in return, $\left(R^{*} \neq R\right)$. We focus on the more interesting case with $R^{*}>R$, so that the special country can be thought of as a rapidly growing or high-yielding emerging market country.

Note that Eqs. (32) and (34) can be combined to obtain,

$$
\begin{aligned}
\sum_{s \in S} q_{s}\left(\left(1-\pi_{s}\right) R^{*}+\pi_{s} p_{s}^{*}\right) & =\sum_{s \in S} q_{s}\left(\left(1-\pi_{s}\right) R+\pi_{s} p_{s}\right) \\
\frac{1-\pi_{s}+\pi_{s} \frac{R^{*}}{p_{s}^{*}}}{1-\pi_{s}+\pi_{s} \frac{R}{p_{s}}} & =\frac{u^{\prime}\left(c_{0}^{*}\right)}{u^{\prime}\left(c_{0}\right)} \text { for each } s \in S .
\end{aligned}
$$

This represents a system of $|S|+1$ equations in $|S|+1$ unknowns, $\left(p_{s}^{*}\right)_{s}, c_{0}^{*}$. In Online Appendix 
A.6, we show that there is a unique solution to this system (see Lemma 4). We characterize the remaining equilibrium allocations by solving the rest of the equations listed in Proposition 7 .

We also show that, when $R^{*}>R$, the solution satisfies $p_{s}^{*}<p_{s}$ for each $s$; that is, the firesale prices in the special country are lower than in regular countries. To understand this result, suppose the countries had identical fire-sale prices, $p_{s}^{*}=p_{s}$. This would violate the indifference condition (40), because foreign banks would strictly prefer to invest in the special country. Foreign investment would increase the inflows into the special country $x^{i n, *}$, and lower the fire-sale prices according to (35). This process stops only when the special country's fire-sale prices are lower and the indifference condition is reestablished. Using more subtle arguments, we show that the special country obtains a lower fire-sale price in every aggregate state $s$.

Furthermore, we show that $p_{s}^{*} / p_{s}$ is strictly increasing in $s$; that is, fire-sale prices in the special country are relatively higher in aggregate states with a greater likelihood of liquidity shocks. Eq. (41) illustrates that local banks in the special country distribute their liquidity across states to equate their expected marginal value. Since (by assumption) crises are more frequent in states with higher $s$, they purchase more liquidity insurance for these states. This mitigates the fire sales caused by the reach-for-yield inflows in states with higher $s$ (e.g., the global financial crisis), at the expense of deepening the fire sales in states with lower $s$ (more localized crises).

The solution satisfies, $c_{0}^{*}<c_{0}$, which implies $\bar{x}^{\text {out,*}}>x$ [cf. Eq. (37)]. Thus, the special country has greater outflows than the regular countries. Put differently, banks in the special country take precautions not only by purchasing more insurance (as in the previous result) but also by holding more foreign assets. Nonetheless, with free capital flows, these attempts to obtain greater insurance make the country attractive to foreigners and ultimately translate into greater inflows. Formally, we show that $x^{i n, *}>\bar{x}^{\text {out,*}}>x$ : the reach for yield increases the special country's inflows more than its outflows. The following result summarizes this discussion.

Proposition 9. Consider the setup in Proposition 7 with $\eta^{*}=\eta$ and $R^{*}>R$. With free financial flows, the special country experiences larger price drops than the regular countries in all states. However, this difference is smaller in more distressed states: $p_{s}^{*} / p_{s}<1$ for each $s$, and $p_{s}^{*} / p_{s}$ is strictly increasing in $s$. The special country's inflows exceed its outflows, $x^{\text {in,* }}>\bar{x}^{\text {out }, *}$, which in turn exceed the gross flows in (otherwise comparable) regular countries, $\bar{x}^{\text {out }, *}>x$.

In Online Appendix A.4, we extend this analysis to the beta model from Section 6 to investigate how global return and risk conditions affect the reach for yield. All else equal, a decline in investment returns in regular countries, $R$, reduces fire-sale prices (on average) in the special country relative to their counterpart in regular countries. Intuitively, lower returns in other countries make investing in high-yielding countries more attractive, but this is countered by lower fire-sale prices as in Proposition 9. These results are consistent with recent findings that depressed interest rates in developed markets cause a surge of capital inflows to emerging markets (see, for instance, Shin (2014); Tillmann (2016)).

We also show in Online Appendix A.4 that a drop in the correlation parameter, $\beta$, reduces fire-sale prices in the special country relative to their counterpart in regular countries. We can 
understand this result by considering the timing of losses on investments made in high-yielding countries. These losses will be less costly for foreign banks if the shocks in the high-yielding country have a lower correlation with aggregate distress states (when $\beta$ is lower). Thus, a reduction in $\beta$ makes investing in high-yielding countries more attractive, which increases their ex-ante inflows and lowers their ex-post fire-sale prices due to fickleness. This result is consistent with the view that reach-for-yield flows rise during "risk-on" environments.

\section{Final Remarks}

We develop a global equilibrium model of capital flows that addresses the tension between destabilizing fickleness and stabilizing retrenchment during liquidity crises. We show that, in a global symmetric equilibrium, gross capital flows create liquidity and stabilize fire sales despite their fickleness. Fickleness, however, creates a coordination problem since it encourages local policymakers to restrict capital inflows. Thus, global policy coordination is important for the regulation of international capital flows.

Asymmetries in returns or liquidity qualify our baseline findings, generating potentially destabilizing reach-for-safety and reach-for-yield scenarios. This instability arises not from gross flows, but rather from imbalances that lead to net flows. Therefore, our model features a clear distinction: symmetric flows are stabilizing while net flows are destabilizing for the (net) receiving country. This highlights net flows as a potential source of instability, although in general other features such as the risk composition of gross flows can also affect stability.

We focus on policies that concern restrictions on capital flows. In so doing, our goal is to highlight and isolate the public-goods aspect of capital flows that local policymakers likely miss, not to argue against macroprudential policies in general. In fact, if we interpret the distressed sellers in our model as banks (see Online Appendix A.5 for a formalization), then macroprudential policies that reduce banks' risks would also be useful in our environment as they would further mitigate fire sales. Moreover, our model illustrates how foreign investment can make banks more stable, though unmodeled features (such as speculation driven by mistaken beliefs) might turn foreign investment into a destabilizing force.

In our model, the main rationale behind capital flows is liquidity insurance. However, capital flows in practice are also driven by other motives such as comparative advantage. Many of the mechanisms we highlight are robust to broadening the rationale behind flows. To see this, consider an alternative scenario in which banks have specialized expertise (e.g., in making certain types of loans). They start in their home market, where their expertise is strongest, and expand into foreign markets as they build sufficient capital. To match the capital flow correlations in the data, suppose also that banks' investments in foreign countries are fickle. Then, reversing these investments during local distress would provide some liquidity insurance as in our model. Moreover, local policymakers would still dislike the fickle nature of capital inflows, although they might be more receptive to inflows than in our model due to the foreign banks' expertise. 
One of our core assumptions is that fickleness stems from a reaction by foreign investors to local conditions. However, capital inflows can also reverse when there is a local shock in the foreigners' home location: that is, foreigners' own retrenchment might feel like fickleness in the receiving country. ${ }^{9}$ This raises the question of whether one can explain the capital flow correlations in the data purely from retrenchment shocks without assuming fickleness. While this mechanism is likely to contribute to gross flows patterns during global crises, it has difficulty explaining the decline in capital flows (and the rise in expected returns) when countries experience non-global shocks (see Section 2).

Finally, an important dimension of crises that we leave for future work is the behavior of exchange rates. The current model already sheds light on which exchange rate implications might arise. For example, Proposition 9 implies that high-yielding countries, $R^{*}>R$, experience greater net outflows during crises (driven by their relatively large ex-ante inflows that are fickle), which is likely to put downward pressure on the exchange rate. Conversely, low-yielding countries, such as Japan, can experience net inflows and a currency appreciation during financial distress (driven by their relatively large ex-ante outflows that retrench).

\footnotetext{
${ }^{9}$ This happens in our model, but the resulting "fickleness" does not hurt receiving countries that do not experience a liquidity shock, because we assume that assets in those countries pay early. We can relax this assumption and generate some contagion in our environment. Nonetheless, retrenchment is still likely to be a stabilizing force, because retrenching (but non-fickle) investors would sell foreign assets at relatively low prices only when they could purchase distressed home assets at even lower prices.
} 


\section{References}

Alberola, E., A. Erce, and J. M. Serena (2016). International reserves and gross capital flows dynamics. Journal of International Money and Finance 60, 151-171.

Allen, F. and D. Gale (1994). Limited market participation and volatility of asset prices. The American Economic Review, 933-955.

Avdjiev, S., B. Hardy, S. Kalemli-Ozcan, and L. Servén (2017). Gross capital flows by banks, corporates and sovereigns. NBER Working Paper no. 23116.

Bernanke, B. S., C. C. Bertaut, L. DeMarco, and S. B. Kamin (2011). International capital flows and the return to safe assets in the united states, 2003-2007. FRB International Finance Discussion Paper (1014).

Bluedorn, J. C., R. Duttagupta, J. Guajardo, and P. Topalova (2013). Capital flows are fickle: Anytime, anywhere. Number 13-183. International Monetary Fund.

Brennan, M. J. and H. H. Cao (1997). International portfolio investment flows. The Journal of Finance 52(5), 1851-1880.

Broner, F., T. Didier, A. Erce, and S. L. Schmukler (2013a). Gross capital flows: Dynamics and crises. Journal of Monetary Economics 60(1), 113-133.

Broner, F., T. Didier, A. Erce, and S. L. Schmukler (2013b). International capital flows during crises: Gross matters. VoxEU.org (March 28).

Broner, F., A. Erce, A. Martin, and J. Ventura (2014). Sovereign debt markets in turbulent times: Creditor discrimination and crowding-out effects. Journal of Monetary Economics 61, 114-142.

Brunnermeier, M., J. De Gregorio, B. Eichengreen, M. El-Erian, A. Fraga, T. Ito, P. Lane, J. PisaniFerry, E. Prasad, R. Rajan, et al. (2012). Banks and cross-border capital flows: Policy challenges and regulatory responses. Committee on International Economic Policy and Reform.

Bruno, V. and H. S. Shin (2013). Capital flows, cross-border banking and global liquidity. NBER Working Paper no. 19038.

Caballero, R. J. (2006, November). On the macroeconomics of asset shortages. In A. Beyer and L. Reichlin (Eds.), The role of money - Money and monetary policy in the twenty-first century, pp. 272-283. European Central Bank.

Caballero, R. J., E. Farhi, and P.-O. Gourinchas (2016). Safe asset scarcity and aggregate demand. American Economic Review 106(5), 513-518.

Caballero, R. J., E. Farhi, P.-O. Gourinchas, et al. (2008). An equilibrium model of "global imbalances" and low interest rates. American Economic Review 98(1), 358-93.

Caballero, R. J. and A. Krishnamurthy (2004). Smoothing sudden stops. Journal of Economic Theory 119(1), 104-127.

Caballero, R. J. and A. Krishnamurthy (2008). Collective risk management in a flight to quality episode. The Journal of Finance 63(5), 2195-2230. 
Caballero, R. J. and G. Lorenzoni (2014). Persistent appreciations and overshooting: A normative analysis. IMF Economic Review 62(1), 1-47.

Caballero, R. J. and A. Simsek (2013). Fire sales in a model of complexity. The Journal of Finance 68(6), 2549-2587.

Calvo, G. A. (2016). Macroeconomics in times of liquidity crises: Searching for economic essentials. The MIT Press.

Coeurdacier, N. and H. Rey (2013). Home bias in open economy financial macroeconomics. Journal of Economic Literature 51(1), 63-115.

Cole, H. L. and M. Obstfeld (1991). Commodity trade and international risk sharing: How much do financial markets matter? Journal of Monetary Economics 28(1), 3-24.

Forbes, K. J. and F. E. Warnock (2012). Capital flow waves: Surges, stops, flight, and retrenchment. Journal of International Economics 88(2), 235-251.

Fostel, A., J. Geanakoplos, G. Phelan, et al. (2015). Global collateral: How financial innovation drives capital flows and increases financial instability. Cowles Foundation Discussion Paper no. 2076 .

Gabaix, X., A. Krishnamurthy, and O. Vigneron (2007). Limits of arbitrage: Theory and evidence from the mortgage-backed securities market. The Journal of Finance 62(2), 557-595.

Gabaix, X. and M. Maggiori (2015). International liquidity and exchange rate dynamics. The Quarterly Journal of Economics 130(3), 1369-1420.

Gehrig, T. (1993). An information based explanation of the domestic bias in international equity investment. The Scandinavian Journal of Economics, 97-109.

Gorton, G. (2016). Safe assets. Annual Review of Economics forthcoming.

Gorton, G., S. Lewellen, and A. Metrick (2012). The safe-asset share. The American Economic Review 102(3), 101-106.

Gourinchas, P.-O. and H. Rey (2007). From world banker to world venture capitalist: US external adjustment and the exorbitant privilege. In G7 Current Account Imbalances: Sustainability and Adjustment, pp. 11-66. University of Chicago Press.

Gourinchas, P.-O., H. Rey, N. Govillot, et al. (2010). Exorbitant privilege and exorbitant duty. Bank of Japan IMES Discussion Paper Series no. 10-E-20.

Gourinchas, P.-O., H. Rey, and K. Truempler (2012). The financial crisis and the geography of wealth transfers. Journal of International Economics 88(2), 266-283.

Gromb, D. and D. Vayanos (2016). Arbitrage and its limits, pp. 1-3. London: Palgrave Macmillan UK.

Grubel, H. G. (1968). Internationally diversified portfolios: welfare gains and capital flows. The American Economic Review 58(5), 1299-1314.

Holmström, B. and J. Tirole (1998). Private and public supply of liquidity. The Journal of Political Economy 106(1), 1-40. 
Holmström, B. and J. Tirole (2001). LAPM: A liquidity-based asset pricing model. The Journal of Finance 56(5), 1837-1867.

IMF (2012). The liberalization and management of capital flows: An institutional view. IMF Policy Paper no. 4720.

Jeanne, O. and A. Korinek (2010). Excessive volatility in capital flows: A pigouvian taxation approach. NBER Working Paper no. 15927.

Jeanne, O. and D. Sandri (2017). Global financial cycle and liquidity management. IMF Working Paper.

Kiyotaki, N. and J. Moore (1997). Credit cycles. Journal of Political Economy 105(2), 211-248.

Korinek, A. and D. Sandri (2016). Capital controls or macroprudential regulation? Journal of International Economics 99, S27-S42.

Krishnamurthy, A. (2010). Amplification mechanisms in liquidity crises. American Economic Journal: Macroeconomics 2(3), 1-30.

Krishnamurthy, A. and A. Vissing-Jorgensen (2012). The aggregate demand for treasury debt. Journal of Political Economy 120(2), 233-267.

Lane, P. R. and G. M. Milesi-Ferretti (2007). The external wealth of nations mark II: Revised and extended estimates of foreign assets and liabilities, 1970-2004. Journal of international Economics 73(2), 223-250.

Lane, P. R. and G. M. Milesi-Ferretti (2012). External adjustment and the global crisis. Journal of International Economics 88(2), 252-265.

Lewis, K. K. (2000). Why do stocks and consumption imply such different gains from international risk sharing? Journal of international Economics 52(1), 1-35.

Lorenzoni, G. (2008). Inefficient credit booms. The Review of Economic Studies 75(3), 809-833.

Milesi-Ferretti, G.-M. and C. Tille (2011). The great retrenchment: International capital flows during the global financial crisis. Economic Policy 26(66), 289-346.

Miranda-Agrippino, S. and H. Rey (2015). World asset markets and the global financial cycle. NBER Working Paper no. 21722.

Obstfeld, M. (2012). Does the current account still matter? NBER Working Paper no. 17877.

Ostry, J. D., A. R. Ghosh, K. Habermeier, M. Chamon, M. S. Qureshi, and D. Reinhardt (2010). Capital inflows: The role of controls. Revista de Economia Institucional 12(23), 135-164.

Ravn, M. O. and H. Uhlig (2002). On adjusting the Hodrick-Prescott filter for the frequency of observations. Review of economics and statistics 84(2), 371-376.

Scott, A. and H. Uhlig (1999). Fickle investors: An impediment to growth? European Economic Review 43(7), 1345-1370.

Shin, H. S. (2014). The second phase of global liquidity and its impact on emerging economies. In Volatile Capital Flows in Korea, pp. 247-257. Springer. 
Shleifer, A. and R. W. Vishny (1992). Liquidation values and debt capacity: A market equilibrium approach. The Journal of Finance 47(4), 1343-1366.

Shleifer, A. and R. W. Vishny (1997). The limits of arbitrage. The Journal of Finance 52(1), $35-55$.

Tillmann, P. (2016). Unconventional monetary policy and the spillovers to emerging markets. Journal of International Money and Finance 66, 136-156.

Uhlig, H. (1996). A law of large numbers for large economies. Economic Theory 8(1), 41-50.

Uhlig, H. (2014). Sovereign default risk and banks in a monetary union. German Economic Review 15(1), 23-41.

Van Nieuwerburgh, S. and L. Veldkamp (2009). Information immobility and the home bias puzzle. The Journal of Finance 64(3), 1187-1215.

Van Wincoop, E. (1994). Welfare gains from international risksharing. Journal of Monetary Economics $34(2), 175-200$. 


\title{
Online Appendix for: A Model of Fickle Capital Flows and Retrenchment
}

\author{
Ricardo J. Caballero \\ Alp Simsek \\ MIT and NBER. caball@mit.eduＭIT, NBER, and CEPR. asimsek@mit.edu
}

These appendices contain supplementary material for A Model of Fickle Capital Flows and Retrenchment. Online Appendix A contains the omitted details and proofs related to our theoretical analysis. Online Appendix B has information about our data sources and details for the empirical analysis.

\section{Online Appendix A: Theory}

This appendix is organized as follows. Online Appendices A.1-A.5 analyze various extensions of the model in the main text. Online Appendix A.6 contains the omitted proofs.

\section{A.1. Endogenizing fickleness with Knightian uncertainty}

In the main text, we assumed that the banks are fickle in the sense that, if there is a liquidity shock in a foreign country, they sell their asset holdings in that country regardless of the price. We view this assumption as a modeling device to capture the observed heterogeneous behavior of foreigners and locals during crises (see Section 2). It also captures various factors that could handicap foreigners during local crises, such as asymmetric information or Knightian uncertainty, deteriorating property rights, asymmetric regulation, and so on. In this section, we explicitly incorporate one such factor, Knightian uncertainty, and illustrate that it can endogenously generate fickleness. ${ }^{1}$

The model is the same as in the main text with the difference that foreign banks do not have to sell their assets in a country that experiences a liquidity shock in period 1. Instead, banks face uncertainty about the asset's payoff in period 2 and choose actions that are robust with respect to this uncertainty.

Formally, consider a country $j^{\prime}$ that experiences a liquidity shock in period 1 , that is, $\omega^{j^{\prime}}=b$. In the main text, we assumed the asset pays $R$ units in period 2 with certainty. We now suppose the banks in country $j$ believe these assets pay $R$ units in period 2 with probability $\phi^{j^{\prime}, j} \in[0,1]$ and zero units in period 2 with probability $1-\phi^{j^{\prime}, j}$. Therefore, the expected payoff of country- $j^{\prime}$ risky assets (when it experiences a liquidity shock) for a country- $j$ bank is given by $\phi^{j^{\prime}, j} R$. Moreover, the banks are uncertain about the parameter $\phi^{j^{\prime}, j}$, in the sense that they consider a range of probabilities possible. We let $\left[\underline{\phi}^{j^{\prime}, j}, \bar{\phi}^{j^{\prime}, j}\right]$ (with $\underline{\phi}^{j^{\prime}, j} \leq \bar{\phi}^{j^{\prime}, j}$ ) denote the range of probabilities the banks find possible regarding the assets in country $j^{\prime}$.

Following Gilboa and Schmeidler (1989)'s Maximin expected utility representation, we assume the banks maximize the following objective function (in period 1 as well as period 0 ),

$$
\min _{\left\{\phi^{j^{\prime}, j} \in\left[\underline{\phi}^{j^{\prime}, j}, \bar{\phi}^{j^{\prime}, j}\right]\right\}_{j^{\prime} \in J}} E\left[u\left(c_{0}^{j}\right)+c_{1, s}^{j}+c_{2, s}^{j}\right] .
$$

\footnotetext{
${ }^{1}$ It is often argued that global banks can hire local experts to remove the information asymmetry. In practice, while delegation to local experts by an uninformed foreign board may operate during normal times, it is unlikely to do so during a large financial distress.
} 
Thus, banks act according to the worst case scenario within the range of probabilities that they believe possible. ${ }^{2}$ We capture fickleness by assuming that banks face greater parametric uncertainty in the foreign market than in the local market,

$$
\underline{\phi}^{j, j}=\bar{\phi}^{j, j}=1 \text { for each } j \text {, and } \underline{\phi}^{j^{\prime}, j} \equiv \underline{\phi}<\bar{\phi}^{j^{\prime}, j}=1 \text { for each } j^{\prime} \neq j .
$$

In particular, banks' worst case success probability in a foreign market, captured by $\underline{\phi}$, is lower than their worst case success probability in the local market, which we assume is equal to one. The latter assumption also implies that banks do not face any parameter uncertainty regarding the risky assets in their own country. This does not play an important role beyond simplifying the analysis.

We let $\chi_{s}^{j^{\prime}, j}$ denote the position that the banks in country $j$ take in period 1 and aggregate state $s$ in the risky assets of country $j^{\prime}$ (conditional on that country experiencing a liquidity shock, $\omega^{j^{\prime}}=b$ ). In the main text, we assumed $\chi_{s}^{j^{\prime}, j}=0$ for each $j^{\prime} \neq j$, and we used the shorthand notation $\chi_{s}^{j} \equiv \chi_{s}^{j, j}$ to capture local investment. Here, the banks make an investment plan for all countries and aggregate states, $\left[\chi_{s}^{j^{\prime}, j} \geq 0\right]_{j^{\prime}, s}$. For each aggregate state $s$, we impose $\chi_{s}^{j, j}$ to be a point mass, and $\chi_{s}^{j^{\prime}, j}$ for $j^{\prime} \neq j$ to be a density with respect to the Lebesgue measure. As before, the banks also choose the period 0 allocations, $\left[x^{j^{\prime}, j} \geq 0\right]_{j^{\prime}}, y^{j},\left(z_{s}^{j}\right)_{s}$, subject to the restrictions described in Section 3.

The equilibrium with symmetric prices is a collection of allocations, $\left[x^{j^{\prime}, j} \geq 0\right]_{j^{\prime}}, y^{j},\left(z_{s}^{j}\right)_{s},\left[\chi_{s}^{j^{\prime}, j}\right]_{j^{\prime}, s}$ that maximizes the objective function in $(A 1)$ for each $j$, and prices $\left(p_{s}\right)_{s}, q_{f},\left(q_{s}\right)_{s}$ that ensure market clearing. The market clearing conditions for the safe asset and the Arrow-Debreu securities are the same as conditions (8) and (9) in the main text, but the market clearing condition for risky assets of country $j$ in period 1 is slightly different and given by [cf. Eq. (7)],

$$
e+x^{i n, j}+x^{j, j}=\tilde{\chi}_{s}^{j}+\chi_{s}^{j, j}+\int_{j^{\prime}} \chi_{s}^{j, j^{\prime}} d j^{\prime}
$$

In particular, we now also take into account the possible demand for the risky asset that comes from other countries' banks, $\int_{j^{\prime}} \chi_{s}^{j, j^{\prime}} d j^{\prime}$.

We characterize the equilibrium for parameters that satisfy Assumption 1 as well as:

Assumption K. $(1-\underline{\phi}) R<\eta / e$.

With these parameters, we conjecture that the equilibrium characterized in Section 4 remains an equilibrium also in this context. In particular, we claim that it is optimal for banks to choose $\chi_{s}^{j^{\prime}, j}=0$ for each $j^{\prime} \neq j$ and aggregate state $s$. To verify this, note that Eq. (15) implies the equilibrium price satisfies $p_{s} \geq \eta / e$ for each $s$. Combining this with Assumption $\mathrm{K}$ implies $p_{s}>(1-\underline{\phi}) R$ for each $s$. Thus, foreign banks believe that the asset's price exceeds its payoff under the worst case success probability. In view of the Maximin preferences in $(A 1)$, it is then easy to check that choosing $\chi_{s}^{j^{\prime}, j}=0$ for each $j^{\prime} \neq j$ is an optimal strategy.

Next note that, after substituting $\chi_{s}^{j^{\prime}, j}=0$ for each $j^{\prime} \neq j$ into the objective function in $(A 1)$ and observing that investors do not face any Knightian uncertainty in their own country, we recover the same objective function as in the main text [cf. Eq. (2)]. Likewise, after substituting $\chi_{s}^{j^{\prime}, j}=0$ for each $j^{\prime} \neq j$ into the market clearing condition $(A 3)$, we recover the same market clearing condition as in the main text [cf. Eq. (7)]. It follows that the equilibrium that we characterized in Section 4 remains an equilibrium also in this context.

\footnotetext{
${ }^{2}$ This behavior is reasonable for situations in which economic agents face ambiguity as opposed to quantifiable uncertainty. Crises are typically associated with this type of uncertainty (see Caballero and Krishnamurthy (2008); Caballero and Simsek (2013) for further discussion).
} 


\section{A.2. Complete markets with respect to local liquidity shocks}

In the main text we assumed that banks cannot trade financial contracts contingent on local liquidity shocks. In this section, we relax this assumption. We first consider the case in which markets are fully complete: in particular, banks can trade contingent contracts with respect to local liquidity shocks subject to nonnegative consumption constraints only. In this case, we show that capital flow fickleness does not affect fire-sale prices. Since our goal is to analyze the tension between fickleness and retrenchment, this motivates the incompletemarkets setting that we adopt as our baseline model. We then consider the case in which markets are partially complete: in particular, banks can sell a limited amount of contingent contracts with respect to local liquidity shocks subject to a collateral constraint. We show that our analysis naturally generalizes to this setting. This illustrates that our results do not require the extreme form of market incompleteness that we adopt in our baseline model.

For simplicity, we focus attention on the case in which there is a single aggregate state $s$ so there is no aggregate risk (the results can be generalized). This implies that the Arrow-Debreu securities for aggregate states are redundant, so we drop them from the notation (equivalently, we set $z_{s}^{j}=0$ for each $j$ ). Throughout, we drop the subscript $s$ from the notation.

\section{A.2.1. Fully-complete markets}

The model with complete markets. We expand the set of assets to include country-specific ArrowDebreu securities. The security for country $j$ pays one unit of the consumption good if $\omega^{j}=b$ is realized in period 1 , and zero units if $\omega^{j}=g$ is realized. In period 0, the Arrow-Debreu security for country $j$ is traded at an endogenous price $q_{c}^{j}$ (where the subscript $c$ stands for "country-specific"). We concentrate our attention on symmetric equilibria in which the price of Arrow-Debreu securities is the same across countries, that is, $q_{c}^{j} \equiv q_{c}$ for each $j$. Country-specific Arrow-Debreu securities are in zero net supply.

In period 0 , banks in country $j$ choose an investment strategy on these Arrow-Debreu securities denoted by $z_{c}^{j^{\prime}, j}$. We impose that $z_{c}^{j, j}$ is point mass, and $z_{c}^{j^{\prime}, j}$ for $j^{\prime} \neq j$ is a density with respect to the Lebesgue measure. As before, banks also choose the investment strategy on risky assets, $x^{j^{\prime}, j}$, and their position on the risk-free asset, $y^{j}$. Their budget constraint in period 0 is the following analogue of Eq. (3),

$$
\begin{aligned}
& c_{0}^{j}+x^{j, j}+x^{\text {out }, j}+y^{j} q_{f}+\left(z_{c}^{j, j}+z_{c}^{\text {out }, j}\right) q_{c}=1+\eta q_{f}, \\
& \text { where } x^{\text {out }, j}=\int_{j^{\prime} \neq j} x^{j^{\prime}, j} d j^{\prime} \text { and } z_{c}^{\text {out }, j}=\int_{j^{\prime} \neq j} z_{c}^{j^{\prime}, j} d j^{\prime} .
\end{aligned}
$$

As before, banks are not allowed to short-sell risky assets, $x^{j^{\prime}, j} \geq 0$ for each $j^{\prime}$, but they are allowed to take unrestricted positions on the risk-free asset or country-specific Arrow-Debreu securities subject to obtaining nonnegative consumption in all periods and states.

In period 1 , if $\omega^{j}=g$, then banks receive zero units from the Arrow-Debreu security for their own country. By an exact law of large numbers, they also receive $\pi z_{c}^{o u t, j}$ units from the Arrow-Debreu securities on other countries. Combining this with the analysis in Section 3, the banks' budget constraint in state $\omega^{j}=g$ is the following analogue of Eq. (5),

$$
\begin{aligned}
c_{1}^{j}\left(\omega^{j}=g\right) & =x^{j, j} R+x^{o u t, j} \bar{R}+y^{j}+\pi z_{c}^{o u t, j} \\
\text { and } c_{2}^{j}\left(\omega^{j}=g\right) & =0 .
\end{aligned}
$$

If instead $\omega^{j}=b$, then banks receive $z_{c}^{j, j}$ units from the Arrow-Debreu security of their own country, 
and still $\pi z_{c}^{o u t, j}$ units from the Arrow-Debreu securities in other countries. Their budget constraint in state $\omega^{j}=b$ is then the following analogue of Eq. (6),

$$
\begin{aligned}
c_{1}^{j}\left(\omega^{j}=b\right)+\chi^{j} p & =x^{j, j} p+x^{o u t, j} \bar{R}+y^{j}+z_{c}^{j, j}+\pi z_{c}^{o u t, j}, \\
c_{2}^{j}\left(\omega^{j}=b\right) & =\chi^{j} R .
\end{aligned}
$$

Putting everything together, banks in each country $j$ make an investment plan, $\left[x^{j^{\prime}, j} \geq 0\right]_{j^{\prime}}, y^{j},\left[z_{c}^{j^{\prime}, j} \geq 0\right]_{j^{\prime}}, \chi^{j}$, to maximize their expected utility, $E\left[u\left(c_{0}^{j}\right)+c_{1}^{j}+c_{2}^{j}\right]$, where $c_{0}^{j}$ is determined by Eq. (3), $c_{1}^{j}\left(\omega^{j}=g\right)$ and $c_{2}^{j}\left(\omega^{j}=g\right)$ are determined by Eq. $(A 5), c_{1}^{j}\left(\omega^{j}=b\right)$ and $c_{2}^{j}\left(\omega^{j}=b\right)$ are determined by Eq. $(A 6)$, and consumption in all periods and states is nonnegative, $c_{0}^{j} \geq 0, c_{1}^{j} \geq 0, c_{2}^{j} \geq 0$.

The equilibrium with symmetric prices is a collection of optimal allocations for distressed sellers and banks, together with prices $p, q_{f}, q_{c}$, that ensure market clearing. The market clearing conditions for risky and safe assets are the same as Eqs. (7) and (8) in the main text. For each country $j$, there is also a market clearing condition for the corresponding Arrow-Debreu security, which can be written as,

$$
z_{c}^{j, j}+z_{c}^{i n, j}=0 \text { for each } j, \text { where } z_{c}^{i n, j}=\int_{j^{\prime} \neq j} z_{c}^{j, j^{\prime}} d j^{\prime} .
$$

Liquidity creation with complete markets. We characterize the equilibrium under the following strengthening of Assumption 1.

Assumption $1^{\mathrm{C}} \cdot e R / \lambda<\eta<e R \pi-\underline{x}(1-\pi) R$, where $\underline{x} \in(0,1)$ is the solution to $u^{\prime}(1-\underline{x})=R$.

For any $\pi \in(0,1)$, the required upper bound on the supply of safe assets $\eta$ is smaller than its counterpart in Assumption 1, eR. However, it approaches that upper bound as $\pi \rightarrow 1$. Hence, any $\eta$ that satisfies Assumption 1 also satisfies Assumption $1^{\mathrm{C}}$ provided that the probability of a liquidity shock, $\pi$, is sufficiently high.

Under Assumption $1^{\mathrm{C}}$, we conjecture an equilibrium with symmetric prices that satisfy $p \in(R / \lambda, R)$. As before, distressed sellers sell their entire endowments, $\tilde{\chi}^{j}=0$. For banks, we conjecture symmetric equilibrium allocations that satisfy, $x^{\text {out }, j}=x^{\text {out }}=x^{\text {in }}=x$ and $y^{j} \equiv y$, as well as,

$$
z_{c}^{o u t, j} \equiv-z \text { and } z_{c}^{j, j} \equiv z
$$

Hence, banks choose symmetric allocations on foreign Arrow-Debreu securities, which we denote by $-z$. They also take the opposite position in the Arrow-Debreu security of their own country, denoted by $z$, so that the market clearing condition $(A 7)$ is satisfied.

Following similar steps as in Section 4, the budget constraints $(A 4),(A 5),(A 6)$ imply,

$$
\begin{aligned}
c_{0}^{j}+x^{j, j}+x^{\text {out }} & =1, \\
c_{1}^{j}\left(\omega^{j}=g\right) & =x^{j, j} R+x^{\text {out }} \bar{R}+\eta-\pi z, \\
c_{2}^{j}\left(\omega^{j}=b\right) & =\left(x^{j, j} p+x^{\text {out }} \bar{R}+\eta+z-\pi z\right) \frac{R}{p} .
\end{aligned}
$$

Substituting these expressions into the objective function and rearranging terms, the representative investor 
solves the following analogue of problem (10),

$$
\begin{aligned}
& \max _{x^{j, j}, x^{\text {out }, z}} u\left(1-x^{j, j}-x^{\text {out }}\right)+\left[\begin{array}{c}
(1-\pi)\left(x^{j, j} R+x^{\text {out }} \bar{R}+\eta-\pi z\right) \\
+\pi\left(x^{j, j} p+x^{\text {out }} \bar{R}+\eta+(1-\pi) z\right) \frac{R}{p}
\end{array}\right], \\
& \text { s.t. } \quad c_{2}^{j}\left(\omega_{1}^{j}\left(\omega^{j}=b\right)=\left(x^{j, j} p+x^{\text {out }} \bar{R}+\eta+(1-\pi) z\right) \frac{R}{p} \geq 0 .\right.
\end{aligned}
$$

Note that banks' marginal value from increasing $z$ is given by $\pi(1-\pi)(-1+R / p)$, which is strictly positive because $p<R$. Thus, banks set $z$ as large as possible subject to the nonnegative consumption constraints in $(A 9)$. Since the optimal allocation features $z>0$, the constraint binds for the state without a liquidity shock, $\omega^{j}=g$. This implies,

$$
z=\frac{x^{j, j} R+x^{\text {out }} \bar{R}+\eta}{\pi} .
$$

Intuitively, increasing $z$ is similar to purchasing insurance with respect to local liquidity shocks: it transfers wealth from the state without a shock to the state with a shock. Banks purchase as much insurance as possible (subject to nonnegative consumption) because their marginal value is greater when there is a local liquidity shock.

After substituting (A10), banks' problem $(A 8)$ can be written as,

$$
\max _{x^{j, j}, x^{\text {out }}} u\left(1-x^{j, j}-x^{\text {out }}\right)+\left(\pi\left(x^{j, j} p+x^{\text {out }} \bar{R}+\eta\right)+(1-\pi)\left(x^{j, j} R+x^{\text {out }} \bar{R}+\eta\right)\right) \frac{R}{p} .
$$

Note that the ex-ante marginal value from foreign investment is given by $\bar{R} \frac{R}{p}$. Likewise, the ex-ante marginal value from local investment is given by, $(\pi p+(1-\pi) R) \frac{R}{p}$. Since $\bar{R}=(1-\pi) R+\pi p$, the two expressions are the same. In particular, and unlike in the main text, banks are indifferent between local and foreign investment. Intuitively, as illustrated by Eq. (A11), banks choose the asset that has the higher expected payoff in period 1. This is because banks use the country-specific Arrow-Debreu securities to transfer all of their expected wealth in period 1 into the state with a local liquidity shock. Since local and foreign assets have the same expected payoff in period 1, banks are indifferent between the two options. Consequently, the equilibrium level of foreign investment is indeterminate.

To keep the analysis parallel to the main text, let us resolve the indeterminacy by assuming that banks do not invest in the local asset, $x^{j, j}=0$. The amount of foreign investment is then determined by the following analogue of the optimality condition (13),

$$
u^{\prime}(1-x)=((1-\pi) R+\pi p) \frac{R}{p},
$$

where we substituted $\bar{R}=(1-\pi) R+\pi p$ and $x^{\text {out }}=x$.

Following similar steps as in Section 4, the market clearing condition for risky assets can be written as the following analogue of Eq. (14),

$$
p=\frac{\eta+x^{\text {out }} \bar{R}+(1-\pi) z}{e+x^{\text {in }}} .
$$

As before, the intuition is that the price is determined by the cash-in-the-market per asset for sale. After 
substituting $z$ from Eq. (A10) and using $x^{\text {out }}=x^{i n}=x$ (and $x^{j, j}=0$ ), we obtain,

$$
p=\frac{\left(\eta+x^{o u t} \bar{R}\right) / \pi}{e+x} .
$$

After substituting $\bar{R}=(1-\pi) R+\pi p$ and solving the equation for $p$, we further obtain the following analogue of Eq. (15),

$$
p=\frac{\eta+x(1-\pi) R}{e \pi} .
$$

To understand this condition, note that the denominator, ex, captures the aggregate amount of liquidity distressed sellers need in period 1 . The numerator captures the aggregate amount of liquidity available in period 1, which comes from the supply of the safe asset, $\eta$, as well as the aggregate payoff from investments in countries that do not experience a liquidity shock, $x(1-\pi) R$. Intuitively, the insurance provided by complete markets enables all available liquidity to flow to countries that experience a liquidity shock, where it is used to finance distressed sellers' projects.

The equilibrium is characterized as the pair, $(x, p)$, that solves Eqs. (A12) and (A13). Under Assumption $1^{\mathrm{C}}$, we can check that there is a unique solution that satisfies $x \in(\underline{x}, 1)$ and $p \in(R / \lambda, R)$, verifying our conjecture. Banks' positions in Arrow-Debreu securities are characterized by Eq. (A10) given the equilibrium levels of $x$ and $p$.

It follows that, as long as aggregate liquidity is sufficiently scarce, the equilibrium features fire sales in this case as well. Complete markets help distribute all available liquidity to countries that experience liquidity shocks, thereby making it harder to obtain fire sales in equilibrium, but they do not necessarily prevent fire sales. As this intuition suggests, the fire-sale price in the complete-markets case is always strictly greater than its counterpart in the baseline model. Specifically, comparing Eqs. (A12) and (A13) with Eqs. (13) and (15) in the baseline setting, note that both curves (in the $x-p$ space) are shifted upwards in this setting. This leads to a greater fire-sale price, $p$. The upward shift of the market clearing curve reflects the more efficient allocation of liquidity. The upward shift of the optimality curve means that, for a given fire-sale price $p$, banks undertake greater foreign investment. Both effects increase the fire-sale price, $p$. On the other hand, the equilibrium level of $x$ might be lower than before, because a high fire-sale price lowers the need for obtaining liquidity via foreign investment.

On the other hand, fully-complete markets also imply that fickleness does not affect fire-sale prices. To see this, it is instructive to consider the market clearing conditions for the baseline and the complete-markets models side-by-side:

$$
p=\frac{\eta+x(1-\pi) R}{e+x(1-\pi)} \text { and } p=\frac{\eta+x(1-\pi) R}{e \pi} .
$$

The expression on the left-hand side is the market clearing condition for the baseline model [cf. Eq. (15)]. In this case, greater foreign investment increases the amount of asset sales when there is a liquidity shock, as captured by $x$ in the denominator of the expression, because foreign investors are fickle. The expression on the right-hand side is the market clearing condition for the complete-markets model [cf. Eq. (A13)]. In this case, $x$ does not appear in the denominator of the expression. This illustrates that greater foreign investment does not affect the amount of asset sales when there is a liquidity shock, despite the fact that foreign investors are fickle. The intuition is as follows: complete markets transfer all available liquidity in period 1 to non-fickle local banks whose country experiences a liquidity shock, which renders fickleness irrelevant for the determination of fire-sale prices. ${ }^{3}$ Foreign investment still exerts an upward influence on

\footnotetext{
${ }^{3}$ Formally, recall from our earlier analysis that banks' consumption in the state without a liquidity shock is zero,
} 
fire-sale prices, due to local banks' retrenchment, but there is no counteracting force due to foreign banks' fickleness.

Our goal in this paper is to capture the tension between fickleness and retrenchment (and investigate its normative and positive implications). Therefore, we work with our baseline model with incomplete markets, which features this tension.

\section{A.2.2. Partially-complete markets}

The model with partially-complete markets. We next show that a limited amount of market completeness can be introduced into our setting without changing anything substantive. To this end, consider the above setup with the only difference that banks face the additional constraint,

$$
-\pi z_{c}^{o u t, j} \leq \kappa\left(x^{j, j} R+x^{o u t, j} \bar{R}+y^{j}\right) .
$$

for some $\kappa \in[0,1]$. The expression on the left-hand side, $-\pi z_{c}^{\text {out }, j}$, denotes the amount that banks are required to pay to foreign banks in period 1 due to their sales of country-specific Arrow-Debreu securities in period 0 [cf. Eq. (A5)]. The expression on the right-hand side, $x^{\text {out }, j} \bar{R}+y^{j}$, denotes the amount banks receive in period 1 from their foreign investments or safe assets. Eq. (A14) says that insurance promises to foreign banks need to be collateralized by payoffs from foreign investments, safe assets, or local investments (when there is no local liquidity shock, $\omega^{j}=g$ ). ${ }^{4}$ The parameter, $\kappa$, captures the tightness of the collateral constraint. When $\kappa=0$, the constraint is very tight and banks cannot sell (or buy) any liquidity insurance, so we recover the baseline incomplete-markets model. When $\kappa=1$, the constraint is loose and banks can sell insurance subject to nonnegative consumption constraints only. In this case, we recover the earlier model with fully-complete markets. When $\kappa \in(0,1)$, we capture the intermediate cases in which markets are partially complete. In practice, collateral constraints along the lines of Eq. (A14) emerge naturally due to a variety of reasons that range from institutional factors (e.g., regulation or limited enforcement) to information asymmetries (e.g., moral hazard or adverse selection).

Liquidity creation with partially-complete markets. The characterization of equilibrium is similar to the case with fully-complete markets. As before, suppose parameters satisfy Assumption $1^{\mathrm{C}}$ and consider an equilibrium with symmetric prices, $p \in(R / \lambda, R)$, and symmetric allocations that satisfy, $x^{\text {out }, j}=x^{\text {out }}=x^{\text {in }}=x$ and $y^{j} \equiv y$, as well as $z_{c}^{\text {out }, j} \equiv-z$ and $z_{c}^{j, j} \equiv z$. Following the same steps as earlier, banks set $z$ as large as possible subject to the collateral constraint in (A14). This implies the following analogue of Eq. (A10),

$$
z=\frac{\kappa\left(x^{j, j} R+x^{o u t} \bar{R}+\eta\right)}{\pi} .
$$

After substituting this expression, banks' problem can be written as the following analogue of Eq. (A11),

$$
\max _{x^{j, j}, x^{\text {out }}} u\left(1-x^{j, j}-x^{\text {out }}\right)+\left[\begin{array}{c}
(1-\pi)(1-\kappa)\left(x^{j, j} R+x^{\text {out }} \bar{R}+\eta\right) \\
+\left(\pi\left(x^{j, j} p+x^{\text {out }} \bar{R}+\eta\right)+(1-\pi) \kappa\left(x^{j, j} R+x^{\text {out }} \bar{R}+\eta\right)\right) \frac{R}{p}
\end{array}\right] .
$$

$c_{1}^{j}\left(\omega^{j}=g\right)=c_{2}^{j}\left(\omega^{j}=g\right)=0$.

${ }^{4}$ Unlike diversified foreign investment, local investment is risky and pays $p<R$ in period 1 when there is a local liquidity shock, $\omega^{j}=b$. Hence, the collateral constraint in $(A 14)$ is arguably favorable to local investment relative to foreign investment. We work with this specification because we will establish that, despite a favorable collateral constraint, local investment is strictly dominated by foreign investment as long as markets are not fully complete, $\kappa \in[0,1)$. 
Note that the ex-ante marginal value from local investment, $x^{j, j}$, is given by,

$$
(1-\pi)(1-\kappa) R+(\pi p+(1-\pi) \kappa R) \frac{R}{p} .
$$

The ex-ante marginal value from foreign investment, $x^{\text {out }}$, is given by,

$$
(1-\pi)(1-\kappa) \bar{R}+(\pi \bar{R}+(1-\pi) \kappa \bar{R}) \frac{R}{p} .
$$

It is easy to check that, for any $\kappa \in[0,1)$, the latter expression is strictly greater than the former. Thus, local investment is strictly dominated by the foreign investment, as in the baseline model, as long as the markets are not fully complete.

After substituting $x^{j, j}=0$, problem $(A 16)$ can be solved to obtain the following analogue of the optimality condition $(A 12)$,

$$
u^{\prime}(1-x)=(1-\pi)(1-\kappa) \bar{R}+(\pi \bar{R}+(1-\pi) \kappa \bar{R}) \frac{R}{p} .
$$

As before, the amount of foreign investment is determined by the ex-ante marginal value from foreign investment. When $\kappa=0$, Eq. (A17) reduces to its counterpart in the baseline model, Eq. (13). When $\kappa=1$, Eq. (A12) reduces to its counterpart in the fully-complete markets model, Eq. (A12).

Next note that the market clearing condition (14) still applies in this setting. Substituting for $z$ from $(A 15)$ and using $x^{\text {out }}=x^{\text {in }}=x$, we obtain,

$$
p=\frac{\pi+\kappa(1-\pi)}{\pi} \frac{\eta+x \bar{R}}{e+x} .
$$

After substituting $\bar{R}=(1-\pi) R+\pi p$ and solving the equation for $p$, we obtain the following analogue of Eq. (A13),

$$
p=\frac{\pi+\kappa(1-\pi)}{\pi} \frac{\eta+x(1-\pi) R}{e+x(1-\pi)(1-\kappa)} .
$$

As before, the equilibrium fire-sale price is determined by cash-in-the-market per asset sale. When $\kappa=0$, Eq. (A18) reduces to its counterpart in the baseline model, Eq. (15). When $\kappa=1$, Eq. (A12) reduces to its counterpart in the fully-complete markets model, Eq. (A13).

The equilibrium is the pair, $(x, p)$, that solves Eqs. $(A 17)$ and $(A 18)$. Under Assumption $1^{\mathrm{C}}$, we can check that there is a unique solution that satisfies $x \in(\underline{x}, 1)$ and $p \in(R / \lambda, R)$. Moreover, it can be checked that the equilibrium is the same as in the baseline model when $\kappa=0$, and it is the same as in the fully-complete markets model when $\kappa=1$.

Finally, note that for any $\kappa \in[0,1)$ gross investments appear in the denominator of the market clearing condition, Eq. (A18). In particular, as long as markets are not fully complete, fickleness affects fire-sale prices in the same direction as in our baseline model. This illustrates that our results do not require the extreme form of market incompleteness that we adopt in our baseline model.

\section{A.3. Equilibrium with bans on capital flows}

This section completes the analysis we described in Section 5.2, with policymakers that choose whether to ban capital inflows. Recall that the banning decision is denoted by $b^{j} \in\{0,1\}$. Banks choose their portfolio, $\left[x^{j^{\prime}, j} \geq 0\right]_{j^{\prime}}$, subject to the additional constraint that $x^{j^{\prime}, j}=0$ for each $j^{\prime} \neq j$ with $b^{j^{\prime}}=1$. The remaining 
ingredients are the same as in Section 3. Recall also that we focus on the limit, $\lambda \rightarrow \infty$. We first illustrate that in this limit, policymakers can be equivalently thought of as maximizing the local fire-sale price, $p^{j}$. We then characterize the equilibrium for a given configuration of banning decisions. Finally, we consider the Nash equilibrium in which the banning decisions are optimal and prove Proposition 4.

To characterize the objective function when $\lambda \rightarrow \infty$, note that distressed sellers' expected consumption in a liquidity shock is given by [cf. Eq. (1)],

$$
\tilde{c}_{2}^{j}\left(\omega^{j}=b\right)=\max _{\tilde{\chi}^{j}}\left(\tilde{\chi}^{j} R+\lambda\left(e-\tilde{\chi}^{j}\right) p^{j}\right)
$$

Thus, as long as $p^{j}$ is bounded from below (which is the case in equilibrium), $\lim _{\lambda \rightarrow \infty} \tilde{c}_{2}^{j}\left(\omega^{j}=b\right) / \lambda=e p^{j}$. Next note that utilitarian social welfare function satisfies,

$$
\frac{W^{j}}{\lambda}=\frac{u\left(c_{0}^{j}\right)+E\left[c_{1}^{j}+c_{2}^{j}\right]+(1-\pi) \tilde{c}_{2}^{j}\left(\omega^{j}=g\right)}{\lambda}+\pi \frac{\tilde{c}_{2}^{j}\left(\omega^{j}=b\right)}{\lambda} .
$$

Taking the limit as $\lambda \rightarrow \infty$, and observing that all terms except for the last one approach zero, we obtain, $\lim _{\lambda \rightarrow \infty} W^{j} / \lambda=\pi e p^{j}$. Since $\pi, e>0$, maximizing this expression is the same as maximizing the local fire-sale price, $p^{j}$. Intuitively, in this limit the balance sheet channel is very strong, and the planners focus on increasing the investment of distressed sellers.

Next consider the equilibrium for a given configuration of banking decisions. The extreme cases in which $b^{j}=0$ for each $j$ (free capital flows), or $b^{j}=1$ for each $j$ (autarky) are characterized in Section 4.1. Consider the intermediate case in which capital flows are banned in some countries. Specifically, suppose the sets of countries with $b^{j}=1$ ("banned countries") and $b^{j}=0$ ("free countries") are Lebesgue measurable, respectively with measures $B \in[0,1)$ and $1-B>0$. In this case, we consider a symmetric equilibrium in which each country invests the same amount in the safe asset and contingent securities, $y^{j}=\eta$ and $z=0$; each ban country makes a symmetric investment in each free country, denoted by $x^{\text {ban }}$, and obtains a price denoted by $p^{b a n}$; and each free country makes a symmetric investment in each free country (other than itself), denoted by $x^{\text {free }}$, and obtains a price denoted by $p^{\text {free }}$. Under Assumption 1 , we also conjecture that a symmetric equilibrium features fire sales and strictly positive outflows in both banned and free countries, $p^{\text {ban }}, p^{\text {free }} \in(0, R)$ and $x^{b a n}, x^{\text {free }}>0$. It is convenient to work with the modified variables, $X^{\text {ban }}=(1-B) x^{\text {ban }}, X^{\text {free }}=(1-B) x^{\text {free }}$ that describe the total amount of foreign investment made by each banned and free country, respectively.

First consider the free countries. Following similar steps as in Section 4, banks solve the following analogue of problem (10),

$$
\max _{x^{j, j} \geq 0, X^{\text {free }} \geq 0} u\left(1-x^{j, j}-X^{\text {free }}\right)+x^{j, j} R+\left(X^{\text {free }} \bar{R}^{\text {free }}+\eta\right) M^{\text {free }},
$$

where $\bar{R}^{\text {free }}=(1-\pi) R+\pi p^{\text {free }}$ and $M^{\text {free }}=1-\pi+\pi R / p^{\text {free }}$. By Lemma 1 , we have $M^{\text {free }} \bar{R}^{\text {free }}=$ $\mu\left(p^{\text {free }}\right)>R$. Thus, in free countries, local investment is dominated, $x^{j, j}=0$, and foreign investment is characterized by the optimality condition,

$$
u^{\prime}\left(1-X^{\text {free }}\right)=\mu\left(p^{\text {free }}\right)
$$


Note also that each free country's inflows are given by,

$$
x^{i n, j}=\int_{j^{\prime}} x^{j, j^{\prime}} d j^{\prime}=(1-B) x^{\text {free }}+B x^{b a n}=X^{\text {free }}+\frac{B X^{b a n}}{1-B} .
$$

Using Eq. (6) (and symmetry), its banks' asset demand in period 1 is given by $\chi^{j}=\left(\eta+X^{\text {free }} \bar{R}^{\text {free }}\right) / p^{j}$. Note also that, since we consider the limit in which $\lambda \rightarrow \infty$ and the fire-sale price is positive, distressed sellers sell all of their endowments, $\tilde{\chi}^{j}=0$ [cf. Eq. (1)]. Substituting these expressions into Eq. (7), we obtain the market clearing condition,

$$
p^{\text {free }}=\frac{\eta+X^{\text {free }} \bar{R}^{\text {free }}}{e+X^{\text {free }}+B X^{\text {ban }} /(1-B)} .
$$

Next consider the banned countries. Banks solve a similar problem,

$$
\max _{x^{j, j} \geq 0, X^{\text {ban }} \geq 0} u\left(1-x^{j, j}-X^{b a n}\right)+x^{j, j} R+\left(X^{b a n} \bar{R}^{\text {free }}+\eta\right) M^{b a n}
$$

where $M^{b a n}=1-\pi+\pi R / p^{b a n}$. In this case, $\bar{R}^{\text {free }} M^{\text {ban }}$ is not necessarily strictly greater than $R$, and there might be some local investment. Using our conjecture, $X^{\text {ban }}>0$, the optimality conditions can be written as,

$$
\begin{aligned}
& u^{\prime}\left(1-x^{j, j}-X^{\text {ban }}\right)=M^{\text {ban }} \bar{R}^{\text {free }} \\
& u^{\prime}\left(1-x^{j, j}-X^{\text {ban }}\right) \geq R \text { with strict inequality only if } x^{j, j}=0 .
\end{aligned}
$$

To simplify these conditions, we let $\bar{p}^{b a n} \in(0, R)$ denote the unique solution to the equation,

$$
\left(1-\pi+\pi R / \bar{p}^{\text {ban }}\right)\left((1-\pi) R+\pi p^{\text {free }}\right)=R .
$$

We then combine the two optimality conditions to obtain the following,

$$
\left\{\begin{array}{cc}
u^{\prime}\left(1-X^{b a n}\right)=\left(1-\pi+\pi R / p^{b a n}\right) \bar{R}^{\text {free }} & \text { if } p^{\text {ban }}<\bar{p}^{\text {ban }} \\
X^{\text {ban }} \in[0, \underline{x}] & \text { if } p^{\text {ban }}=\bar{p}^{\text {ban }}
\end{array},\right.
$$

where $\underline{x}$ denotes the solution to $u^{\prime}(1-\underline{x})=R$. Hence, if the fire-sale price is equal to the upper bound, $\bar{p}^{b a n}$, then banks in banned countries are indifferent between local and foreign investment. If the price is below this level, they make only foreign investment.

Finally, note that a banned country's inflows are zero, $x^{i n, j}=0$. Following similar steps as in free countries, we obtain the market clearing condition,

$$
p^{\text {ban }}=\frac{\eta+X^{\text {ban }} \bar{R}^{\text {free }}}{e} .
$$

The equilibrium is characterized by the tuple, $\left(X^{\text {free }}, p^{\text {free }}, X^{\text {ban }}, p^{\text {ban }}\right)$, that solve Eqs. $(A 19),(A 20),(A 22)$, and $(A 23)$. The following lemma, the proof of which is relegated to the end of this section, verifies that there exists an equilibrium that satisfies, $p^{\text {free }}, p^{\text {ban }} \in(0, R), X^{\text {free }}, X^{\text {ban }} \in(0,1)$. It also shows that, in every such equilibrium, fire-sale prices in banned countries are greater than in free countries. 
Lemma 3. For each $B \in[0,1)$, there exists a tuple, $p^{\text {free }}, p^{\text {ban }} \in(0, R), X^{\text {free }}, X^{\text {ban }} \in(0,1)$, that solves Eqs. $(A 19),(A 20),(A 22)$, and (A23). Moreover, every solution satisfies $p^{\text {ban }}>p^{\text {free }}$.

We next use this analysis to characterize the Nash equilibrium and prove Proposition 4.

Proof of Proposition 4. Consider a Nash equilibrium in which policymakers choose $b^{j} \in\{0,1\}$ to maximize $p^{j}$. Since every symmetric equilibrium with $B \in[0,1)$ features $p^{\text {ban }}>p^{\text {free }}$, the only candidate for a Nash equilibrium is the autarky allocation in which all policymakers ban inflows, $b^{j}=1$ for each $j$ and $B=1$.

We next show that, under no arbitrage, the autarky allocation is a Nash equilibrium. Recall that in autarky every country (which is a banned country) invests a positive amount in the local risky asset, $\underline{x}>0$, and features the price, $p^{b a n}=\eta / e$. Suppose the policymaker in an (infinitesimal) country $j$ switches to $b^{j}=0$ and allows capital flows. We let $p^{\text {free }}$ denote the equilibrium fire-sale price that would obtain in this country. Under no arbitrage, this price satisfies $p^{\text {free }}<p^{\text {ban }}=\eta / e$. To see this, suppose $p^{\text {free }} \geq p^{\text {ban }}$. This would imply $M^{\text {ban }} \bar{R}^{\text {free }} \geq M^{\text {free }} \bar{R}^{\text {free }}>R$ (cf. Lemma 1 ), which in turn would violate no arbitrage, because in equilibrium banned countries invest a positive amount in local risky assets. This proves $p^{\text {free }}<p^{\text {ban }}$, which in turn proves that the autarky allocation is a Nash equilibrium.

Proof of Lemma 3. First note that, given any $X^{\text {ban }} \in(0,1)$, there exists a unique pair, $p^{\text {free }} \in(0, R)$ and $X^{\text {free }} \in(0,1)$, that solves Eqs. $(A 19)$ and $(A 20)$. Moreover, increasing $X^{\text {ban }}$ weakly decreases $p^{\text {free }}$ and weakly increases $X^{\text {free }}$. We therefore denote the solution with $\mathbf{p}^{\text {free }}\left(X^{\text {ban }}\right)$ and $\mathbf{X}^{\text {free }}\left(X^{\text {ban }}\right)$, and note that $\mathbf{p}^{\text {free }}(\cdot)$ is a weakly decreasing function and $\mathbf{X}^{\text {free }}(\cdot)$ is a weakly increasing function. Note also that $\mathbf{p}^{\text {free }}(0)=p$ and $\lim _{X^{\text {ban } \rightarrow 1}} \mathbf{p}^{\text {free }}\left(X^{\text {ban }}\right)=0$, where $p$ denotes the equilibrium price in the baseline model with free flows.

Next note that Eq. $(A 22)$ describes $p^{\text {ban }}$ as a function of $X^{\text {ban }}$ and $p^{\text {free }}$, which we denote with $\mathbf{p}_{1}^{\text {ban }}\left(X^{\text {ban }}, p^{\text {free }}\right)$. We can check that $\mathbf{p}_{1}^{\text {ban }}(\cdot)$ is weakly decreasing in $X^{\text {ban }}$ and strictly increasing in $p^{\text {free }}$. Hence, after substituting the weakly decreasing function, $\mathbf{p}^{\text {free }}\left(X^{\text {ban }}\right)$, we obtain the weakly decreasing function, $f\left(X^{\text {ban }}\right) \equiv \mathbf{p}_{1}^{\text {ban }}\left(X^{\text {ban }}, \mathbf{p}^{\text {free }}\left(X^{\text {ban }}\right)\right)$. Note also that $\lim _{X^{\text {ban } \rightarrow 1}} f\left(X^{\text {ban }}\right)=0$, and

$$
f(0)=\mathbf{p}_{1}^{b a n}(0, p)=\bar{p}^{b a n}>p
$$

where the last inequality follows from applying Eq. (A21) with $p^{\text {free }}=p$ and observing that $\mu(p)>R$.

Likewise, note that Eq. (A23) describes $p^{\text {ban }}$ as another function of $X^{\text {ban }}$ and $p^{\text {free }}$, which we denote with $\mathbf{p}_{2}^{\text {ban }}\left(X^{\text {ban }}, p^{\text {free }}\right)$. After substituting $\mathbf{p}^{\text {free }}\left(X^{\text {ban }}\right)$, we obtain the continuous function, $g\left(X^{\text {ban }}\right) \equiv$ $\mathbf{p}_{2}^{\text {ban }}\left(X^{\text {ban }}, \mathbf{p}^{\text {free }}\left(X^{\text {ban }}\right)\right)$. Note also that $\lim _{X^{\text {ban } \rightarrow 1}} g\left(X^{\text {ban }}\right)>0$ and $g(0)=\eta / e<p$ (since $p$ denotes the equilibrium in the baseline model).

Using the continuity of functions $f(\cdot)$ and $g(\cdot)$, it follows that there exists $X^{\text {ban }} \in(0,1)$ such that $f\left(X^{\text {ban }}\right)=g\left(X^{\text {ban }}\right)$. By definitions of $f(\cdot)$ and $g(\cdot), X^{\text {ban }}$ corresponds to a solution. The remaining variables are found from, $p^{\text {free }}=\mathbf{p}^{\text {free }}\left(X^{\text {ban }}\right), X^{\text {free }}=\mathbf{X}^{\text {free }}\left(X^{\text {ban }}\right)$, and $p^{\text {ban }}=f\left(X^{\text {ban }}\right)$. We can also check that the solution is interior and satisfies $p^{\text {free }}, p^{\text {ban }} \in(0, R), X^{\text {free }}, X^{\text {ban }} \in(0,1)$.

We next show that, in every solution, the banned countries feature greater fire-sale prices, $p^{\text {ban }}>p^{\text {free }}$. Suppose, to reach a contradiction, that $p^{\text {ban }} \leq p^{\text {free }}$. Eq. (A21) implies that $\bar{p}^{\text {ban }}>p^{\text {free }}$. Thus, we have $p^{b a n} \leq p^{\text {free }}<\bar{p}^{\text {ban }}$. Eq. $(A 22)$ then implies that $x^{j, j}=0$ and outflows are determined by

$$
u^{\prime}\left(1-X^{b a n}\right)=\left(1-\pi+\pi R / p^{\text {ban }}\right) \bar{R}^{\text {free }} \geq \mu\left(p^{\text {free }}\right),
$$

where the last inequality follows since $p^{\text {ban }} \leq p^{\text {free }}$. Combining this with Eq. (A19) implies that $X^{\text {ban }} \geq$ 
$X^{\text {free }}$. Combining this inequality with Eqs. $(A 20)$ and $(A 23)$ then implies $p^{\text {ban }}>p^{\text {free }}$, which yields a contradiction and completes the proof.

\section{A.4. Reach for safety and yield in the beta model}

In Section 7, we assumed $\pi_{1}>0$ (liquidity shocks have positive probability in all aggregate states) to simplify the exposition. In this section, we characterize the equilibrium when $\pi_{1}=0$. A special case is the beta model we introduced in Section 6. After we characterize the equilibrium, we use the beta model to establish additional comparative statics of the reach-for-safety and -yield.

As in Section 7, we consider a special country that has potentially different parameters, $\left(\eta^{*}, R^{*}\right)$. As before, the parameters satisfy Assumption 2. The new assumption is that $\pi_{1}=0$, that is, there exists an aggregate state in which the conditional probability of liquidity shocks is zero. As before, we denote the equilibrium allocations in the special country with $x^{*, *}, x^{i n, *},\left(l_{s}^{*}\right)_{s},\left(\tilde{\chi}_{s}^{*}\right)_{s},\left(p_{s}^{*}\right)_{s}$. Recall that $l_{s}^{*}=x^{\text {out }, *} \bar{R}_{s}+$ $y^{*}+z_{s}^{*}-\eta^{*}$ denotes the banks' liquidity purchase (and the individual components, $x^{\text {out, },}, y^{*}, z_{s}^{*}$, are not uniquely determined).

In Proposition 7, we show that $x^{*, *}=0$ and the remaining equilibrium allocations in the special country are characterized as the solution to Eqs. $(32-36)$. Most of these equations continue to apply in this setting with the exception of the optimality condition for outflows, Eq. (34). In this case, since liquidity shocks happen with zero probability in state $s=1$, banks in the special country might prefer to bring zero net liquidity to this state. Thus, we need to allow for the possibility of a corner solution in this state. To this end, we replace the optimality condition (34) with the following conditions,

$$
\begin{aligned}
& \frac{M_{s}^{*}}{u^{\prime}\left(c_{0}^{*}\right)}=\frac{q_{s}}{\gamma_{s}}=\frac{M_{s}}{u^{\prime}\left(c_{0}\right)} \text { for each } s>1, \\
& \text { and } \quad\left\{\begin{array}{c}
\text { either } c_{0}^{*}<c_{0}, l_{1}^{*}=-\eta^{*} \\
\text { or } c_{0}^{*}=c_{0}, l_{1} \geq-\eta^{*}, p_{1}^{*}=p_{1}
\end{array}\right.
\end{aligned}
$$

Here, Eq. (A24) says that the earlier optimality conditions continue to apply for states $s>1$ (that feature $\left.\pi_{s}>0\right)$. Eq. $(A 25)$ is the optimality condition for state $s=1$. To understand this condition, note that $\pi_{1}=0$ implies $M_{1}^{*}=M_{1}=1$. For regular countries, we have an interior solution for this state (in a symmetric equilibrium), which implies that banks are indifferent to investing in this state, $M_{1} / u^{\prime}\left(c_{0}\right)=q_{1} / \gamma_{1}$. Eq. (A25) presents the optimality condition for the banks in the special country depending on whether $c_{0}^{*}<c_{0}$ or $c_{0}^{*}=c_{0}$ (the remaining case, $c_{0}^{*}>c_{0}$, can be ruled out). If $c_{0}^{*}<c_{0}$, then the special country features $M_{1}^{*} / u^{\prime}\left(c_{0}^{*}\right)<q_{1} / \gamma_{1}$, which implies that banks strictly prefer to reduce their investment in this state and there is a corner solution, $l_{1}^{*}=-\eta^{*}$. If $c_{0}^{*}=c_{0}$, the special country features $M_{1}^{*} / u^{\prime}\left(c_{0}^{*}\right)=q_{1} / \gamma_{1}$, which implies the banks are indifferent to investing in this state. In this case, $p_{1}^{*}$ is not uniquely determined. ${ }^{5}$ But this indeterminacy is innocuous since $\pi_{1}=0$ and liquidity shocks happen with zero probability in this state. We resolve this indeterminacy by assuming, $p_{1}^{*}=p_{1}$.

The following result, which is the analogue of Proposition 7 for this setting, summarizes this discussion and establishes the existence of an equilibrium. The proof is relegated to Online Appendix A.6.

Proposition 10. Consider the model with Assumption 1 and $\pi_{1}=0$, together with a special country that satisfies Assumption 2. There exists an equilibrium in which the allocations and prices for regular countries

\footnotetext{
${ }^{5}$ This indeterminacy arises because the banks in the special country can transfer liquidity from state 1 to other states (therefore lowering $p_{1}^{*}$ ), and banks in regular countries can send greater inflows into the special country to neutralize the price impact of these liquidity transfers (therefore leaving $p_{s}^{*}$ unchanged for $s>1$ ).
} 
are characterized by Propositions 1-2. In the special country, there is no local investment, $x^{*, *}=0$. The remaining allocations, $x^{i n, *}, c_{0},\left(l_{s}^{*}\right)_{s},\left(p_{s}^{*}\right)_{s},\left(\tilde{\chi}_{s}^{*}\right)_{s}$, are characterized as the unique solution to the system of equations $(32-36)$ after replacing Eq. (34) with Eqs. (A24-A25).

As before, we adopt the convention that total inflows are equal to the inflows into risky assets, $\bar{x}^{i n, *} \equiv$ $x^{i n, *}$. Total outflows account for the net trade of safe and contingent assets and are given by Eq. (37).

Next consider the beta model we analyzed in Section 6. Note that Proposition 10 also applies for this model. We use this special case to analyze the determinants of reach-for-safety and -yield.

Reach for safety in the beta model. First suppose $R^{*}=R$ and consider the effect of asymmetries in the liquidity supply, $\eta^{*}$. It is easy to verify that the closed-form solution described in Section 7.2 also applies in this setting. Thus, the results in Proposition 8 apply. In particular, fire-sale prices are independent of $\eta^{*}$. A country with $\eta^{*}>\eta$ features more inflows than outflows, $x^{\text {in }, *}>\bar{x}^{\text {out,*}}=x$, and it also has riskier (more leveraged) outflows relative to its inflows, $\Lambda>1$. A country with $\eta^{*}<\eta$ features more outflows than inflows, $\bar{x}^{\text {out,*}}=x>x^{i n, *}$, and safer (less leveraged) outflows than regular countries, $\Lambda<1$.

We next analyze the comparative statics of equilibrium with respect to global risk conditions, which we capture with $\beta$ (see Section 6). Suppose $\beta$ increases so that the liquidity shocks become more correlated. As captured by Proposition 6 , this decreases the symmetric flows, $x$, as well as the risk-free rate, $R_{f}$. Consider the effect on net imbalances (as a fraction of outflows), $\left|x^{\text {in }, *}-x\right| / x$, as well as the absolute value of a country's relative leverage ratio, $|\Lambda-1|$. After rearranging Eqs. (38), we obtain closed-form expressions,

$$
\begin{aligned}
\frac{\left|x^{\mathrm{in}, *}-x\right|}{x} & =\left(\frac{e}{x}+1\right)|\Lambda-1| \\
|\Lambda-1| & =\frac{\left|\eta^{*}-\eta\right|}{x R_{f}+\eta} .
\end{aligned}
$$

Since an increase in $\beta$ reduces $x$ and $R_{f}$, it also increases both $|\Lambda-1|$ and $\frac{\left|x^{\mathrm{in}, *}-x\right|}{x}$. In particular, for a developed country with $\eta^{*}>\eta$, it increases the (proportional) current account deficit and makes the outflows riskier. Conversely, for an emerging market with $\eta^{*}<\eta$, it increases the (proportional) current account surplus and makes the outflows safer. The following result, which is the analogue of Proposition 8 for this setting, summarizes this discussion.

Proposition 11. Consider the setup in Proposition 10 for the special case of the beta model described in Section 6. Suppose the parameters satisfy $R^{*}=R$ and $\eta^{*} \neq \eta$. All of the results stated in Proposition 8 apply in this setting. In addition, an increase in $\beta$ (the liquidity shocks become more correlated) increases $\left|x^{i n, *}-x\right| / x$ and $|\Lambda-1|$.

Reach for yield in the beta model. Next suppose $\eta^{*}=0$ and consider the effect of asymmetries in return, $R^{*}$. As in the main text, we consider the case with $R^{*}>R$. Using Proposition 10, and Eqs. (23) and (24), the foreigners' optimality (or indifference) condition (32) can be rewritten as,

$$
q_{1} R^{*}+q_{2}\left((1-\pi) R^{*}+\pi p_{2}^{*}\right)+q_{3} p_{3}^{*}=q_{1} R+q_{2}\left((1-\pi) R+\pi p_{2}\right)+q_{3} p_{3}
$$

Likewise, local banks' optimality conditions (A24) for states 2 and 3 can be rearranged as,

$$
\frac{1-\pi+\pi \frac{R^{*}}{p_{2}^{*}}}{1-\pi+\pi \frac{R}{p_{2}}}=\frac{\frac{R^{*}}{p_{3}^{*}}}{\frac{R}{p_{3}}}=\frac{u^{\prime}\left(c_{0}^{*}\right)}{u^{\prime}\left(c_{0}\right)}
$$


Eqs. (A26) and $(A 27)$ determine $\left(p_{2}^{*}, p_{3}^{*}\right)$, as well as $c_{0}^{*}$. Lemma 4 in Online Appendix A.6 establishes that there is a unique solution. Moreover, the solution satisfies $\frac{u^{\prime}\left(c_{0}^{*}\right)}{u^{\prime}\left(c_{0}\right)}>1$. By $(A 25)$, this implies $l_{1}^{*}=-\eta^{*}$ (there is a corner solution for state 1$)$. The remaining allocations, $x^{i n, *}, p_{1}^{*},\left(l_{s}^{*}\right)_{s \in\{2,3\}},\left(\tilde{\chi}_{s}\right)_{s}$, are characterized by solving Eqs. $(32-36)$ with the exception of Eq. (34). The price in state 1 is zero, $p_{1}^{*}=0$, since banks have zero net liquidity in this state, $l_{1}^{*}+\eta^{*}=0$.

Lemma 4 further shows that the solution satisfies $p_{2}^{*}<p_{2}$ and $p_{3}^{*}<p_{3}$, that is, the country experiences more severe fire sales in both distressed states. Moreover, the relative depth of fire sales is greater in the idiosyncratic shock state than in the aggregate shock state, $p_{2}^{*} / p_{2}<p_{3}^{*} / p_{3}$. It can also be seen that $x^{\text {in,* }}>\bar{x}^{\text {out }, *}>x$, that is, the reach for yield increases the country's outflows, but it increases its inflows more than its outflows. Hence, all of the results in Proposition 9 apply in this case as long as we focus on the prices for aggregate states $s>1$ (with $\pi_{s}>0$ ). The remaining price is equal to zero, $p_{1}^{*}=0$.

We next investigate the comparative statics of equilibrium with respect to the global return and risk conditions, which we capture with $R$ and $\beta$. To this end, we substitute $q_{s}=\gamma_{s} \frac{M_{s}}{u^{\prime}\left(c_{0}\right)}$ [cf. Eq. (34)] into Eq. (A26) and rearrange terms to obtain,

$$
\begin{aligned}
& \left(R^{*}-R\right)(1-\pi)\left(M_{1} \beta+M_{2}(1-\beta)\right)=\left(\bar{p}-\bar{p}^{*}\right) \pi\left(M_{2}(1-\beta)+M_{3} \beta\right), \\
& \text { where } \bar{p}=\frac{p_{2} M_{2}(1-\beta)+p_{3} M_{3} \beta}{M_{2}(1-\beta)+M_{3} \beta} \text { and } \bar{p}^{*}=\frac{p_{2}^{*} M_{2}(1-\beta)+p_{3}^{*} M_{3} \beta}{M_{2}(1-\beta)+M_{3} \beta} .
\end{aligned}
$$

Here, the second line defines weighted average fire-sale prices (weighted by probability and price). Eq. (A28) captures the trade-off from investing in the special country relative to other countries. Banks collect net positive returns if there is no crisis (captured by the left side), but they make net negative returns if there is a crisis (captured by the right side). Net gains are multiplied by the probability of no crisis $(1-\pi)$ and the average marginal value conditional on no crisis. Net losses are calculated in similar fashion. The indifference condition obtains when the weighted net gains and net losses are equated.

Eq. (A28) shows that, all else equal, a decline in investment returns in other countries, $R$, makes investing in the special country more attractive. In equilibrium, this tends to decrease the relative fire-sale price in the special country, so as to counter the greater net gains with greater net losses conditional on a crisis. However, the result does not immediately follow since the marginal values are endogenous and depend on $R$. In Online Appendix A.6, we formally establish that a decrease in $R$ decreases $\bar{p}^{*}-\bar{p}$.

Eq. (A28) also shows that, all else equal, a decline in the correlation parameter, $\beta$, makes investing in the special country relatively more attractive: it decreases the weighting term on the right (loss) side while increasing the weighting term on the left (gain) side since $M_{1}<M_{2}<M_{3}$. In equilibrium, this tends to reduce the relative fire-sale price in the special country. In Online Appendix A.6, we formally show a decrease in $\beta$ decreases $\bar{p}^{*}-\bar{p}$. The following proposition, which is the analogue of Proposition 9 for this setting, summarizes this discussion.

Proposition 12. Consider the setup in Proposition 10 for the special case of the beta model described in Section 6. Suppose the parameters satisfy $\eta^{*}=\eta$ and $R^{*}>R$. All of the results stated in Proposition 9 continue to apply in this setting for states $s \in\{2,3\}$ with $\pi_{s}>0$. The remaining state $s=1$ (with $\pi_{1}=0$ ) features $l_{1}^{*}=-\eta^{*}$ and $p_{1}^{*}=0$. In addition, a decrease in $R$ as well as a decrease in $\beta$ reduces the special country's relative weighted average fire-sale price, $\bar{p}^{*}-\bar{p}$ [defined in (A28)]. 


\section{A.5. An alternative model with distressed banks}

In the main text, we built a model in which liquidity shocks are events such that a group of agents ("distressed sellers") sell financial assets at fire-sale prices to invest in a profitable project, and another group of agents ("banks") arbitrage these fire sales. In practice, crises and fire-sales are often associated with losses to financial institutions, which we call "banks" in our model. In this appendix, we build a model in which there are no distressed sellers, and liquidity shocks are events such that banks experience losses (so they are the distressed agents). When this happens, banks are forced to sell their assets to another group of agents, "secondary buyers," that reside in the same country as the banks. We show that the equivalent of our main result (Proposition 1) applies in this case.

We then characterize the constrained optimal allocation in this environment and establish the equivalent of our main welfare result (Proposition 3). In this setting, fire sales are costly because they tighten banks' financial constraints and generate a misallocation of productive resources to secondary buyers (similar to Kiyotaki and Moore (1997)). As long as banks are net sellers of risky assets in a liquidity shock, the constrained optimum features higher ex-ante foreign investment and higher ex-post fire-sale prices compared to the competitive equilibrium, because the planner internalizes that greater prices relax banks' financial constraints.

Taken together, our results in this appendix highlight that the "distressed sellers" in our main model are a modeling device that introduces the standard balance sheet channel into the model while simplifying the analysis. These agents generate the liquidity demand that triggers fire sales, and when the return from their projects $(\lambda)$ is high, they also capture the social cost of fire sales.

For simplicity, we focus attention on the case in which there is a single aggregate state $s$ so there is no aggregate risk (the results can be generalized). Throughout, we drop the subscript $s$ from the notation.

An alternative model. As before, there are three periods, $t \in\{0,1,2\}$, and a single consumption good in each period. There is a continuum of mass one of countries denoted by superscript $j \in J$. A random variable $\omega^{j}$ is drawn for each country $j$ and i.i.d. across $j$, with $\pi=\operatorname{Pr}\left(\omega^{j}=b\right)$ and $1-\pi=\operatorname{Pr}\left(\omega^{j}=g\right)$. We say that a country with $\omega^{j}=b$ experiences a liquidity shock.

There are two types of assets. First, in each country, there is a linear technology in period 0: investing one unit of the consumption good produces one unit of a country-specific risky asset. If $\omega^{j}=g$, then the asset generates $R+G$ units of the consumption good in period 1 (and 0 units in period 2), where $R$ denotes the baseline payoff and $G$ denotes an additional gain realized in the good state. If $\omega^{j}=b$, then the asset generates $R$ units of the consumption good in period 2. But it also generates a loss of $L$ units of consumption good in period 1 (that is, the asset's owner is obliged to pay $L$ units of the consumption good). To simplify the exposition, we assume $G(1-\pi)=\pi L$, so that the asset's expected payoff after accounting for the gains and losses is still $R$.

When $\omega^{j}=b$, the asset is traded at an endogenous price. We let $p^{j}$ denote the price after the payment of $L$. As before, we concentrate on symmetric equilibria in which this price is the same across all countries, that is, $p^{j} \equiv p$ for each $j$.

As before, there is a risk-free asset that pays 1 unit of the consumption good in period 1 (and 0 units in period 2). The risk-free asset is in fixed supply: specifically, there are $\eta$ units in each country (endowed to the local banks that we describe below). In period 0, the risk-free asset is traded at an endogenous price $q_{f}$. (We do not introduce the Arrow-Debreu securities since there is only a single aggregate state).

In each country, there are two types of agents, which we refer to as "secondary buyers" and "banks."

The secondary buyers have preferences $E\left[\tilde{c}_{1}^{j}\right]$. When the local state is $\omega^{j}=b$, they have access to a concave 
technology that converts the asset in their country into consumption goods in period 1 . If they purchase $\tilde{\chi}^{j} \geq 0$ units of the asset, then they produce $\psi R \log \left(\tilde{\chi}^{j} / \psi+1\right)$ units of the consumption good (for some $\psi>0$ ). Thus, their consumption is given by

$$
\tilde{c}_{1}^{j}=\psi R \log \left(\tilde{\chi}^{j} / \psi+1\right)-p \tilde{\chi}^{j}
$$

We chose the functional form for their production to obtain a simple expression for demand. Specifically, the optimality condition implies the secondary buyers' demand for the asset is given by

$$
\tilde{\chi}^{j}=\psi(R / p-1) \text { for each } p \leq R
$$

The role of these buyers is to generate misallocation and welfare losses from fire sales (as in Kiyotaki and Moore (1997)).

As before, banks are the main agents in our model and their preferences are,

$$
E\left[u\left(c_{0}^{j}\right)+c_{1}^{j}+c_{2}^{j}\right]
$$

Banks are endowed with $e$ units of the asset in their country, which we refer to as legacy assets (as in the main text). Banks are not allowed to sell their legacy assets in period 0 , which ensures that they have a minimum amount of exposure to the local risky asset in period 1. We could endogenize this by introducing some local expertise with diminishing returns. In particular we view the legacy assets as representing the comparative advantage of local banks to lend in the local market.

In addition, banks are endowed with 1 unit of the consumption good in period 0 as well as $\eta$ units of the risk-free asset (as in the main text).

Banks in country $j$ choose an investment strategy, $x^{j^{\prime}, j}$, in risky assets across countries, $j^{\prime}$. They also choose how many consumption units to invest in the risk-free asset, $y^{j}$. Banks' budget constraint in period 0 is

$$
c_{0}^{j}+x^{j, j}+x^{o u t, j}+y^{j} q_{f}=1+\eta q_{f}, \text { where } x^{o u t, j}=\int_{j^{\prime} \neq j} x^{j^{\prime}, j} d j^{\prime} .
$$

Here, $x^{\text {out }, j}$ denotes the outflows: i.e., what country $j$ banks invest in other countries. Banks are not allowed to short-sell risky assets, $x^{j^{\prime}, j} \geq 0$ for each $j^{\prime}$, but they are allowed to take unrestricted positions on the risk-free asset subject to obtaining nonnegative consumption in all periods and states.

In period 1 , banks receive $x^{o u t, j} \bar{R}$ units of the consumption good from their foreign positions, where we define $\bar{R}=(1-\pi) R+\pi p$ similar to the main text. Note that banks' losses and gains on average cancel (by assumption) and we are left with the same expression as in the main text. Banks also receive $y^{j}$ units of the consumption good from their investments in the safe asset.

If $\omega^{j}=g$, they also receive $\left(e+x^{j, j}\right)(R+G)$ units from the local asset. Moreover, banks do not have a remaining investment opportunity so they consume all of their available resources in period 1. In particular, their budget constraint in this state can be written as,

$$
\begin{aligned}
c_{1}^{j}\left(\omega^{j}=g\right) & =\left(e+x^{j, j}\right)(R+G)+x^{o u t, j} \bar{R}+y^{j} \\
\text { and } c_{2}^{j}\left(\omega^{j}=g\right) & =0 .
\end{aligned}
$$

If $\omega^{j}=b$, then banks lose $\left(e+x^{j, j}\right) L$ units from the local asset. We let $\chi^{j} \geq 0$ denote banks' position in the local risky asset in period 1 when $\omega^{j}=b$. Then, their budget constraint in this state can be written 
as,

$$
\begin{aligned}
c_{1}^{j}\left(\omega^{j}=b\right)+\chi^{j} p & =\left(e+x^{j, j}\right)(p-L)+x^{o u t, j} \bar{R}+y^{j}, \\
c_{2}^{j}\left(\omega^{j}=g\right) & =\chi^{j} R .
\end{aligned}
$$

As before, banks choose $\left[x^{j^{\prime}, j} \geq 0\right]_{j^{\prime}}, y^{j},\left(z^{j}, \chi^{j} \geq 0\right)$ to maximize their expected utility subject to nonnegative consumption requirements, $c_{0}^{j} \geq 0, c_{1}^{j} \geq 0, c_{2}^{j} \geq 0$.

The equilibrium is a collection of optimal allocations and market clearing conditions. The market clearing condition for the risky asset in a country $j$ with $\omega^{j}=b$ in period 1 can be written as,

$$
e+x^{i n, j}+x^{j, j}=\tilde{\chi}^{j}+\chi^{j} \text { where } x^{i n, j}=\int_{j^{\prime} \neq j} x^{j, j^{\prime}} d j^{\prime}
$$

The market clearing condition for the risk-free asset in period 0 can be written as,

$$
\int_{j} y^{j} d j=\int_{j} \eta d j=\eta
$$

Equilibrium in the alternative model. We assume the parameters satisfy

Assumption $\mathbf{1}^{\mathrm{A}} \cdot e L-\psi R<\eta<e L$.

The right side of the inequality ensures the equilibrium features fire sales, $p<R$. The left side ensures the fire-sale price is strictly positive, $p>0$. Specifically, we conjecture an equilibrium with symmetric fire-sale prices, $p \in(0, R)$. We also conjecture symmetric equilibrium allocations, denoted by $x^{\text {out }}, y$. Later, we strengthen this assumption to facilitate the welfare analysis. As before, the symmetry implies that $y=\eta$ and that inflows and outflows are the same, $x^{i n}=x^{\text {out }}$. When it is clear from the context, we denote symmetric flows with $x$.

Since banks have linear utility between periods 1 and 2 , the presence of fire sales $(p<R)$ implies that banks in countries with state $\omega^{j}=b$ invest all of their resources in period 1 in the risky asset. Combining this observation with the budget constraints stated earlier, we obtain $c_{1}^{j}\left(\omega^{j}=b\right)=0$ and

$$
\chi^{j}=\frac{\left(e+x^{j, j}\right)(p-L)+x^{o u t, j} \bar{R}+\eta}{p} .
$$

In addition, since countries are symmetric, the market clearing condition implies $y^{j}=\eta$. Combining these observations with the budget constraints,

$$
\begin{aligned}
c_{0}^{j}+x^{j, j}+x^{\text {out }} & =1, \\
c_{1, s}^{j}\left(\omega^{j}=g\right) & =\left(e+x^{j, j}\right)(R+G)+x^{\text {out }} \bar{R}+\eta, \\
c_{2, s}^{j}\left(\omega^{j}=b\right) & =\frac{\left(e+x^{j, j}\right)(p-L)+x^{\text {out }, j} \bar{R}+\eta}{p} R .
\end{aligned}
$$

Substituting these expressions into the objective function and rearranging terms, the banks' problem can be written as,

$$
\max _{x^{j, j}, x^{\text {out }}} u\left(1-x^{j, j}-x^{\text {out }}\right)+\left(e+x^{j, j}\right) R^{j, j}+\left(x^{\text {out }} \bar{R}+\eta\right) M,
$$


where $M=1-\pi+\pi \frac{R}{p}$ as in the main text and

$$
R^{j, j}=(1-\pi)(R+G)+\pi \frac{p-L}{p} R
$$

denotes the ex-ante marginal value from investing in the local asset. It is easy to check that $R^{j, j}<R<\bar{R} M$ (the last inequality follows from Lemma 1), which implies $x^{j, j}=0$. As before, local investment in period 0 is dominated by foreign investment.

Banks' foreign investment is then characterized by solving

$$
u^{\prime}(1-x)=\mu(p) \equiv \bar{R} M
$$

where $\bar{R}=(1-\pi) R+\pi p$ and $M=1-\pi+\pi \frac{R}{p}$ as in the main text. As before, this yields a decreasing relationship between $x$ and $p$.

Next consider the determination of the fire-sale asset price, $p$. Substituting $\tilde{\chi}^{j}, \chi^{j}$ from Eqs. (A29) and (A31) into the market clearing condition (A34) (and using $x^{j, j}=0$ and $y^{j}=\eta$ ) we obtain,

$$
p=\frac{\psi R+e(p-L)+x^{\text {out }} \bar{R}+\eta}{\psi+e+x^{i n}} .
$$

After substituting $x^{i n}=x^{o u t}=x$ and rearranging terms, we obtain,

$$
p=\frac{\psi R+\eta-e L+x \bar{R}}{\psi+x} .
$$

Substituting the expression for $\bar{R}$ and rearranging, we further obtain,

$$
p=\frac{\psi R+\eta-e L+x(1-\pi) R}{\psi+x(1-\pi)} .
$$

As before, this provides an increasing relation between $x$ and $p$.

The equilibrium is characterized by Eqs. $(A 32)$ and $(A 34)$. Under Assumption $1^{\mathrm{A}}$, there exists a unique solution, $(x, p)$, that also satisfies $p \in(0, R)$ and $x \in(0,1)$.

Global liquidity creation in the alternative model. We next illustrate that our main result regarding the liquidity-creation role of gross flows (Proposition 1) extends to this setting. To this end, we start by characterizing the autarky allocation in which foreign flows are banned. In particular, banks solve the problem described above with the additional restriction $x^{o u t, j}=0$. In this case, there might be some local investment. Specifically, we have,

$$
u^{\prime}\left(1-x^{j, j}\right) \geq(1-\pi)(R+G)+\pi \frac{p^{a u t}-L}{p^{a u t}} R,
$$

with strict inequality only if $x^{j, j}=0$. Note that this describes a (weakly) increasing relation between $p^{a u t}$ and $x^{j, j}$. Following similar steps as above, the market clearing condition becomes,

$$
p^{a u t}=\frac{\psi R+\eta-\left(e+x^{j, j}\right) L}{\psi} .
$$


This describes a decreasing relation between $p^{a u t}$ and $x^{j, j}$. The autarky equilibrium is characterized by solving Eqs. (A35) and (A36). Under Assumption $1^{\mathrm{A}}$, there exists a unique solution, $\left(p^{a u t}, x^{j, j}\right)$, that satisfies $p^{a u t} \in(0, R)$ and $x^{j, j} \in[0, \underline{x})$ (recall that $\underline{x}$ denotes the solution to $u^{\prime}(1-\underline{x})=R$ ).

Comparing Eqs. (A34) and (A36), we have,

$$
p>\frac{\psi R+\eta-e L}{\psi} \geq \frac{R \psi+\eta-\left(e+x^{j, j}\right) L}{\psi}=p^{a u t} .
$$

Here, the first inequality follows since $x>0$ and the second inequality follows since $x^{j, j} \geq 0$. It follows that the equilibrium fire-sale price exceeds the autarky level, $p>p^{a u t}$, as in the baseline model. Intuitively, as illustrated by Eq. (A33), gross flows create liquidity also in the alternative model because inflows are liquidated at the fire-sale price $p$, whereas outflows provide liquidity at a higher return $\bar{R}$.

Public goods aspect of liquidity creation in the alternative model. Eq. (A33) also illustrates that outflows increase local fire-sale prices whereas inflows tend to reduce them. The coordination problem between local policymakers that we highlighted in the main text also extends to this setting. In particular, suppose local policymakers want to raise local fire-sale prices, $p^{j}$, and they can choose whether or not to ban capital flows, $b^{j} \in\{0,1\}$ (as in Section 5.2). It is then easy to check that a global policymaker that could coordinate policy across countries would prescribe $b^{j}=0$ for each $j$, whereas the Nash equilibrium features $b^{j}=1$ for each $j$ and results in the autarky allocation. Hence, absent coordination, local policymakers set excessive restrictions on capital flows, which leads to lower liquidity creation and lower fire-sale prices compared to a coordinated outcome.

Constrained optimal allocation and externalities in the alternative model. We next characterize the constrained optimal allocation in this environment and illustrate the externalities. As in Section 5.1, suppose the policymakers have the utilitarian social welfare function,

$$
W^{j}=u\left(c_{0}^{j}\right)+E\left[c_{1}^{j}+c_{2}^{j}\right]+E\left[\tilde{c}_{2}^{j}\right] .
$$

Consider a global planner that can dictate (symmetric) period 0 local and foreign investment in each country but otherwise cannot interfere with equilibrium allocations. We denote local investment with $x^{j, j}$, foreign investment with $x$, and the resulting equilibrium price with $p$. Using the functional form for secondary buyers' demand [cf. Eq. (A29)] and following similar steps as in Section 5.1, we calculate the planner's objective function as,

$$
\begin{aligned}
W^{j} & =u\left(1-x-x^{j, j}\right)+\left(x^{j, j}+x+e\right) R+\eta+\pi f(\tilde{\chi}), \\
\text { where } \tilde{\chi} & =\psi(R / p-1) \text { and } f(\tilde{\chi})=-\tilde{\chi} R+\psi R \log (\tilde{\chi} / \psi+1) .
\end{aligned}
$$

This expression is the analogue of Eq. (20) for this setting. The term $f(\tilde{\chi})$ captures the net production that results from transferring resources from banks to secondary buyers. It is easy to check that $f(0)=0$ and $f^{\prime}(\tilde{\chi})<0$ for each $\tilde{\chi} \geq 0$. Thus, net production is negative (and increasingly so for greater levels of $\tilde{\chi}$ ). This illustrates that transferring assets to secondary buyers reduces the utilitarian social welfare.

Following similar steps as above, the market clearing condition is given by the following analogue of Eq. $(A 34)$,

$$
p=\frac{\psi R+\eta-\left(e+x^{j, j}\right) L+x(1-\pi) R}{\psi+x(1-\pi)} .
$$


The constrained social planner chooses $\left(x, x^{j, j}, p\right)$ to maximize the expression in $(A 37)$ subject to this condition. It is easy to check that the ex-ante marginal value from foreign investment strictly exceeds $R$ whereas the marginal value from local investment is strictly less than $R$. Hence, local investment is dominated, and $x^{j, j}=0$ (as in the main text). Intuitively, the planner prefers foreign investment because it increases the fire-sale price and reduces misallocation, whereas local investment further reduces the fire-sale price and exacerbates misallocation.

After setting $x^{j, j}=0$, the market clearing condition (A38) is equivalent to its counterpart in equilibrium, condition (A34). Thus, the planner maximizes (A37) subject to this condition. Taking the first order conditions, we obtain the following analogue of Eq. (21) in Section 5.1,

$$
\begin{aligned}
u^{\prime}(1-x) & =R+\pi f^{\prime}(\tilde{\chi}) \frac{d \tilde{\chi}}{d p} \frac{d p}{d x} \\
\text { where } f^{\prime}(\tilde{\chi}) & =-R+\frac{R}{1+\tilde{\chi} / \psi}=-(R-p), \\
\frac{d \tilde{\chi}}{d p} & =-\frac{\psi R}{p^{2}} \\
\frac{d p}{d x} & =\frac{(1-\pi)}{\psi+x(1-\pi)}(R-p) .
\end{aligned}
$$

Here, the second line uses the definition of $f(\cdot)$ in $(A 37)$, the third line uses the definition of $\tilde{\chi}$ in $(A 29)$, and the last line uses the expression for $p$ in $(A 34)$ to evaluate the corresponding derivatives.

Combining these expressions, the planner's optimality condition becomes

$$
u^{\prime}(1-x)=R+R \pi\left(\frac{R}{p}-1\right)^{2} \frac{\psi(1-\pi)}{\psi+x(1-\pi)} .
$$

As before, this represents a decreasing relationship between $(x, p)$. The equilibrium is characterized by solving this expression together with Eq. (A39). Under Assumption $1^{\mathrm{A}}$, there exists a solution that satisfies $p \in(0, R)$ and $x \in(0,1)$.

As in Section 5.1, the equilibrium and the constrained optimum share the market clearing condition (A34) but they differ because they are associated with different optimality conditions (A39) and (A32). After comparing the right-hand terms of conditions $(A 39)$ and $(A 32)$ and rearranging terms, it is easy to check that the constrained optimal allocation features greater $x$ (and greater $p$ ) if and only if the following inequality holds:

$$
\frac{\psi}{\psi+x^{e q}(1-\pi)}>\frac{p^{e q}}{R}=\frac{\psi+\frac{\eta-e L}{R}+x^{e q}(1-\pi)}{\psi+x^{e q}(1-\pi)} .
$$

Here, $\left(x^{e q}, p^{e q}\right)$ denote the competitive equilibrium allocation and the equality follows from Eq. (A34). After rearranging terms and combining with Eq. (A31), the previous inequality is equivalent to

$$
e L>\eta+R x^{e q}(1-\pi) .
$$

When this inequality is satisfied, the constrained optimum features greater $(x, p)$ than the equilibrium. Otherwise, it features smaller $(x, p)$. Hence, the analogue of Proposition 3 in Section 5.1 applies in this setting.

To understand condition (A40), suppose the parameters are such that banks' demand for assets in 
equilibrium satisfies [cf. Eq. (A31)],

$$
\chi^{j}=\frac{e\left(p^{e q}-L\right)+x^{e q} \bar{R}^{e q}+\eta}{p^{e q}}<e .
$$

This says that local banks are net sellers of the risky asset in the sense that their demand $\chi^{j}$ is below their endowment $e$. This condition implies Eq. (A40), that is, if local banks are net sellers in equilibrium, then the constrained optimum features greater $(x, p)$. The intuition is that increasing fire-sale prices via greater foreign investment reduces the wealth of secondary buyers but increases the wealth of local banks (when they are net sellers) as well as fickle foreign banks. Since the secondary buyers have lower marginal value than both local and foreign banks, foreign investment is associated with positive externalities, and the equilibrium features insufficient liquidity creation and depressed prices. ${ }^{6}$

Condition $(A 41)$ is implied by the following strengthening of Assumption $1^{\mathrm{A}}$.

Assumption $\mathbf{1}^{\mathrm{A}^{\prime}} \cdot e L-\psi R<\eta<e L-R$.

In particular, as long as banks' losses during liquidity shocks are sufficiently large (so that the right side of the inequality holds), then banks are net sellers of risky assets. Then, the equilibrium features too little foreign investment and depressed fire-sale prices compared to the constrained optimum.

\section{A.6. Omitted proofs}

Proof of Lemma 1. Using the definition of $\mu_{s}\left(p_{s}\right)$ in Eq. (12), we have,

$$
\begin{aligned}
\mu_{s}^{\prime}\left(p_{s}\right) & =\pi_{s}\left(1-\pi_{s}+\frac{R}{p_{s}} \pi_{s}\right)-\pi_{s} \frac{R}{p_{s}^{2}}\left(\left(1-\pi_{s}\right) R+\pi_{s} p_{s}\right) \\
& =\pi_{s}\left(1-\pi_{s}\right)\left(1-\frac{R^{2}}{p_{s}^{2}}\right) .
\end{aligned}
$$

Hence, $\mu_{s}\left(p_{s}\right)$ is strictly decreasing over the range $p_{s} \in(0, R)$. Using Eq. (12), we also obtain $\mu_{s}(R)=R$. It follows that $\mu_{s}\left(p_{s}\right)>R$ for $p_{s} \in(0, R)$. This in turn implies $x^{j, j}=0$.

Proof of Lemma 2. Taking the derivative of Eq. (15), we obtain,

$$
\frac{d}{d x}\left(\frac{\eta+x\left(1-\pi_{s}\right) R}{e+x\left(1-\pi_{s}\right)}\right)=\frac{\left(1-\pi_{s}\right)}{e+x\left(1-\pi_{s}\right)}\left(R-P_{s}^{m c}(x)\right)>0 .
$$

Here, the inequality follows since $\eta<e R$ implies $P_{s}^{m c}(x)=\frac{\eta+x\left(1-\pi_{s}\right) R}{e+x\left(1-\pi_{s}\right)}<R$, which completes the proof.

Proof of Proposition 1. Most of the equilibrium characterization is provided in the main text. It remains to check that a unique solution to Eqs. (13) and (15) exists. To this end, define the function,

$$
F(X)=u^{\prime}(1-X)-\sum_{s} \gamma_{s} \mu_{s}\left(p_{s}\right), \text { where } p_{s}=\frac{\eta+X\left(1-\pi_{s}\right) R}{e+X\left(1-\pi_{s}\right)} \text { for each } s .
$$

\footnotetext{
${ }^{6}$ Note that conditions $(A 40)$ and $(A 41)$ are similar but not identical. In particular, there might be parameters in which the latter is violated, so that banks are net buyers, but the former is satisfied so that the constrained optimum features greater $(x, p)$ than the equilibrium. Intuitively, when local banks are net buyers, increasing the price reduces the wealth of secondary buyers and local banks while raising the wealth of fickle foreign banks. Since secondary buyers have lower marginal utility than foreign banks, but local banks have higher marginal utility than foreign banks, the effect of this wealth transfer is ambiguous.
} 
By Lemma $2, F(X)$ is strictly increasing over the range $X \in(0,1)$. Note also that,

$$
\begin{aligned}
F(0) & =u^{\prime}(1)-\sum_{s} \gamma_{s} \mu_{s}\left(\frac{\eta}{e}\right) \\
& <R-\sum_{s} \gamma_{s} \mu_{s}\left(\frac{\eta}{e}\right)<0
\end{aligned}
$$

Here, the first inequality follows from our assumption that $u^{\prime}(1)<R$. The second inequality arises from combining $\eta<e R$ (by Assumption 1) with Lemma 1, to obtain $\mu_{s}\left(\frac{\eta}{e}\right)>R$. Finally, note that $F(1)=\infty$ since we assume $u^{\prime}(0)=\infty$. By continuity, there exists a unique solution to the equation, $F(x)=0$, over the range, $(0,1)$. This proves the existence and the characterization of equilibrium.

The bounds for the equilibrium price can then be derived by combining Assumption 1 with the market clearing relation, Eq. (15). Using $\eta<e R$, we obtain $P_{s}^{m c}(x)=\frac{\eta+x\left(1-\pi_{s}\right) R}{e+x\left(1-\pi_{s}\right)}<R$. Therefore, the equilibrium also satisfies $p_{s}<R$ for each $s$. Likewise, using $\eta>e R / \lambda$ we obtain $P_{s}^{m c}(x)>P_{s}^{m c}(0)=\eta / e>R / \lambda$. This implies $p_{s}>R / \lambda$ for each $s$.

We next characterize the autarky equilibrium in which all banks are required to make zero foreign investment $x^{j^{\prime}, j}=0$ for each $j^{\prime} \neq j$. In this case, banks solve problem (10) with the additional constraint, $x^{o u t, j}=0$. It follows that there is some local investment in period 0 , and the level of local investment is given by $x^{j, j}=\underline{x}>0$, where $\underline{x}$ denotes the solution to $u^{\prime}(1-\underline{x})=R$. In period 1 , when a country experiences a liquidity shock, linear utility between periods 1 and 2 (combined with $p_{s}<R$ ) implies that local banks use all their available liquidity to purchase risky assets. Therefore, we can use Eq. (6) with $c_{1, s}^{j}\left(\omega^{j}=b\right)=0$ and $z_{s}^{j}=0, y^{j}=\eta$ (from symmetry across countries) to obtain $\chi^{j}=x^{j, j}+\eta / p_{s}$. Substituting this into Eq. (7), we obtain $p_{s}=p^{\text {aut }} \equiv \eta / e$ for each $s$. This is equal to $P_{s}^{m c}(0)$ [cf. Eq. (15)]: that is, the equilibrium price is the same as in the baseline model after setting foreign investment equal to zero. Using Lemma 2 and $x>0$, this implies $p_{s}>p^{\text {aut }}$ for each $s$ with $\pi_{s}<1$. We also have $p_{s}=p^{\text {aut }}$ for a state with $\pi_{s}=1$. This completes the proof.

Proof of Proposition 2. Provided in the main text.

Proof of Proposition 3. The analysis in the main text characterizes the allocation that obtains when the planner chooses $x, x^{j, j}$. In particular, Eq. (15) applies, conditional on the planner's choice of $x$. Under Assumption 1, the resulting price satisfies $p \in(R / \lambda, R)$.

Next consider the social welfare that results from this allocation. Note that distressed sellers sell all of their endowments to invest in new projects with return $\lambda$. Thus, their expected equilibrium consumption is given by

$$
E\left[\tilde{c}_{2}^{j}\right]=\lambda e \bar{R}
$$

where $\bar{R}=(1-\pi) R+\pi p$. For banks, following similar steps as in Section 4, we have,

$$
\begin{aligned}
c_{0}^{j} & =1-x-x^{j, j}, \\
c_{1}^{j}\left(\omega^{j}=g\right) & =\eta+x \bar{R}+x^{j, j} R \text { and } c_{2}^{j}\left(\omega^{j}=g\right)=0, \\
\text { and } c_{2}^{j}\left(\omega^{j}=b\right) & =\left(\eta+x \bar{R}+x^{j, j} p\right) \frac{R}{p} \text { and } c_{1}^{j}\left(\omega^{j}=b\right)=0,
\end{aligned}
$$

where $(x, p)$ are characterized as the unique solution to Eqs. (13) and (15).

Substituting these expressions into the utilitarian social welfare function, $u\left(c_{0}^{j}\right)+E\left[c_{1}^{j}+c_{2}^{j}\right]+\lambda E\left[\tilde{c}_{2}^{j}\right]$, 
we obtain,

$$
\begin{aligned}
W^{j} & =u\left(1-x-x^{j, j}\right)+(1-\pi)\left(\eta+x \bar{R}+x^{j, j} R\right)+\pi\left(\eta+x \bar{R}+x^{j, j} p\right) \frac{R}{p}+\lambda e \bar{R} \\
& =u\left(1-x-x^{j, j}\right)+\eta+x^{j, j} R+x \bar{R}+\pi(\eta+x \bar{R})\left(\frac{R}{p}-1\right)+\lambda e \bar{R} \\
& =u\left(1-x-x^{j, j}\right)+\eta+x^{j, j} R+x R+\pi(R-p)\left(\frac{\eta+x \bar{R}}{p}-x\right)+\lambda e \bar{R} \\
& =u\left(1-x-x^{j, j}\right)+\eta+x^{j, j} R+x R+\pi(R-p) e+\lambda e \bar{R} .
\end{aligned}
$$

Here, the second line groups terms together, the third line substitutes $\bar{R}=R-(R-p) \pi$, and the last line substitutes $p=\frac{\eta+x \bar{R}}{e+x}$ [cf. Eq. (14)].

Substituting $(R-p) \pi=R-\bar{R}$ into the previously displayed equation, we finally obtain Eq. (20) in the main text, which we report here for convenience:

$$
W^{j}=u\left(1-x-x^{j, j}\right)+\left(x^{j, j}+x+e\right) R+\eta+(\lambda-1) e \bar{R},
$$

where $\bar{R}=(1-\pi) R+\pi p$. The social planner chooses $x, x^{j, j}$ to maximize this expression subject to the market clearing condition (15). The constrained optimum features $x^{j, j}=0$ because $\frac{d W^{j}}{d x^{j, j}}=R<\frac{d W^{j}}{d x}=$ $R+(\lambda-1) e \pi \frac{d p}{d x}$.

The optimality condition for foreign investment results in Eq. (21) in the main text, which we report here,

$$
\begin{aligned}
u^{\prime}(1-x) & =R+(\lambda-1) e \pi \frac{d p}{d x} \\
\text { where } \frac{d p}{d x} & =\frac{(1-\pi)}{e+x(1-\pi)}(R-p) .
\end{aligned}
$$

Note that this describes a strictly decreasing relation between $p$ and $x$. Eq. (15) describes a strictly increasing relation. Under Assumption 1, there exists a unique intersection that satisfies $x \in(0,1)$ and $p \in(R / \lambda, R)$.

We next analyze how the constrained optimum compares with the equilibrium. Note that the constrained optimum features greater $x$ (and $p$ ) than the equilibrium if and only if the right-hand side of Eq. (21) exceeds the right-hand side of Eq. (13),

$$
R+(\lambda-1) e \pi \frac{d p}{d x}>M \bar{R}
$$

when both expressions are evaluated at the equilibrium allocation $\left(x^{e q}, p^{e q}\right)$. After substituting $M, \bar{R}$ and $\frac{d p}{d x}$ from Eq. (21), and dividing both sides by $R$, this inequality becomes,

$$
1+(\lambda-1) e \frac{\pi(1-\pi)}{e+x^{e q}(1-\pi)} \frac{R-p^{e q}}{R}>\left(1-\pi+\pi \frac{R}{p^{e q}}\right)\left(1-\pi+\pi \frac{p^{e q}}{R}\right) .
$$

After expanding the terms on the right hand side and canceling terms from both sides, this inequality becomes,

$$
\frac{\lambda e+x^{e q}(1-\pi)}{e+x^{e q}(1-\pi)}>\frac{R}{p^{e q}} .
$$

This is equivalent to condition (22), which completes the proof.

Proof of Proposition 4. Provided in Online Appendix A.3. 
Proof of Proposition 5. The analysis in the main text shows that $d x / d \eta<0$ and $d p_{2} / d \eta>0$, that is, reducing $\eta$ increases $x$ and reduces $p_{2}$ (see Figure 3). Using (29), $p_{3}$ also declines. Combining these results with Eq. (30), $E\left[\bar{R}_{s}\right]$ also declines.

To show the effect on $R_{f}$, note that Eq. (31) can be rewritten as,

$$
\begin{aligned}
R_{f} & =\frac{E\left[\bar{R}_{s} M_{s}\right] / M_{2}}{E\left[M_{s}\right] / M_{2}} \\
\text { where } \frac{E\left[\bar{R}_{s} M_{s}\right]}{M_{2}} & =\beta \frac{1}{(1-\pi) / R+\pi / p_{2}}+(1-\beta)\left((1-\pi) R+\pi p_{2}\right) \\
\text { and } \frac{E\left[M_{s}\right]}{M_{2}} & =\beta \frac{1-\pi+\pi R / p_{3}}{1-\pi+\pi R / p_{2}}+1-\beta .
\end{aligned}
$$

Note that the term in the numerator, $E\left[\bar{R}_{s} M_{s}\right] / M_{2}$, is an average of the arithmetic and the harmonic averages of $R$ and $p_{2}$. Since $d p_{2} / d \eta>0$, we also have $\frac{d\left(E\left[\bar{R}_{s} M_{s}\right] / M_{2}\right)}{d \eta}>0$. For the term in the denominator, note that,

$$
\frac{d E\left[M_{s}\right] / M_{2}}{d \eta}=\frac{\beta \pi\left(1-\pi+\pi R / p_{3}\right)}{1-\pi+\pi R / p_{2}}\left(-\frac{d p_{3} / d \eta}{p_{3}} \frac{1}{(1-\pi) p_{3}+\pi R}+\frac{d p_{2} / d \eta}{p_{2}} \frac{1}{(1-\pi) p_{2}+\pi R}\right) .
$$

This is strictly negative since $\frac{d p_{3} / d \eta}{p_{3}}>\frac{d p_{2} / d \eta}{p_{2}}$ and $\frac{1}{(1-\pi) p_{3}+\pi R}>\frac{1}{(1-\pi) p_{2}+\pi R}$. Combining the effects on the numerator and the denominator, we obtain $\frac{d R_{f}}{d \eta}>0$. In particular, decreasing $\eta$ decreases $R_{f}$.

Finally, to show that reducing $\eta$ increases the risk premium in a neighborhood of $\eta=e R$, we let $x(\eta),\left[p_{s}(\eta)\right]_{s}$ denote the equilibrium as a function of $\eta$. The analysis in the proof of Proposition 1 implies that $x(\cdot)$ and $\left[p_{s}(\cdot)\right]_{s}$ are continuous functions for $\eta<e R$. Taking the limit of Eq. (15) we obtain, $\lim _{\eta \rightarrow e R} p_{s}=R$. Using Eqs. (4) and (11), we further obtain $\lim _{\eta \rightarrow e R} \bar{R}_{s}=R$ and $\lim _{\eta \rightarrow e R} M_{s}=1$ for each $s$. Using Eq. (18), we obtain $\lim _{\eta \rightarrow e R} R_{f}=R$. Thus, the risk premium in the limit is zero, $\lim _{\eta \rightarrow e R} E\left[\bar{R}_{s}\right]-R_{f}=0$. However, by Eq. (19), $E\left[\bar{R}_{s}\right]-R_{f}>0$ for each $\eta<e R$. It follows that reducing $\eta$ increases the risk premium in a lower neighborhood of $\eta=e R$, completing the proof.

Proof of Proposition 6. The analysis in the main text shows that $d x / d \beta<0$ and $d p_{2} / d \beta<0$, that is, increasing $\beta$ reduces $x$ and $p_{2}$ (see Figure 3). Combining these results with Eq. (30), $E\left[\bar{R}_{s}\right]$ also declines.

Next consider the effect on $R_{f}$. Combining Eqs. (31) and (27), we obtain,

$$
\begin{aligned}
R_{f} & =\frac{u^{\prime}(1-x)}{E\left[M_{s}\right]} \\
\text { where } E\left[M_{s}\right] & =\beta\left(1-\pi+\pi R / p_{3}\right)+(1-\beta)\left(1-\pi+\pi R / p_{2}\right) .
\end{aligned}
$$

First consider the effect on the numerator. Since $d x / d \beta<0$, we have $d\left(u^{\prime}(1-x)\right) / d \beta<0$. Next consider the effect on the denominator, which can be evaluated as,

$$
\frac{d E\left[M_{s}\right]}{d \beta}=\pi\left(\frac{R}{p_{3}}-\frac{R}{p_{2}}\right)-(1-\beta) \pi \frac{R}{\left(p_{2}\right)^{2}} \frac{d p_{2}}{d \beta}>0 .
$$

Here, the inequality follows since $p_{3}<p_{2}$ and $d p_{2} / d \beta<0$. Combining the two effects shows $d R_{f} / d \beta<0$, that is, increasing $\beta$ reduces $R_{f}$.

Finally, consider the effect on the risk premium, $E\left[\bar{R}_{s}\right]-R_{f}$. Following similar steps as in the proof of Proposition 5, we have $\lim _{\beta \rightarrow 0} E\left[\bar{R}_{s}\right]-R_{f}=0$, and $E\left[\bar{R}_{s}\right]-R_{f}>0$ for any $\beta>0$. This shows that 
increasing $\beta$ also increases the risk premium, $E\left[\bar{R}_{s}\right]-R_{f}$, in a neighborhood of $\beta=0$, completing the proof.

The following lemma is used in the proofs of Propositions 7, 9, and 10 analyzed in Section 7 and Online Appendix A.4. The lemma considers the system of equations (40) and (41) in the main text, which we reproduce below,

$$
\begin{aligned}
\sum_{s \in S} q_{s}\left(\left(1-\pi_{s}\right) R^{*}+\pi_{s} p_{s}^{*}\right) & =\sum_{s \in S} q_{s}\left(\left(1-\pi_{s}\right) R+\pi_{s} p_{s}\right) \\
\frac{1-\pi_{s}+\pi_{s} \frac{R^{*}}{p_{s}^{*}}}{1-\pi_{s}+\pi_{s} \frac{R}{p_{s}}} & =\frac{u^{\prime}\left(c_{0}^{*}\right)}{u^{\prime}\left(c_{0}\right)} \text { for each } s \in \bar{S}=\left\{s \in S \quad \mid \pi_{s}>0\right\}
\end{aligned}
$$

Here, $\left(c_{0},\left(p_{s}\right)_{s \in S}\right)$ correspond to the equilibrium variables in regular countries characterized in Proposition 1. The set $\bar{S} \subset S$ includes the aggregate states in which liquidity shocks happen with strictly positive probability. In Section 7, we assume $\pi_{1}>0$ which implies $\bar{S}=S$. In Online Appendix A.4, we assume $\pi_{1}=0$ which implies that $\bar{S}$ corresponds to all states except for state 1 , that is, $\bar{S}=S \backslash\{1\}$.

Lemma 4. Under Assumption 2, there exists a unique solution to the system of equations $(A 43-A 44)$, denoted by $\left(c_{0}^{*},\left(p_{s}^{*}\right)_{s \in \bar{S}}\right)$. When $R^{*}=R$, the solution satisfies $c_{0}^{*}=c_{0}$ and $p_{s}^{*}=p_{s}$ for each $s \in \bar{S}$. When $R^{*}>R$, the solution satisfies $\frac{u^{\prime}\left(c_{0}^{*}\right)}{u^{\prime}\left(c_{0}\right)}>\frac{R^{*}}{R}>1$, and $p_{s}^{*} / p_{s}<1$ for each $s \in \bar{S}$. It also satisfies $p_{s}^{*} / p_{s}<p_{s^{\prime}}^{*} / p_{s^{\prime}}$ for each $s, s^{\prime} \in \bar{S}$ with $s<s^{\prime}$ (that satisfies $\pi_{s}<\pi_{s^{\prime}}$ ).

Proof. We first show that a unique solution exists. Throughout, $\left(c_{0},\left(p_{s}\right)_{s}\right)$ are fixed (and characterized by Proposition 1). Note that, for any fixed $C_{0}^{*} \in\left(0, c_{0}\right]$ and state $s$, Eq. $(A 44)$ has a unique solution for $p_{s}^{*}$. We denote the solution with the function $P_{s}^{*}\left(C_{0}^{*}\right)$ defined over the range $C_{0}^{*} \in\left(0, c_{0}\right]$. Note also that $P_{s}^{*}\left(C_{0}^{*}\right)$ is strictly increasing in $C_{0}^{*}$ and it satisfies $\lim _{C_{0}^{*} \rightarrow 0} P_{s}^{*}\left(C_{0}^{*}\right)=0$ and $P_{s}^{*}\left(c_{0}\right)=\frac{R^{*}}{R} p_{s} \geq p_{s}$.

We next substitute $P_{s}^{*}\left(C_{0}^{*}\right)$ into Eq. $(A 43)$ and put all terms on the same side to obtain the function,

$$
F\left(C_{0}^{*}\right)=\sum_{s} q_{s}\left(\left(1-\pi_{s}\right) R^{*}+\pi_{s} P_{s}^{*}\left(C_{0}^{*}\right)\right)-\sum_{s} q_{s}\left(\left(1-\pi_{s}\right) R+\pi_{s} p_{s}\right) .
$$

The equilibrium level of consumption in the special country is determined as the zero of this function over the range $\left(0, c_{0}\right]$, that is, $F\left(c_{0}^{*}\right)=0$.

Next note that $F\left(C_{0}^{*}\right)$ is strictly increasing over $C_{0}^{*} \in\left(0, c_{0}\right]$. Moreover, at the upper bound of this range, it is weakly positive, $F\left(c_{0}\right) \geq 0$, since $R^{*} \geq R$ and $P_{s}^{*}\left(c_{0}\right) \geq p_{s}$. Conversely, at the lower bound of the range, it is weakly negative. To see this, note that,

$$
\begin{aligned}
\lim _{C_{0}^{*} \rightarrow 0} F\left(C_{0}^{*}\right) & =\sum_{s} q_{s}\left(1-\pi_{s}\right) R^{*}-\sum_{s} q_{s}\left(\left(1-\pi_{s}\right) R+\pi_{s} p_{s}\right) \\
& \leq \sum_{s} q_{s}\left(1-\pi_{s}\right)\left(R^{*}-R\right)-\sum_{s} q_{s} \pi_{s} \eta / e \\
& <0 .
\end{aligned}
$$

Here, the first line uses $\lim _{C_{0}^{*} \rightarrow 0} P_{s}^{*}\left(C_{0}^{*}\right)=0$, the second line follows from $p_{s} \geq \eta / e$ [cf. Eq. (15)], and the last line follows from Assumption 2. It follows that there exists a unique level of consumption, $c_{0}^{*} \in\left(0, c_{0}\right]$, that satisfies $F\left(c_{0}^{*}\right)=0$. This in turn implies that the induced level of asset prices, $\left(P_{s}^{*}\left(c_{0}^{*}\right)\right)_{s \in \bar{S}}$, solves the system $(A 43-A 44)$.

Next suppose $R^{*}=R$. In this case, it is easy to check (by guess and verify) that the solution features $c_{0}^{*}=c_{0}$ and $p_{s}^{*}=p_{s}$ for each $s \in \bar{S}$. 
Next suppose $R^{*}>R$. In this case, we first show that $\frac{u^{\prime}\left(c_{0}^{*}\right)}{u^{\prime}\left(c_{0}\right)}>\frac{R^{*}}{R}$. To prove this inequality, let $\bar{c}_{0}$ denote the level of consumption that satisfies $\frac{u^{\prime}\left(\bar{c}_{0}\right)}{u^{\prime}\left(c_{0}\right)}=\frac{R^{*}}{R}$. From our earlier analysis, it suffices to show that $F\left(\bar{c}_{0}\right)>0$. To this end, we substitute $\frac{u^{\prime}\left(\bar{c}_{0}\right)}{u^{\prime}\left(c_{0}\right)}=\frac{R^{*}}{R}$ into Eq. $(A 44)$ and observe that $P_{s}^{*}\left(\bar{c}_{0}\right)$ satisfies,

$$
\left(1-\pi_{s}\right)\left(\frac{1}{R^{*}}-\frac{1}{R}\right)+\pi_{s}\left(\frac{1}{P_{s}^{*}\left(\bar{c}_{0}\right)}-\frac{1}{p_{s}}\right)=0 .
$$

Since $R^{*}>R$, this equation implies $P_{s}^{*}\left(\bar{c}_{0}\right) \leq p_{s}$, with strict inequality if $\pi_{s}<1$. Note also that we have $p_{s}<R<R^{*}$ (see Proposition 1). Using these expressions, we obtain,

$$
\begin{aligned}
\left(1-\pi_{s}\right)\left(R^{*}-R\right)+\pi_{s}\left(P_{s}^{*}\left(\bar{c}_{0}\right)-p_{s}\right) & =\left(1-\pi_{s}\right) \frac{\left(R^{*}-R\right)}{R^{*} R}+\pi_{s} \frac{\left(P_{s}^{*}\left(\bar{c}_{0}\right)-p_{s}\right)}{R^{*} R} \\
& \geq\left(1-\pi_{s}\right) \frac{\left(R^{*}-R\right)}{R^{*} R}+\pi_{s} \frac{\left(P_{s}^{*}\left(\bar{c}_{0}\right)-p_{s}\right)}{P_{s}^{*}\left(\bar{c}_{0}\right) p_{s}} \\
& =0,
\end{aligned}
$$

with strict inequality if $\pi_{s}<1$. Here, the inequality follows because $P_{s}^{*}\left(\bar{c}_{0}\right)-p_{s} \leq 0$ and $P_{s}^{*}\left(\bar{c}_{0}\right) p_{s}<R^{*} R$, and the last line follows from Eq. (A45). After multiplying the previously displayed inequality with $q_{s}$ and summing over $s$ (and observing that $\pi_{s}<1$ for at least one state), we obtain $F\left(\bar{c}_{0}\right)>0$. This proves that $c_{0}^{*}<\bar{c}_{0}$ and thus $\frac{u^{\prime}\left(c_{0}^{*}\right)}{u^{\prime}\left(c_{0}\right)}>\frac{R^{*}}{R}$.

This analysis also implies that $p_{s}^{*} / p_{s}<1$ for each $s \in \bar{S}$, because

$$
p_{s}^{*}=P_{s}^{*}\left(c_{0}^{*}\right)<P_{s}^{*}\left(\bar{c}_{0}\right) \leq p_{s} .
$$

Here, the first inequality follows since the function $P_{s}^{*}(\cdot)$ is strictly increasing and the second inequality follows from Eq. (A45).

We next show that $p_{s}^{*} / p_{s}$ is strictly increasing in $s$. To reach a contradiction, suppose there exist $s, s^{\prime} \in \bar{S}$ with $s<s^{\prime}$ (and thus, $0<\pi_{s}<\pi_{s^{\prime}}$ ) such that,

$$
p_{s}^{*} / p_{s} \geq p_{s^{\prime}}^{*} / p_{s^{\prime}}
$$

Note that this implies $p_{s^{\prime}}^{*} \leq p_{s}^{*} \frac{p_{s^{\prime}}}{p_{s}}<p_{s}^{*}$ (since $p_{s^{\prime}}<p_{s}$ for regular countries). Using the inequalities $p_{s^{\prime}}^{*}<p_{s}^{*}$ and $p_{s^{\prime}}<p_{s}$, together with $R^{*}>R, p_{s}^{*}<p_{s}, p_{s^{\prime}}^{*}<p_{s^{\prime}}$, we further obtain,

$$
\frac{R^{*}}{p_{s^{\prime}}^{*}}>\frac{R^{*}}{p_{s}^{*}} \ldots \frac{R}{p_{s^{\prime}}}>\frac{R}{p_{s}} .
$$

Here, the notation with three dots means that we cannot compare the terms, $\frac{R^{*}}{p_{s}^{*}}$ and $\frac{R}{p_{s^{\prime}}}$, but all the other inequalities hold. Next note that (A46) implies the inequality,

$$
\frac{R^{*}}{p_{s^{\prime}}^{*}} \frac{R}{p_{s}} \geq \frac{R^{*}}{p_{s}^{*}} \frac{R}{p_{s^{\prime}}}
$$


Combining this with the ordering in $(A 47)$, we also obtain the inequality, ${ }^{7}$

$$
\frac{R^{*}}{p_{s^{\prime}}^{*}}+\frac{R}{p_{s}} \geq \frac{R^{*}}{p_{s}^{*}}+\frac{R}{p_{s^{\prime}}}
$$

Using these inequalities, we next obtain,

$$
\begin{aligned}
\frac{u^{\prime}\left(c_{0}^{*}\right)}{u^{\prime}\left(c_{0}\right)} & =\frac{1-\pi_{s}+\pi_{s} \frac{R^{*}}{p_{s}^{*}}}{1-\pi_{s}+\pi_{s} \frac{R}{p_{s}}} \\
& <\frac{1-\pi_{s^{\prime}}+\pi_{s^{\prime}} \frac{R^{*}}{p_{s}^{*}}}{1-\pi_{s^{\prime}}+\pi_{s^{\prime}} \frac{R}{p_{s}}} \\
& \leq \frac{1-\pi_{s^{\prime}}+\pi_{s^{\prime}} \frac{R^{*}}{p_{s^{\prime}}}}{1-\pi_{s^{\prime}}+\pi_{s^{\prime}} \frac{R}{p_{s^{\prime}}}}=\frac{u^{\prime}\left(c_{0}^{*}\right)}{u^{\prime}\left(c_{0}\right)},
\end{aligned}
$$

which yields a contradiction. Here, the first and last equalities follow from Eq. (A44). The inequality in the second line follows since $\frac{R^{*}}{p_{s}^{*}}>\frac{R}{p_{s}}$ and $\pi_{s^{\prime}}>\pi_{s}$. The inequality in the third line follows from the inequalities in $(A 48)$ and $(A 49)$.

This proves by contradiction that the opposite of $(A 46)$ must hold, that is, $p_{s}^{*} / p_{s}<p_{s^{\prime}}^{*} / p_{s^{\prime}}$ for each $s, s^{\prime} \in \bar{S}$ with $s<s^{\prime}$. This completes the proof of the lemma.

Proof of Proposition 7. First consider banks' decisions in period 0. Following similar steps as in Section 4, they solve the following problem,

$$
\begin{aligned}
& \max _{x^{*, *}, x^{\text {out }, *}, y^{*},\left(z_{s}^{*}\right)_{s}} u\left(c_{0}^{*}\right)+x^{*, *} R^{*}+\sum_{s} \gamma_{s}\left(x^{\text {out }, *} \bar{R}_{s}+y^{*}+z_{s}^{*}\right) M_{s}^{*}, \\
& \text { where } c_{0}^{*}+x^{*, *}+x^{\text {out }, *}+q_{f} y^{*}+\sum_{s} q_{s} z_{s}^{*}=1+q_{f} \eta^{*} \\
& \text { and } M_{s}^{*} \equiv 1-\pi_{s}+\pi_{s} \frac{R^{*}}{p_{s}^{*}}
\end{aligned}
$$

Substituting $l_{s}^{*}=x^{\text {out }, *} \bar{R}_{s}+y^{*}+z_{s}^{*}-\eta^{*}$ and using the pricing relations $\sum_{s} q_{s} \bar{R}_{s}=1$ and $\sum_{s} q_{s}=q_{f}$, the problem reduces to solving the following problem (which we also state in the main text),

$$
\begin{aligned}
& \max _{x^{*, *} \geq 0,\left(l_{s}^{*} \geq-\eta^{*}\right)_{s}} u\left(c_{0}^{*}\right)+x^{*, *} R^{*}+\sum_{s} \gamma_{s} l_{s}^{*} M_{s}^{*}, \\
& \text { where } c_{0}^{*}+x^{*, *}+\sum_{s} q_{s} l_{s}^{*}=1 .
\end{aligned}
$$

Here, the constraint $l_{s}^{*} \geq-\eta^{*}$ follows since banks are required to have nonnegative consumption.

We next show that $x^{*, *}=0$, that is, banks in the special country also strictly prefer foreign risky assets (in period 0) to local risky assets. By Eq. (32), we have $E\left[\bar{R}_{s}^{*} \frac{q_{s}}{\gamma_{s}}\right]=1$. This implies that one of the following two conditions must hold: (i) there exists an aggregate state $\tilde{s}$ such that $\bar{R}_{\tilde{s}}^{*} \frac{q_{\tilde{s}}}{\gamma_{\tilde{s}}}<1$, or (ii) $\bar{R}_{s}^{*} \frac{q_{s}}{\gamma_{s}}=1$ for each $s$.

\footnotetext{
${ }^{7}$ To prove this, consider four numbers ordered according to, $a>b \ldots c>d$, and that satisfy $a d \geq b c$. Without loss of generality, suppose also $b>c$ (the other case is symmetric). We claim that $a+d \geq b+c$. To reach a contradiction, suppose $a+d<b+c$. This implies $d<c-(a-b)$. Multiplying this with $a-(a-b)=b$, we obtain $a d-(a-b) d<b c-(a-b) b$. Since $a d \geq b c$ and $-d>-b$ (and $a-b>0$ ), this yields a contradiction and proves that $a+d \geq b+c$.
} 
First suppose (i) holds so that there exists an aggregate state $\tilde{s}$ such that $\bar{R}_{\tilde{s}}^{*} q_{\tilde{s}}<1$. From problem $(A 50)$, the marginal value from investing in the Arrow-Debreu security for state $\tilde{s}$ is given by $\frac{\gamma_{\tilde{s}}}{q_{\tilde{s}}} M_{\tilde{s}}^{*}$. Combining this with the inequality $\bar{R}_{\tilde{s}}^{*} \frac{q_{\tilde{s}}}{\gamma_{\tilde{s}}}<1$, we obtain,

$$
\frac{\gamma_{\tilde{s}}}{q_{\tilde{s}}} M_{\tilde{s}}^{*}>M_{\tilde{s}}^{*} \bar{R}_{\tilde{s}}^{*} \geq R^{*}
$$

Here, the second inequality follows since Lemma 1 shows $M_{\tilde{s}}^{*} \bar{R}_{\tilde{s}}^{*}>R^{*}$ if $\pi_{\tilde{s}} \in(0,1)$, and we can check that $M_{\tilde{s}}^{*} \bar{R}_{\tilde{s}}^{*}=R^{*}$ if $\pi_{\tilde{s}}=0$ or $\pi_{\tilde{s}}=1$. Thus, in this case, investing in the aggregate state $\tilde{s}$ strictly dominates investing in the local risky asset.

Now suppose (ii) holds so that $\bar{R}_{s}^{*} \frac{q_{s}}{\gamma_{s}}=1$ for each $s$. Let $\bar{s}$ be a state with $\pi_{\bar{s}} \in(0,1)$. Then, the marginal value from investing in the Arrow-Debreu security for state $\bar{s}$ is given by

$$
\frac{\gamma_{\bar{s}}}{q_{\bar{s}}} M_{\bar{s}}^{*}=M_{\bar{s}}^{*} \bar{R}_{\bar{s}}^{*}>R^{*},
$$

where the second inequality follows from Lemma 1 . Thus, in this case, investing in the aggregate state $\bar{s}$ strictly dominates investing in the local risky asset.

Combining the two cases, we conclude that $x^{*, *}=0$. Next consider the optimal liquidity holdings, $l_{s}^{*}$. Assuming there is an interior solution, the optimality conditions for problem (A50) result in Eqs. (34) listed in the main text.

Next consider banks' and distressed sellers' decisions in period 1. Banks spend all of their available liquidity in period 1 to purchase risky assets, which implies $\chi_{s}^{*}=\left(l_{s}^{*}+\eta^{*}\right) / p_{s}^{*}$. Distressed sellers' optimal demand, $\tilde{\chi}_{s}^{*}$, is determined by Eq. (36). Substituting these expressions (as well as $x^{*, *}=0$ ) into Eq. (7), we obtain the market clearing condition (35).

It remains to show that (under Assumption 2) there exists a unique solution, $x^{i n, *}, c_{0},\left(l_{s}^{*}\right)_{s},\left(p_{s}^{*}\right)_{s},\left(\tilde{\chi}_{s}^{*}\right)_{s}$, to the equations listed. Note that Eqs. (32) and (34) correspond to the system of equations analyzed in Lemma 4. Using the lemma, there exists a unique solution to these equations that satisfies $c_{0}^{*} \leq c_{0}$ and $p_{s}^{*} \leq p_{s}$ for each $s \in S$ (note that $S=\bar{S}$ since $\pi_{1}>0$ ). Given prices, Eq. (36) uniquely determines distressed sellers' demand levels, $\tilde{\chi}_{s}^{*}$.

To characterize the remaining allocations, we multiply the market clearing conditions (35) by $q_{s}$ and aggregate over all states to obtain,

$$
\sum_{s} q_{s} p_{s}^{*}\left(e-\tilde{\chi}_{s}^{*}+x^{i n, *}\right)=\sum_{s} q_{s}\left(\eta^{*}+l_{s}^{*}\right)=1+q_{f} \eta^{*}-c_{0}^{*}
$$

Here, the second equality follows from the budget constraint (33). Hence, the inflows solve the equation, $G\left(x^{i n, *}\right)=0$, where we define the function

$$
G\left(X^{i n}\right)=\sum_{s} q_{s} p_{s}^{*}\left(e-\tilde{\chi}_{s}^{*}+X^{i n}\right)+c_{0}^{*}-\left(1+q_{f} \eta^{*}\right)
$$

Note that $G\left(X^{i n}\right)$ is increasing in $X^{i n}$ with $\lim _{\tilde{x}^{i n} \rightarrow \infty} G\left(X^{i n}\right)=\infty$. Note also that

$$
\begin{aligned}
G(0) & \leq \sum q_{s} p_{s} e+c_{0}-\left(1+q_{f} \eta^{*}\right) \\
& =1+q_{f} \eta-\sum_{s} q_{s} p_{s} x-\left(1+q_{f} \eta^{*}\right) \\
& =q_{f}\left(\eta-\eta^{*}\right)-\sum_{s} q_{s} p_{s} x<0 .
\end{aligned}
$$


Here, the first line follows since $p_{s}^{*} \leq p_{s}, c_{0}^{*} \leq c_{0}, \tilde{\chi}_{s}^{*} \geq 0$; the second line follows since the analogue of Eq. (A51) also holds for regular countries; and the last line follows from Assumption 2. It follows there exists a unique solution, $x^{i n, *}>0$, to the equation $G\left(x^{i n, *}\right)=0$, which determines the equilibrium level of inflows.

Finally, using Eq. (35), we obtain the equilibrium liquidity holdings,

$$
l_{s}^{*}=p_{s}^{*}\left(e-\tilde{\chi}_{s}^{*}+x^{i n, *}\right)-\eta^{*} \text { for each } s .
$$

These liquidity holdings satisfy the budget constraint (33) since $x^{i n, *}$ satisfies Eq. (A51). This characterizes the equilibrium and completes the proof of Proposition 7.

Proof of Proposition 10. Most of this proof parallels the proof of Proposition 7. Specifically, the same steps as in that proof imply that $x^{*, *}=0$ in this case as well. It remains to show that (under Assumption 2) there exists a unique solution, $x^{i n, *}, c_{0},\left(l_{s}^{*}\right)_{s},\left(p_{s}^{*}\right)_{s},\left(\tilde{\chi}_{s}^{*}\right)_{s}$, to the equations listed.

First consider the consumption level, $c_{0}^{*}$, as well as the fire-sale prices, $p_{s}$, for states $s>1$ (that feature $\left.\pi_{s}>0\right)$. Note that Eqs. (32) and (A24) correspond to the system of equations analyzed in Lemma 4. Using the lemma, there exists a unique solution to these equations that satisfies $c_{0}^{*} \leq c_{0}$ and $p_{s}^{*} \leq p_{s}$ for each $s$ with $\pi_{s}>0$.

Next consider the state $s=1$ (that features $\pi_{1}=0$ ). For this state, the price is characterized by Lemma 4 and Eq. (A25). When $R^{*}=R$, we have an interior solution with $c_{0}^{*}=c_{0}$ and $p_{1}=p_{1}^{*}$. When $R^{*}>R$, we have a corner solution with $c_{0}^{*}<c_{0}, l_{1}^{*}=-\eta^{*}$. This also implies $p_{1}=0$ in view of Eq. (35).

It follows that the equilibrium consumption level and prices, $\left(c_{0}^{*},\left(p_{s}^{*}\right)_{s \in S}\right)$, are uniquely characterized and they satisfy $c_{0}^{*} \leq c_{0}$ and $p_{s}^{*} \leq p_{s}$ for each $s$. The rest of the proof follows the steps in the proof of Proposition 7. In particular, distressed sellers' levels of demand $\tilde{\chi}_{s}^{*}$, are determined by Eq. (36) given prices. The inflows are characterized as the unique solution to $G\left(x^{i n, *}\right)=0$ (where $G(\cdot)$ denotes the function defined in $(A 52)$ ). There exists a unique and strictly positive solution to this equation because $p_{s}^{*} \leq p_{s}, c_{0}^{*} \leq c_{0}, \tilde{\chi}_{s}^{*} \geq 0$ and the parameters in the special country satisfy Assumption 2. The equilibrium liquidity purchases are determined by $l_{s}^{*}=p_{s}^{*}\left(e-\tilde{\chi}_{s}^{*}+x^{i n, *}\right)-\eta^{*}$, given the remaining allocations.

Proof of Proposition 8. We can check that Eqs. (38) solve the equation system (32-36). By Proposition 7 , this solution correspond to the equilibrium in the special country. The remaining statements in the proposition follow by inspecting the closed-form solution.

Proof of Proposition 11. Eqs. (38) solve the equation system $(32-36)$ after replacing Eq. (34) with Eqs. (A24-A25). By Proposition 10, this solution corresponds to the equilibrium in the special country. The remaining statements in Proposition 8 follow from inspecting the closed-form solution. We provide the proof for the comparative static results with respect to $\beta$ in Online Appendix A.4.

Proof of Proposition 9. The results regarding prices follow directly from Lemma 4. Note that the lemma also implies $c_{0}^{*}<c_{0}$, which in turn implies $\bar{x}^{\text {out }, *}=1-c_{0}^{*}>x=1-c_{0}$. It remains to show that $x^{i n, *}>\bar{x}^{\text {out }, *}=1-c_{0}^{*}$. To this end, consider the function $G(\cdot)$ defined by Eq. (A52) in the proof of Proposition 7. Recall that the inflows are defined as the solution to $G\left(x^{i n, *}\right)=0$. We have established in the proof of 7 that this equation has a solution. We next claim that evaluating the function at outflows leads to the inequality, $G\left(\bar{x}^{\text {out,*}}\right)<0$. Since $G(\cdot)$ is an increasing function, combining this claim with the equality, $G\left(x^{i n, *}\right)=0$, implies that the inflows exceed the outflows, that is, $x^{i n, *}>\bar{x}^{\text {out }, *}$. 
It remains to prove the remaining claim, $G\left(\bar{x}^{\text {out }, *}\right)<0$. To this end, note that Eq. $(A 52)$ implies,

$$
\begin{aligned}
G\left(\bar{x}^{\text {out }, *}\right) & =\sum_{s} q_{s}\left(e-\tilde{\chi}_{s}^{*}+\bar{x}^{\text {out }, *}\right) p_{s}^{*}+c_{0}^{*}-\left(1+q_{f} \eta^{*}\right) \\
& <\sum_{s} q_{s}\left(e+\bar{x}^{\text {out }, *}\right) p_{s}+c_{0}^{*}-\left(1+q_{f} \eta\right) \\
& =c_{0}^{*}-c_{0}+\left(\bar{x}^{\text {out }, *}-x\right) \sum_{s} q_{s} p_{s} \\
& =\left(c_{0}^{*}-c_{0}\right)\left(1-\sum_{s} q_{s} p_{s}\right) .
\end{aligned}
$$

Here, the second line uses $p_{s}^{*}<p_{s}, \tilde{\chi}_{s}^{*} \geq 0, \eta^{*}=\eta$; the third line follows since the analogue of Eq. (A51) also holds for the regular countries; and the last line substitutes $\bar{x}^{\text {out }, *}=1-c_{0}^{*}$ and $x=1-c_{0}$. Next note that $\sum_{s} q_{s} \bar{R}_{s}=1$ [cf. Eq. (32)]. Since $p_{s} \leq \bar{R}_{s}$, with strict inequality for states with $\pi_{s}>0$, this implies $\sum_{s} q_{s} p_{s}<1$. Combining this with $c_{0}^{*}<c_{0}$, we obtain $G\left(\bar{x}^{\text {out }, *}\right)<0$. This completes the proof.

Proof of Proposition 12. Note that Eqs. (40) and (A27) are a special case of the system of equations analyzed in Lemma 4 when $S=\{1,2,3\}$ and $\pi_{1}=0$ (so $\bar{S}=\{2,3\}$ ). Applying the lemma, there exists a unique solution, $\left(c_{0}^{*}, p_{2}^{*}, p_{3}^{*}\right)$, that features $c_{0}^{*}<c_{0}$ and $p_{2}^{*} / p_{2}<p_{3}^{*} / p_{3}<1$. Since $c_{0}^{*}<c_{0}$, by Eq. (A25), we also have $l_{1}^{*}=-\eta^{*}$. By Eq. (35), this also implies $p_{1}^{*}=0$. The inequalities, $x^{\text {in,* }}>\bar{x}^{\text {out,*}}$ and $\bar{x}^{\text {out }, *}>x$, follow from the same argument as in the proof of Proposition 9.

It remains to establish the comparative statics with respect to $R$ and $\beta$. First consider a decrease in $R$. Let $\tilde{p}_{2}=p_{2} / R$ denote the price-to-return ratio in state 2 . Then, equations (27) and (28) (that characterize the equilibrium in regular countries) can be written in terms of $\left(\tilde{p}_{2}, x\right)$ as,

$$
\begin{aligned}
u^{\prime}(1-x) & =R\left(\beta+(1-\beta)\left(1-\pi+\pi \tilde{p}_{2}\right)\left(1-\pi+\pi \frac{1}{\tilde{p}_{2}}\right)\right), \\
\text { and } \tilde{p}_{2} & =\frac{\eta / R+x(1-\pi)}{e+x(1-\pi)} .
\end{aligned}
$$

As before, the first equation describes $\tilde{p}_{2}$ as a decreasing function of $x$, the second equation describes $\tilde{p}_{2}$ as an increasing function of $x$, and the equilibrium corresponds to their intersection. Moreover, decreasing $R$ strictly decreases the first curve for each $x$, and (under Assumption 1) strictly increases the second curve for each $x$. It follows that decreasing $R$ decreases the equilibrium level of foreign investment, $x$. Therefore, by market clearing, decreasing $R$ also decreases the price level, $p_{2}=\frac{\eta+R x(1-\pi)}{e+x(1-\pi)}$, while leaving $p_{3}=\min \left(R, \frac{\eta}{e}\right)$ unchanged.

Next note that Eq. (A28) implies,

$$
\frac{\bar{p}-\bar{p}^{*}}{R^{*}-R}=\frac{1-\pi}{\pi} \frac{M_{1} \beta+M_{2}(1-\beta)}{M_{2}(1-\beta)+M_{3} \beta} .
$$

This implies that $\frac{\bar{p}-\bar{p}^{*}}{R^{*}-R}<\frac{1-\pi}{\pi}$ since $M_{1}<M_{2}<M_{3}$. After substituting for $M_{s}=1-\pi_{s}+\pi_{s} \frac{R}{p_{s}}$, the equation can also be written as,

$$
\frac{\bar{p}-\bar{p}^{*}}{R^{*}-R} \frac{\pi}{1-\pi}=\frac{\beta \frac{1}{R}+(1-\beta) \xi(R)}{(1-\beta) \xi(R)+\beta \frac{1}{p_{3}}}, \text { where } \xi(R)=(1-\pi) \frac{1}{R}+\pi \frac{1}{p_{2}} .
$$

Increasing $\xi(R)$ increases the right-hand side (since the right-hand side is less than one). Thus, decreasing 
$R$ increases the ratio on the left-hand side, $\frac{\bar{p}-\bar{p}^{*}}{R^{*}-R}$, both directly via the $1 / R$ term in the numerator on the right-hand side, and indirectly by increasing $\xi(R)=(1-\pi) \frac{1}{R}+\pi \frac{1}{p_{2}}$. Note also that decreasing $R$ increases the denominator of the ratio, $\frac{\bar{p}-\bar{p}^{*}}{R^{*}-R}$. Thus, it can increase the ratio only if it increases the numerator. It follows that decreasing $R$ increases $\bar{p}-\bar{p}^{*}$. Equivalently, it decreases $\bar{p}^{*}-\bar{p}$, which corresponds to the special country's relative weighted average fire-sale price.

Next consider a decrease in $\beta$. By Proposition 6 , this increases $x$, which in turn increases $p_{2}$ and leaves $p_{3}$ unchanged. Thus, $M_{2}$ decreases $M_{1}$ and $M_{3}$ are unchanged.

Inspecting Eq. (A53) illustrates that decreasing $\beta$ tends to increase $\frac{\bar{p}-\bar{p}^{*}}{R^{*}-R}$ by decreasing the weight on the smaller marginal value $\left(M_{1}\right)$ in the numerator as well as decreasing the weight on the larger marginal value $\left(M_{3}\right)$ in the denominator. However, decreasing $\beta$ generates an indirect effect as well since it also decreases $M_{2}$. The indirect effect tends to decrease $\frac{\bar{p}-\bar{p}^{*}}{R^{*}-R}$, counteracting the direct effect. We conjecture that the indirect effect does not overturn the direct effect, that is, $\frac{d}{d \beta}\left(\frac{\bar{p}-\bar{p}^{*}}{R^{*}-R}\right)<0$, which in turn implies that decreasing $\beta$ decreases $\bar{p}-\bar{p}^{*}$ (equivalently, increases $\bar{p}^{*}-\bar{p}$ ).

To prove this conjecture, we differentiate Eq. (A53) with respect to $\beta$, which implies that $\frac{d}{d \beta}\left(\frac{\bar{p}-\bar{p}^{*}}{R^{*}-R}\right)<0$ if and only if,

$$
\frac{M_{1} \beta+M_{2}(1-\beta)}{M_{2}(1-\beta)+M_{3} \beta}>\frac{M_{1}+\frac{d}{d \beta}\left(M_{2}(1-\beta)\right)}{M_{3}+\frac{d}{d \beta}\left(M_{2}(1-\beta)\right)} .
$$

We make a second conjecture that $\frac{d}{d \beta}\left(M_{2}(1-\beta)\right)<0$. Under this conjecture, the above inequality holds because,

$$
\frac{M_{1} \beta+M_{2}(1-\beta)}{M_{2}(1-\beta)+M_{3} \beta}>\frac{M_{1}}{M_{3}}>\frac{M_{1}+\frac{d}{d \beta}\left(M_{2}(1-\beta)\right)}{M_{3}+\frac{d}{d \beta}\left(M_{2}(1-\beta)\right)} .
$$

Here, the first equality follows from $M_{1}<M_{2}<M_{3}$, and the second inequality uses $M_{1}<M_{3}$ together with $\frac{d}{d \beta}\left(M_{2}(1-\beta)\right)<0$.

Hence, it remains to prove the second conjecture, $\frac{d}{d \beta}\left(M_{2}(1-\beta)\right)<0$. To this end, note that Eq. (27) in Section 6 implies,

$$
u^{\prime}(1-x)=R \beta+\left((1-\pi) R+\pi p_{2}\right)(1-\beta) M_{2} .
$$

Taking the derivative with respect to $\beta$, and using $\frac{d u^{\prime}(1-x)}{d \beta}<0$ (since increasing $\beta$ decreases $x$ ), we obtain,

$$
R+\pi \frac{d p_{2}}{d \beta}(1-\beta) M_{2}+\left((1-\pi) R+\pi p_{2}\right) \frac{d}{d \beta}\left(M_{2}(1-\beta)\right)<0 .
$$

From here, note that $R+\pi \frac{d p_{2}}{d \beta}(1-\beta) M_{2}>0$ implies that $\frac{d}{d \beta}\left(M_{2}(1-\beta)\right)<0$. That is, our second conjecture follows from a third conjecture,

$$
(1-\beta) \pi\left(\frac{-d p_{2}}{d \beta}\right) M_{2}<R
$$

To prove the third conjecture, note that Eq. (27) can also be written as,

$$
\frac{u^{\prime}(1-x)}{R}=\beta+(1-\beta)\left(1-\pi+\pi \frac{p_{2}}{R}\right)\left(1-\pi+\pi \frac{R}{p_{2}}\right) .
$$


Taking the derivative with respect to $\beta$, and using $\frac{d u^{\prime}(1-x) / R}{d \beta}<0$, we obtain,

$$
(1-\beta) \pi\left(\frac{-d p_{2}}{d \beta}\right) \frac{M_{2}}{R}<\frac{\left(1-\pi+\pi \frac{p_{2}}{R}\right)\left(1-\pi+\pi \frac{R}{p_{2}}\right)-1}{\frac{1-\pi+\pi \frac{p_{2}}{R}}{(1-\pi) \frac{1}{R}+\pi \frac{1}{p_{2}}} \frac{R}{p_{2}^{2}}-1}<1
$$

The last inequality follows since it is equivalent to $\left(1-\pi+\pi \frac{R}{p_{2}}\right)\left((1-\pi) \frac{1}{R}+\pi \frac{1}{p_{2}}\right)<\frac{R}{p_{2}^{2}}$, which in turn holds since $1-\pi+\pi \frac{R}{p_{2}}<\frac{R}{p_{2}}$ and $(1-\pi) \frac{1}{R}+\pi \frac{1}{p_{2}}<\frac{1}{p_{2}}$. This establishes the third conjecture in (A54), which in turn implies $\frac{d}{d \beta}\left(\frac{\bar{p}-\bar{p}^{*}}{R^{*}-R}\right)<0$. This completes the proof. 


\section{Online Appendix B: Data}

In this appendix, we present the details of the data sources and variables' construction used in Section 2. We then describe the details of our regression analysis and present the empirical results (tables) omitted from Section 2. Finally, we present additional empirical analysis on the evolution of cross-country correlations of risky asset prices (beta), which we discuss in Section 6 .

\section{B.1. Data sources and variables' construction}

Capital flows. We obtain this data from the IMF's Balance of Payments (BOP) database. This dataset contains, among other things, the financial transactions between residents and nonresidents for individual countries. In particular, there is data on the residents' net lending to nonresidents in different functional categories, which can be combined to obtain a measure of capital outflows by residents. There is also data on the residents' net borrowing from nonresidents in different functional categories, which can be combined to obtain a measure of capital inflows by nonresidents. ${ }^{8}$

Specifically, to replicate and extend the analysis in Broner et al. (2013a), we obtain data at annual frequency for 1970-2017. We define capital outflows as the sum of the following items (all measured in nominal US dollars):

- Net direct investment by domestic agents. IMF indicator code: "BFDA_BP6_USD". Indicator name: "Financial Account, Net Lending (+) / Net Borrowing (-) (Balance from Financial Account), Direct Investment, Net Acquisition of Financial Assets, US Dollars"

- Net portfolio investment by domestics agents. IMF indicator code: "BFPA_BP6_USD". Indicator name: "Financial Account, Direct Investment, Net Acquisition of Financial Assets, US Dollars."

- Net other investment by domestics agents. IMF indicator code: "BFOA_BP6_USD". Indicator name: "Financial Account, Other Investment, Net Acquisition of Financial Assets, US Dollars."

- Net change in official reserves: IMF indicator code: "BFRA_BP6_USD". Indicator name: "Financial Account, Reserve Assets, US Dollars."

Likewise, we define capital inflows as the sum of the following items (all measured in nominal US dollars):

- Net direct investment by foreign agents. IMF indicator code: "BFDL_BP6_USD". Indicator name: "Financial Account, Net Lending (+) / Net Borrowing (-) (Balance from Financial Account), Direct Investment, Net Incurrence of Liabilities, US Dollars"

- Net portfolio investment by foreign agents. IMF indicator code: "BFPL_BP6_USD". Indicator name: "Financial Account, Direct Investment, Net Incurrence of Liabilities, US Dollars."

- Net other investment by foreign agents. IMF indicator code: "BFOL_BP6_USD". Indicator name: "Financial Account, Other Investment, Net Incurrence of Liabilities, US Dollars."

\footnotetext{
${ }^{8}$ The IMF BOP data is calculated by reporting countries in accordance with the sixth edition of the Balance of Payments and International Investment Position Manual, BPM6 (https://www.imf.org/external/pubs/ft/bop/2007/pdf/bpm6.pdf). The functional categories for net lending and net borrowing are described in Chapter 6 .
} 
Capital flow to GDP ratios (CIF and COD). Following Broner et al. (2013a), we scale the capital inflow and outflow measures by trend GDP. Specifically, for each country, we obtain nominal GDP in US dollars from the World Bank's national accounts database (available at https://data.worldbank.org/indicator/ny.gdp.mktp.cd. World Bank indicator code: "NY.GDP.MKTP.CD"). We compute trend GDP by applying the Hodrick-Prescott filter to this series with a parameter of $6.25 .{ }^{9}$ We then divide the capital inflow and outflow series with trend GDP in the corresponding year to obtain yearly series for capital inflow to GDP and capital outflow to GDP ratios. Following Broner et al. (2013a), we refer to these scaled measures as capital inflows by foreigners (CIF) and capital outflows by domestic agents (COD). Figure 1 plots these measures for three countries.

Standardized CIF and COD. To obtain meaningful units for our regression analysis, we construct standardized versions of the CIF and COD series. We standardize each measure by using its mean and standard deviation within each country over the period between 1970 and 2017.

Stock price index and the dividend yield. We obtain this data from Global Financial Data's GFDATABASE (GFD). This is a proprietary database that contains a wealth of information on various asset prices (see https://www.globalfinancialdata.com for details).

Specifically, we focus on the 30 OECD countries for which the GFD has information on dividend-to-price ratio (typically constructed for a broad sample of stocks chosen by the GFD). We obtain this data at monthly frequency, and convert to yearly frequency by averaging over all months within the year. We then combine this information with data on stock price indices. Specifically, we pick a popular stock price index for each country (based on Internet searches). We obtain daily price data on this index from the GFD. This data is daily, and we convert it to yearly frequency by taking the value for the last (trading) day of the year. Figure 1 plots these stock index measures for three countries.

The GFD tickers corresponding to our selection of stock indices are as follows:

- United States: GFD ticker “_SPXD” (S\&P500 Index)

- United Kingdom: GFD ticker “_FTSED” (UK FTSE100 Index).

- Australia: GFD ticker “_AXJOD” (Australia S\&P/ASX 200 Index).

- South Korea: GFD ticker “_KS11D” (Korea SE Stock Price Index: KOSPI).

- Germany: GFD ticker “_GDAXIPD” (Germany DAX Price Index).

- New Zealand: GFD ticker “_NZ15D” (NZSX-15 Index).

- France: GFD ticker “_FCHID” (Paris CAC-40 Index).

- Denmark: GFD ticker “_OMXC20D” (OMX Copenhagen-20 Index).

- Finland: GFD ticker “_OMXH25D” (OMX Helsinki-25 Index).

- Sweden: GFD ticker “_OMXS30D” (OMX Stockholm-30 Index).

- Israel: GFD ticker “_TA125D” (Tel Aviv SE 125 Broad Index).

- Italy: GFD ticker “_BCIJD” (Milan SE MIB-30 Index).

- Spain: GFD ticker “_IBEXD” (Madrid SE IBEX-35 Index).

\footnotetext{
${ }^{9}$ Broner et al. (2013a) apply the Hodrick-Prescott filter using a different parameter (100). We use the parameter 6.25 , following the recommendation from Ravn and Uhlig (2002) for annual data.
} 
- Ireland: GFD ticker “_ISEQD” (Ireland ISEQ Overall Price Index).

- Belgium: GFD ticker “_BFXD” (Belgium CBB Bel-20 Index).

- Greece: GFD ticker “_ATGD” (Athens SE General Index).

- Netherlands: GFD ticker “_AEXD” (Amsterdam AEX Stock Index).

- Norway: GFD ticker “_OSEAXD” (Oslo SE All-Share Index).

- Japan: GFD ticker “_N225D” (Nikkei 225 Stock Index).

- Switzerland: GFD ticker “_SSMID” (Swiss Market Index).

- Canada: GFD ticker “_GSPTSED” (Canada S\&P/TSX 300 Index).

- Austria: GFD ticker “_ATXD” (Austrian Traded Index: ATX).

- Chile: GFD ticker “_IGPAD” (Chile General Stock Price Index: IGPA)

- Czech Republic: GFD ticker “_PXGLD” (Prague PX Index)

- Hungary: GFD ticker “_HTLD” (Hungarian Traded Index: CHTX)

- Mexico: GFD ticker “_MXXD” (Mexico IPC Index)

- Poland: GFD ticker “_WIG20D” (Warsaw WIG20 Index)

- Portugal: GFD ticker “_PSI20D” (Portugese PSI20 Index)

- Slovakia: GFD ticker “_SAXD” (Slovakia SAX Index)

- Turkey: GFD ticker, “_XU100D” (Borsa Istanbul 100 Index). We drop the stock price data for Turkey before 2000 since the high inflation in 1990s led to extreme outliers in measured stock returns.

Stock return in local currency. We construct stock returns in local currency by combining the data on dividend-to-price ratio with the data on the stock price index. Specifically, for each country $j$ and year $t$, we calculate the corresponding gross stock return as follows,

$$
1+R_{t}^{j}=D P_{t}^{j}+\frac{P_{t}^{j}}{P_{t-1}^{j}},
$$

where $D P_{t}^{j}$ denotes the dividend-to-price ratio in year $t$ (obtained by averaging over the year) and $P_{t}^{j}$ denotes the stock price index at the end of year $t$. This gives the return in local currency because stock price indices are based on the local currency. In our regression analysis, we use log returns defined as,

$$
r_{t}^{j}=\log \left(1+R_{t}^{j}\right)
$$

In particular, our dependent variables correspond to the annualized log returns over the $h$-year forward horizon, defined as,

$$
r_{t, h}^{j}=\left(\sum_{i=1}^{h} r_{t+i}^{j}\right) / h .
$$


Exchange rate with respect to US dollar. We obtain this data from the Bank for international Settlements' (BIS) dataset on US Dollar Exchange Rates (available at https://www.bis.org/statistics/xrusd.htm). This dataset includes the value of the US dollar in terms of local currency for a large number of countries. We obtain the data at daily frequency, and we convert to yearly frequency by taking the value for the last (trading) day of the year.

Stock return in US dollars. We construct the stock return in US dollars by combining the stock return in local currency with the exchange rate with respect to the US dollar. Specifically, for each country $j$ and year $t$, we calculate the corresponding gross return in US dollars as,

$$
1+R_{t}^{j, U S D}=\left(1+R_{t}^{j}\right) \frac{X_{t-1}^{j, U S D}}{X_{t}^{j, U S D}},
$$

where $1+R_{t}^{j}$ denotes the stock return in local currency (calculated earlier) and $X_{t}^{j, U S D}$ denotes the value of the US dollar in terms of local currency at the end of year $t$. We define the log return in US dollars as,

$$
r_{t}^{j, U S D}=\log \left(1+R_{t}^{j, U S D}\right) .
$$

We also define the annualized log return over the $h$-year forward horizon as,

$$
r_{t, h}^{j, U S D}=\left(\sum_{i=1}^{h} r_{t+i}^{j, U S D}\right) / h .
$$

\section{B.2. Details of the regression analyses in Section 2}

Sample selection. Our full sample covers 170 countries from 1970 until 2017 for which we have both capital inflow and outflow measures. Our OECD sample covers 30 countries over the same period for which we have stock returns in addition to capital inflows and outflows. Tables A1 and A2 below describe the summary statistics that enter our regression analysis for, respectively, the full sample and the OECD sample. Both samples are unbalanced due to imperfect data coverage (especially in earlier years).

Correlations between capital flows. To quantify the correlations between flows, we regress capital outflows on capital inflows. Specifically, we estimate equations of the type:

$$
(C O D \text {-std })_{t}^{j}=\left\{\zeta^{j} t \text { or } \zeta^{j} t+\gamma_{t}\right\}+\beta(C I F-\text { std })_{t}^{j}+\varepsilon_{t}^{j} .
$$

Here, $j$ denotes the country, $t$ denotes the year, and $C O D$-std and $C I F$-std denote capital inflow and outflow measures scaled by GDP and standardized within the country (defined in Online Appendix B.1). In all specifications, we include country-specific linear time trends, since Figure 1 suggests different countries are subject to different time trends. We exclude time fixed effects in our baseline analysis but we include these effects in subsequent analysis. ${ }^{10}$ Throughout, we estimate the coefficient $\beta$ via ordinary least squares, and we report double clustered standard errors by country and year (that is, we allow for correlated shocks

\footnotetext{
${ }^{10}$ We do not include country fixed effects since the capital flow variables are already standardized within each country.
} 
across countries for a given year, as well as correlated shocks over time for a given country). We also report $R^{2}$ values from within-country variation.

The first two columns of Table 1 in the main text describe our estimation results without time fixed effects for the full sample (first column) as well as the OECD sample (second column). The estimated $\beta$ is statistically significant and large in both cases, which means that outflows in a country are highly correlated with inflows. The magnitude of $\beta$ is greater for the OECD sample than in the full sample, which means that the flows in OECD countries are more correlated than in other countries.

The last two columns of Table 1 describe the results when we also include time fixed effects. The estimated $\beta$ coefficients are statistically significant and similar in magnitude to their counterparts in the first two columns. This means that inflows and outflows are highly correlated, even after controlling for the average flows in sample countries (see Section 2 for further discussion).

Return predictions from capital flows. To investigate the relationship between flows and expected stock returns, we regress future realized stock returns on current capital flows. Specifically, we estimate equations of the type:

$$
\tilde{r}_{t}^{j}=\left\{\alpha^{j}+\zeta^{j} t \text { or } \alpha^{j}+\zeta^{j} t+\gamma_{t}\right\}+\beta\{C I F-\text { std or } C O D-\text { std }\}_{t}^{j}+\varepsilon_{t}^{j} .
$$

Here, the dependent variable, $\tilde{r}_{t}^{j}$, denotes an annualized measure of log stock returns in subsequent years. In the main text, we focus on the annualized log stock return in local currency over the five-year forward horizon, that is, $\tilde{r}_{t}^{j}=r_{t, 5}^{j}$. The main explanatory variable is either $C I F$-std or $C O D$-std, which respectively denote capital inflow and outflow measures scaled by GDP and standardized within the country (defined in Online Appendix B.1). We include country fixed effects as well as country-specific linear time trends in all specifications. We exclude time fixed effects in our baseline analysis but we include these effects in the subsequent analysis. We run these regressions for the OECD sample because we do not have stock return data for the remaining countries.

The first two columns of Table 2 in the main text describes our estimation results without time fixed effects and with capital inflows (first column) or capital outflows (second column) as the main explanatory variable. The estimated $\beta$ is statistically significant and negative in both cases, which means that a decline in inflows or outflows in an OECD country is associated with an increase in stock returns in the subsequent five years (see Section 2 for further discussion).

The last two columns of Table 2 describe the results when we also include time fixed effects. The estimated $\beta$ coefficients remain statistically significant and negative but with a smaller magnitude than their counterparts in the first two columns. This means that a local decline in capital flows in an OECD country is associated with high future local stock returns even after controlling for the average flows and average stock returns in other OECD countries. The smaller magnitudes suggest that "a local shock" that lowers capital flows in an individual OECD country without an effect on the average flows in OECD countries is associated with a smaller increase in stock returns compared to "a global shock" that lowers the average flows in OECD countries.

These results are robust to using alternative measures of future stock returns. Table A3 below presents analogous results when annualized log stock returns are measured in US dollars as opposed to local currency, that is, $\tilde{r}_{t}^{j}=r_{t, 5}^{j, U S D}$ (defined in Online Appendix B.1). The estimated $\beta$ coefficients are statistically significant and similar in magnitude to their counterparts in Table 2. Table A4 presents analogous results when annualized log stock returns are calculated over a three-year forward horizon instead of five, that is, $\tilde{r}_{t}^{j}=r_{t, 3}^{j}$. The results are similar to their counterparts in Table 2. 
Table A1: Summary statistics for the full sample (170 distinct countries)

\begin{tabular}{lcccccc}
\hline \hline & $\mathrm{N}$ & Mean & Std & P10 & P50 & P90 \\
\hline Inflows/trend GDP (percent) & 5102 & 12.16 & 69.73 & 0.00 & 5.91 & 19.43 \\
Outflows/trend GDP (percent) & 5102 & 10.02 & 70.69 & -1.83 & 3.04 & 16.46 \\
Inflows/trend GDP (std) & 5102 & 0.00 & 0.98 & -1.06 & -0.10 & 1.23 \\
Outflows/trend GDP (std) & 5102 & -0.00 & 0.98 & -1.08 & -0.12 & 1.26 \\
\hline
\end{tabular}

Table A2: Summary statistics for the OECD sample (30 distinct countries)

\begin{tabular}{|c|c|c|c|c|c|c|}
\hline & $\overline{\mathrm{N}}$ & Mean & Std & P10 & $\overline{\mathrm{P} 50}$ & P90 \\
\hline Inflows/trend GDP (percent) & 838 & 10.85 & 18.72 & 0.97 & 7.13 & 21.91 \\
\hline Outflows/trend GDP (percent) & 838 & 10.54 & 18.77 & 0.64 & 6.10 & 23.63 \\
\hline Inflows/trend GDP (std) & 838 & 0.10 & 1.01 & -1.03 & -0.02 & 1.45 \\
\hline Outflows/trend GDP (std) & 838 & 0.12 & 1.01 & -1.03 & 0.03 & 1.46 \\
\hline Log stock return (local currency) & 838 & 0.10 & 0.25 & -0.23 & 0.13 & 0.36 \\
\hline Log stock return (dollars) & 835 & 0.09 & 0.28 & -0.26 & 0.13 & 0.38 \\
\hline Log stock return in next 5 years (annualized, local currency) & 716 & 0.09 & 0.10 & -0.03 & 0.09 & 0.22 \\
\hline Log stock return in next 5 years (annualized, dollars) & 715 & 0.09 & 0.11 & -0.03 & 0.08 & 0.22 \\
\hline Log stock return in next 3 years (annualized, local currency) & 776 & 0.09 & 0.14 & -0.08 & 0.10 & 0.25 \\
\hline
\end{tabular}


Table A3: Analogue of Table 2 with returns measured in US dollars

\begin{tabular}{lcccc}
\hline \hline & \multicolumn{4}{c}{ Log stock return in next 5 years (annualized, dollars) } \\
& $(1)$ & $(2)$ & $(3)$ & $(4)$ \\
\hline Inflows/trend GDP (std) & $-0.030^{* *}$ & \multicolumn{3}{c}{$-0.022^{* *}$} \\
& $(0.006)$ & & $(0.006)$ & \\
Outflows/trend GDP (std) & & $-0.028^{* *}$ & & $-0.016^{* *}$ \\
& & $(0.006)$ & & $(0.006)$ \\
\hline Time FE & No & No & Yes & Yes \\
Country FE & Yes & Yes & Yes & Yes \\
Country specific linear trend & Yes & Yes & Yes & Yes \\
Observations & 715 & 715 & 715 & 715 \\
$\mathrm{R}^{2}$ (adjusted, within country) & 0.21 & 0.20 & 0.56 & 0.55 \\
\hline
\end{tabular}

Note: The sample is an unbalanced panel of 30 OECD countries between 1970 and 2017 (see Online Appendix B for details). Estimation is via OLS. Standard errors are in parentheses and double-clustered by country and year. * and ** indicate significance at 0.05 and 0.01 levels, respectively.

Table A4: Analogue of Table 2 with returns measured over a 3-year horizon

\begin{tabular}{lcccc}
\hline \hline & \multicolumn{4}{c}{ Log stock return in next 3 years (annualized, local currency) } \\
& $(1)$ & $(2)$ & $(3)$ & $(4)$ \\
\hline Inflows/trend GDP (std) & $-0.041^{* *}$ & \multicolumn{3}{c}{$-0.020^{* *}$} \\
& $(0.009)$ & & $(0.006)$ & \\
Outflows/trend GDP (std) & & $-0.040^{* *}$ & & $-0.018^{* *}$ \\
& & $(0.009)$ & & $(0.006)$ \\
\hline Time FE & No & No & Yes & Yes \\
Country FE & Yes & Yes & Yes & Yes \\
Country specific linear trend & Yes & Yes & Yes & 776 \\
Observations & 776 & 776 & 776 & 0.53 \\
$\mathrm{R}^{2}$ (adjusted, within country) & 0.17 & 0.16 & 0.54 & \\
\hline
\end{tabular}

Note: The sample is an unbalanced panel of 30 OECD countries between 1970 and 2017 (see Online Appendix B for details). Estimation is via OLS. Standard errors are in parentheses and double-clustered by country and year. * and ** indicate significance at 0.05 and 0.01 levels, respectively. 


\section{B.3. Additional analysis on cross-country price correlations}

In our baseline model (with symmetric countries), capital flows are driven by a liquidity insurance motive. Therefore, as we formalize in Section 6, an increase in the likelihood of global shocks $(\beta)$ reduces capital flows. This can help explaining the decline of gross capital flows in the aftermath of the global financial crisis (GFC), because the GFC arguably increased (real or perceived) correlations of financial shocks across countries. In this appendix, we further evaluate this claim by empirically analyzing the cross-country correlations between stock prices. In particular, we estimate the beta coefficient of the stock price changes of OECD countries (other than the U.S.) with respect to the S\&P 500 index, and we investigate how the average beta coefficient has evolved over time.

As we describe in Section B.1, we have stock price index data for 30 OECD countries at daily frequency. Therefore, we estimate betas using daily data. Specifically, our time unit is US trading days denoted by $d$ (which we infer from our S\&P 500 price data).

Since we also have exchange rate data with respect to the U.S. dollar at daily frequency (see Section B.1), we measure daily price changes in U.S. dollars. Specifically, for each country $j$ and trading day $d$, we define our price change variable as,

$$
\Delta p_{d}^{j}=\log \left(\frac{P_{d}^{j}}{P_{d-1}^{j}} \frac{X_{d-1}^{j, U S D}}{X_{d}^{j, U S D}}\right) .
$$

Here, $P_{d}^{j}$ denotes the stock price index at day $d$, and $X_{d}^{j, U S D}$ denotes the value of the U.S. dollar in terms of local currency at day $d$. Hence, $\Delta p_{d}^{j}$ denotes the log daily stock price change in country $j$ on trading day $d$ evaluated in U.S. dollars. For the U.S., $\Delta p_{d}^{U S}$ simply corresponds to the log change of the S\&P 500 price index on day $d$.

We then estimate equations of the following type,

$$
\Delta p_{d}^{j}=\alpha+\beta \Delta p_{d}^{U S}+\varepsilon_{d}^{j}
$$

Since our goal is to analyze the evolution of $\beta$ over time, we estimate Eq. (A57) separately for each year. Specifically, given country $j$ and year $t$, we estimate Eq. (A57) over all trading days within year $t$. The estimated coefficient $\hat{\beta}_{t}^{j}$ provides a measure of the correlation between stock price changes in country $j$ and the U.S. in year $t$ (in particular, it is equal to the sample covariance of the log price changes divided by the sample variance of the log change of the $\mathrm{S} \& \mathrm{P}$ index).

We then take an (unweighted) average of the estimated betas across all OECD countries in our sample (excluding the U.S.) to obtain a yearly time series of the average beta coefficient, $\left\{\hat{\beta}_{t}\right\}_{t}$. Figure A1 illustrates the evolution of the average beta over time together with the (unweighted) average of capital inflow and outflow to GDP ratios across all OECD countries in our sample (including the U.S.). There is a clear increase in the average beta starting in 2009, shortly after the peak of the GFC. ${ }^{11}$ Moreover, in the years following the GFC, the average beta remains elevated while the average gross capital flows are depressed. This provides suggestive evidence in favor of our claim that part of the decline in gross capital flows after the GFC can be attributed to an increase in correlations of financial shocks across countries.

\footnotetext{
${ }^{11}$ We also perform a more detailed analysis by estimating Eq. (A57) separately for each trading day $\hat{d}$, using a sample of the 252 trading days $d$ immediately before $\hat{d}$ (approximately one year). This analysis reveals that the average beta started to increase in late 2008, around the peak of the GFC.
} 


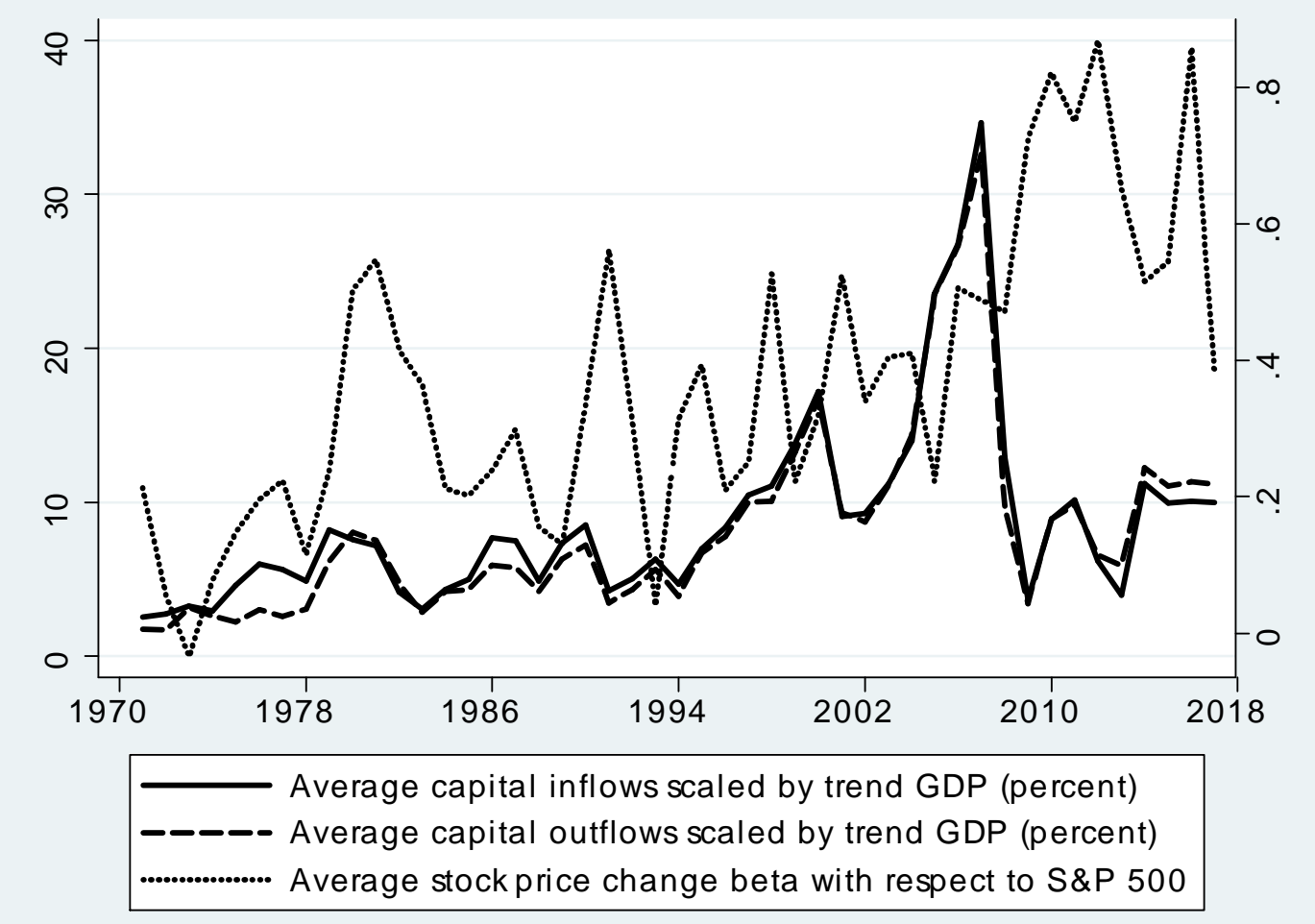

Figure A1: The dotted line illustrates the average $\beta$ of stock price changes in OECD countries excluding the U.S. with respect to the S\&P 500 index (right y-axis). The solid and dashed lines illustrate the average capital flow-to-GDP ratio in OECD countries including the U.S. (left y-axis). 